\title{
Patient Compliance in Hypertension From Measurement to Improvement
}


Patient Compliance in Hypertension. From Measurement to Improvement Gwenndola Elisabeth Clementine Wetzels

Thesis, Universiteit Maastricht, Maastricht, The Netherlands

Universitaire Pers Maastricht

ISBN 10: 90-5278-575-9

ISBN 13: 978-90-5278-575-2

(C) Copyright, Gwenn E.C. Wetzels, Susteren 2006

All rights reserved. No part of this thesis may be reproduced or transmitted in any form or by any means, electronic or mechanical, including photocopying, recording or any information storage or retrieval system without permission in writing from the author, or, when appropriate, from the publisher of the publications. 


\title{
Patient Compliance in Hypertension
}

\section{From Measurement to Improvement}

\author{
PROEFSCHRIFT \\ Ter verkrijging van de graad van doctor \\ aan de Universiteit Maastricht, \\ op gezag van de Rector Magnificus, \\ Prof. mr. G.P.M.F. Mols, \\ volgens het besluit van het college van Decanen, \\ in het openbaar te verdedigen \\ op donderdag 30 november 2006 om 12:00 uur \\ door \\ Gwenndola Elisabeth Clementine Wetzels, \\ Geboren op 24 september 1973 \\ te Heerlen
}




\section{Promotor}

Prof. dr. M.H. Prins

\section{Co-promotores}

Dr. P.J. Nelemans

Dr. J.S.A.G. Schouten

\section{Beoordelingscommissie}

Prof. dr. P.W. de Leeuw (voorzitter)

Prof. dr. Y. van der Graaf (Julius stichting, UMC, Utrecht)

Prof. dr. H.G.M. Leufkens (Universiteit Utrecht)

Prof. dr. J.S.M. Metsemakers

Dr. C. Neef (AZM, Maastricht)

This project was financially supported by the Dutch Health Care Insurance Board.

Financial support by the Netherlands Heart Foundation for the publication of this thesis is gratefully acknowledged.

The studies presented in this thesis were conducted at Maastricht University, at the Department of Epidemiology and were embedded in the Care and Public Health Research Institute (Caphri). Caphri participates in the Netherlands School of Primary Care Research (CaRe), which was acknowledged in 1995 by the Royal Netherlands Academy of Arts and Sciences (KNAW) 
The Aim of Science is Not to Open a Door to Endless Wisdom But to Put a Limit to Endless Error

Bertolt Brecht, The life of Galileo 



\section{CONTENTS}

$\begin{array}{lll}\text { Chapter } 1 \text { General introduction } & 09\end{array}$

Chapter 2 Facts and fiction of poor compliance as a cause of inadequate blood pressure control: a systematic review

Chapter 3 Electronic monitoring of adherence as a method to improve blood pressure control: a randomised controlled trial

Chapter 4 Electronic monitoring of adherence as a tool to improve blood pressure control: Long term follow-up

Chapter 5 Costs and cost-effectiveness of an adherence improving program in hypertensive patients

Chapter 6 Electronic monitoring as a tool to improve blood pressure control: a qualitative study

Chapter 7 Determinants of poor adherence in hypertensive patients: development and validation of the "Maastricht Utrecht Adherence in hypertension (MUHA)" questionnaire

Chapter 8 All that glisters is not gold: a comparison of electronic monitoring versus filled prescriptions: an observational study

Chapter 9 General Discussion

Summary \& Samenvatting

Dankwoord

Curriculum Vitae

List of publications 



\section{Chapter 1}

General introduction 
10 | General introduction 


\section{Introduction}

Hypertension is the most prevalent of all chronic conditions, and has been identified as the leading risk factor for cardiovascular diseases and mortality.1-3 Hypertension affects approximately 1 billion individuals worldwide and is ranked third as a cause of reduction in quality-adjusted life years., ${ }^{2,4}$ The relationship between high blood pressure, and risk of cardiovascular disease events is continuous, consistent, and independent of other risk factors. ${ }^{4}$ The higher the blood pressure, the greater the chance of myocardial infarction, heart failure, stroke and kidney disease. ${ }^{1-4}$ Therefore, the ultimate public health goal of antihypertensive therapy is the reduction of cardiovascular and renal morbidity and mortality. ${ }^{4}$ Hypertension has a 30 -year history of pharmaceutical innovation and expanding, improving treatment, since the first demonstration in 1970 of the mortality-lowering and stroke-reducing benefits of treatment with then-available drugs. Results of the Hypertension Optimal Treatment ${ }^{5}$ trial suggested that control of hypertension is attainable with the agents available nowadays. Clinical trials also demonstrated that antihypertensive therapy has been associated with $35 \%$ to $40 \%$ mean reductions in stroke incidence; 20 to $25 \%$ in myocardial infarction; and more than $50 \%$ in heart failure. ${ }^{4}$

In spite of an increased awareness of hypertension and the availability of a wide variety of highly specific drugs, only $30 \%$ of the patients who use antihypertensive medication achieve adequate blood pressure control., ${ }^{1,3}$ Poor compliance with prescribed antihypertensive drug regimens is assumed to be a major reason for inadequate blood pressure control. Having reached the apogee of pharmaceutical innovation, with convenient once-daily antihypertensive medicines virtually lacking in side effects, the compliance problem still persists. ${ }^{6}$ Pills don't work if you don't take them.

In usual care, this problem is often neglected. The recommended scheme for treating hypertension is a stepwise approach, which starts the patient on a relatively mild regimen of antihypertensive medication (one or two drugs). If the blood pressure does not normalize, proper titration will lead to higher doses or to the addition of one or more antihypertensive drugs. If this step does not normalize the blood pressure, the strength of the regimen is further escalated. The usually final step involves so-called 'triple therapy' with three drugs, generally regarded as most potent. Patients who fail to respond to triple therapy are then usually referred for expert evaluation for 'drug resistant hypertension', which includes invasive diagnostics such as renal angiography to detect renal artery stenosis. The question whether there are other than pharmacologic reasons for lack of response to antihypertensive medication, such as poor compliance, is often left out of consideration. The main reason why this question is not answered satisfactorily lays in the fact that clinical detection of non-compliance is poor. This situation, however, implies that an evidently large majority of non-compliers are treated as if they were non-responders. 


\section{Compliance}

Patient non-compliance with professional recommendations is as old a topic as medicine itself. Hippocrates complained that some patients did not follow medical advice and stated that the "physician" should keep aware of the fact that patients often lie when they state that they have taken certain medicines. ${ }^{7,8}$ Brian Haynes, an editor of the first major compliance bibliography, stated that the first recorded incident of human non-compliance in "Judeo-Christian tradition" occurred when Eve ate the apple in the garden of Eden. ${ }^{8}$

While non-compliance may have been occurring since the time of Hippocrates, only in the 1950s did physicians obtain many truly effective medications for the first time, and only then did it become as important for physicians to make sure that these medications were consumed by patients as it was to make sure they were properly chosen and prescribed. ${ }^{9}$

Patient compliance first appeared as a medical subject heading in the Index Medicus in 1975.9 When studying today's literature on patient compliance, one soon becomes puzzled about the disparity in the results reported. Estimated compliance rates range from less than 20 to over $80 \%$. $^{10-26}$ The World Health Organisation estimates that at least $50 \%$ of the patients in a general hypertensive population do not take their antihypertensive medication as prescribed, ${ }^{27}$ although strong evidence for this assumption is lacking. McGavock stated that "there can be few research fields in which so much published research has led to so little improvement in understanding and effective action, as is the case in that of compliance with prescribed medication". ${ }^{28}$ Different results may arise from differences in study groups, duration of follow-up, methods of assessment of compliance, calculation of compliance measures and drug regimens used in different studies. The fact that many factors influence compliance is strengthening the complexity of the topic. Variations in the prevalence of compliance may occur due to patient-related, medication-related, and disease-related factors. For example, patient factors, such as perceptions and beliefs of illness and medication, will influence the willingness and motivation to comply with the prescribed regimen. Other common patient-related reasons for poor compliance are forgetfulness, a dosage change that is not fully understood or continued medical events or problems that cause the patient to believe that the medication is not helping. ${ }^{29}$ Medication-related factors, such as dose frequency, and the incidence and severity of adverse drug events, also affect compliance. Finally, specific characteristics of the disease may influence compliance. Two of the most important factors contributing to poor compliance are undoubtedly an asymptomatic and lifelong nature of a disease. For this reason, it can be expected that in patients with hypertension, poor compliance is the most important reason of lack of response to treatment. 
The problem of poor compliance is not unique to patients who use antihypertensive medication and compliance-related problems have been described for a wide variety of diseases and conditions such as epilepsy, hypercholesterolemia, diabetes, HIV/AIDS, tuberculosis, depression and asthma. ${ }^{27}$ But hypertension forms an interesting domain for studying compliance issues. This risk factor is very common and in patients with this chronic condition it is possible to study the effect of improved compliance on clinical outcome (blood pressure) on a short term.

\section{Definitions of patient compliance}

Patient compliance, as Roter et al. ${ }^{30}$ noted in their recent review, can cover many aspects of medical advice besides prescription of drug regimens - the keeping of medical appointments, exercise, diet, rest, other aspects of 'lifestyle'- and so forth. Haynes $^{8}$ defined patient compliance as the extent to which the patient's behaviour (in terms of taking medication, following diets, or executing other lifestyle changes) coincides with medical or health advice. Patient compliance presents difficult issues. Several authors have suggested that the term compliance reflects a biomedical paradigm that reinforces patient passivity and stigmatises independent patient judgments about self-treatment as deviant. ${ }^{31,32}$ An alternative term "adherence" has been offered by some investigators to denote a more active patient-physician treatment collaboration than compliance. The term adherence is intended to be non-judgmental, a statement of fact rather than the blame of the prescriber, patient or treatment. ${ }^{33}$ Nowadays, many agree that the term adherence more accurately recognizes the greater degree of patients' responsibility and involvement in their medical care and is a more politically correct term. ${ }^{34}$

An interesting view on definitions of compliance comes from Urquhart. ${ }^{35} \mathrm{He}$ states that the field of patient compliance has a Janus-like character, in which one face looks toward human behaviour and asks why so many patients deviate from medical instructions. The other face looks toward clinical pharmacology and therapeutics and asks what medical consequences arise from various deviations that occur between actual dosing histories and prescribed regimens. Taking clinical pharmacology into account it is important to use a definition that is amenable to quantification and analysis. According to Urquhart, a quantitative analysis is only served by two terms: compliance and persistence, while adherence is used as a more qualitative term. Urquhart definition of compliance is "the extent to which the patient's dosing history corresponds to the prescribed drug regimen".36 Persistence is defined as "the time elapsed between the first dose taken and the time of treatment discontinuation". ${ }^{36}$ Persistence means the continued taking of the prescribed medication in the long term. Persistence is a component of compliance, but it is a coarse measurement, for a patient can be persistent and still be only partially compliant. ${ }^{37}$ 
The terms adherence and compliance will be used interchangeably in this thesis.

\section{Methods to measure patient compliance}

The last decades various methods have been used to determine patient compliance. Rudd, in his editorial "In search for the gold standard for compliance measurement", 38 was the first to wonder what requirements a good compliance measurement instrument would ask for.

An ideal method for measuring compliance would be:36,38-41

- Unobtrusive (to avoid patient sensitisation and maximize cooperation)

- Non-invasive

- Objective (to produce discrete and reproducible data for each subject)

- Practical (to maximize portability and minimize cost)

- Proving ingestion of the drug

- Unsusceptible to manipulation

Unfortunately, at present no single instrument is available that has all these properties and all current compliance measures have flaws and include error. ${ }^{42}$ Methods for measuring compliance can be divided in direct and indirect methods. Direct methods, such as the measurement of drug or metabolite concentrations in plasma, prove ingestion of the drug. Indirect methods do not prove ingestion. These include: patient interviews, self-report tools and questionnaires, physicians' estimates, pill counts, data from pharmacy records, and electronic monitoring of compliance.

\section{Measuring drug concentrations in plasma}

The use of plasma concentration monitoring as a marker of compliance is appealing, but it is limited and biased by two factors. First, the plasma half-life of most drugs is often only part of a day. Secondly, there is good evidence that compliance in the several days prior to a scheduled visit is much better than at other times. ${ }^{41}$ Therefore, monitoring serum concentrations of selected drug doses often does not measure compliance.

\section{Patient interviews, self-report tools and questionnaires}

Although these measures are easy to perform, it also very easy for patients to present a more favourable medication behaviour than their actual behaviour. Patients tend to tell doctors what they think the doctor wants to hear. ${ }^{43}$ Furthermore data are confounded by forgetfulness on the part of the patient ${ }^{44}$ and patient recall may limit questions about compliance during periods longer than one week. ${ }^{42}$ In general, patient interviews are unreliable and overestimate patient compliance. ${ }^{40}$ 


\section{Physicians' estimates}

Mushlin and Apple ${ }^{45}$ have shown that physicians' estimates of compliance of their patients is no better than a coin toss.

Physicians at best accurately predicted $35 \%$ of the actual non-compliers and overall one half of their predictions were incorrect.

\section{Pharmacy refill rates}

Refill records of computerized pharmacy databases, are used increasingly as a source of compliance information. ${ }^{46}$ Because refill compliance data only give information about whether or not the medication is obtained by the patient, it provides an upper bound for medication consumption. It allows identification of those patients that cannot be compliant simply because they do not obtain enough medication. ${ }^{46}$ It is therefore to be expected that the actual proportion of patients with poor compliance is higher.

However, pharmacy-based assessments do offer several advantages, including the possibility of conducting population-based analysis and avoiding a possible Hawthorne effect because the patient is not aware of being evaluated. ${ }^{42,46}$

\section{Pill counts}

Counting returned tablets provide numerical values that convey a false objectivity and precision. ${ }^{41}$ Problems such as pill dumping or pill sharing lead to overestimation of compliance. The extent to which patients discard tablets has been measured in several ways. ${ }^{15,18,47-49}$ Pullar $^{49}$, for example, compared the low dose phenobarbital marker method with tablet counts and concluded that patients regularly fail to return untaken tablets and that the returned tablet count grossly overestimates compliance.

\section{Electronic monitoring systems}

During the last decade, electronic monitoring (EM) has become available as a tool for objective registration of patient compliance. Electronic monitors are caps equipped with micro circuitry that fit medication packages. The micro circuitry records date and time of every opening of the pill package, thus enabling registration of the dosing history during the period of electronic monitoring.

While EM is an indirect method that cannot prove ingestion of the drug, it provides several advantages over the other measurement methods; it provides a detailed actual dosing chronology and it is difficult to falsify, because a patient has to open and close the medication package every day, on schedule, to be classified as a full complier, while with other methods the result of compliance measurement can be modified with one simple act. ${ }^{15,41,44} \mathrm{EM}$ is now sometimes considered as the "gold standard" for compliance measurements. However some studies suggest that monitoring itself actually improves compliance because the patient is aware that dosing patterns are being recorded..$^{12,50,51}$ If this is true, it makes the use of electronic monitoring as gold standard method questionable. 
However, the fact that monitoring itself might increase compliance raises the question to what extent monitoring can be used as an intervention to manage the problem of non-compliance and to achieve better blood pressure control.

\section{Measures of compliance}

Electronic monitoring provides an uniquely detailed dosing history and allows the calculation of compliance variables such as taking compliance, correct dosing, timing compliance, and therapeutic coverage. These measures are shortly described.

- Taking compliance: the percentage of prescribed doses taken, can be calculated as: (total number of recorded medication events / total number of prescribed doses) x 100\%

- Correct dosing: the percentage of days on which the correct number of doses was taken, can be calculated as: (the total number of days with recorded medication events as prescribed / total number of monitored days) $\times 100 \%$

- Timing compliance specifies time-intervals (for example $24 \pm 6$ hours) within which doses should be taken and can be calculated as: (total number of recorded medication events within the specified time-interval / total number of monitored days) x 100\%

- Therapeutic coverage: the percentage of time, wherein concentration of the drug is high enough to perform its therapeutic action. During periods that the interdose intervals exceed the drug's defined duration of therapeutic action, it can be said that there is no "therapeutic coverage" because drug action is insufficient for therapeutic action.

Timing compliance is the most stringent of these measures because it takes the exact timing of medication intake into account whereas taking compliance only refers to the number of tablets taken during a certain period regardless of the timing of intake.

The above-mentioned measures can be used in many ways to enhance the information of the actual dosing history of patients, and to compare specific aspects of the actual dosing history with the prescribed dosing history. Electronic monitoring also makes it possible to detect so-called drug holidays; two or more days of suddenly interrupted dosing followed by sudden resumption, for example during weekends. Recurrent drug holidays are potentially dangerous for drugs that may have hazardous rebound effects, including beta-blocking agents without partial agonist activity, and clonidine. ${ }^{52}$ 


\section{How much compliance is enough?}

How much compliance is needed for adequate blood pressure control? There exists, as with all diagnostic manoeuvres, an intermediate zone where the question of "how much compliance is enough" must be answered in order to distinguish non-responders from non-compliers. ${ }^{53}$ It is now accepted that patients are considered to be compliant with the prescribed medication regimen when they take $80-90 \%$ of their medicines. ${ }^{54-56}$

However, at this stage we do not really know what level of compliance is necessary for individual antihypertensive medications. The answer to the question "how much compliance is enough" requires extended knowledge of the pharmacokinetic and pharmacodynamic properties, which vary between antihypertensive drugs and also vary between individuals. Some drugs are much more "forgiving" than others in term of missed dosing and the timing of ingestion. ${ }^{57}$ The commonly used cutoff point of $80 \%$ adherence, above which adherence is thought to be sufficient, is in many cases meaningless and not based on pharmacoepidemiologic evidence linking frequency of medication taking with clinical outcomes. ${ }^{57}$ It can be concluded that compliance studies should always be linked with the therapeutic outcome to judge the clinical significance of the results reported.

\section{Interventions to improve compliance}

Comparison of studies that evaluated interventions to improve compliance is hampered by the fact that the definition and measurement of compliance differed between studies, and by the poor methodological quality of many trials. ${ }^{20,30,33,58,59}$ McDonald stated that "there are only few rigorous trials of adherence interventions". ${ }^{33}$ The most recent review published on interventions to improve compliance with antihypertensive medication comes from Schroeder et al. ${ }^{59}$ In this review 38 studies were included testing 58 different interventions and containing data on 15519 patients. Simplifying dosing regimens increased adherence in 7 of 9 studies, with a relative increase in compliance of $8 \%$ to $19.6 \%$. Motivational strategies were partly successful in 10 of 24 studies with generally small increases in compliance up to a maximum of $23 \%$. Complex interventions comparing more than one technique increased compliance in 8 of 18 studies, ranging from $5 \%$ to a maximum of $41 \%$. Patient education alone seemed largely unsuccessful. It was concluded that simplification of dosing regimens appears to be the most promising intervention to increase adherence to blood pressure-lowering medication. The evidence of the effect of motivational and more complex interventions is mixed and inconclusive.

These results are in agreement with that of a meta-analysis by Iskedjian et al., ${ }^{20}$ which reported that the average adherence for once daily dosing was significantly higher than for multiple daily dosing (91.4 versus $83.2 \%$ ).

The authors concluded that once-daily regimens for antihypertensive medications were associated with higher compliance. 
Although studies suggest that simplifying the dose regimen seems to be an effective method to improve compliance, a lot of patients who use blood pressure lowering medication are already on a simple once-daily regimen but compliance still remains a problem. There is still much need for effective and easy-to-use interventions aimed at improving compliance.

\section{The current thesis}

This thesis addresses several problems related to the measurement of compliance and describes the effect of an intervention aimed at improving compliance with antihypertensive medication.

The objectives of this thesis are:

- To acquire insight into the magnitude of compliance problems in hypertensive patients and to investigate what is known about the prevalence of poor compliance from studies which used the "gold standard", electronic monitoring

- To measure the prevalence of poor compliance as measured by electronic monitoring and agreement with other methods of measurement such as refill compliance and self-reported compliance

- To evaluate the effectiveness of an experimental strategy based on electronic monitoring in comparison with typical routine care (usual care) in patients who are treated for hypertension in the primary care setting. The experimental strategy is designed to avoid the pitfall of treating poor compliers as if they are non-responders, and thereby to prevent unnecessary and costly dose or drug escalation

- To evaluate the cost-effectiveness of an experimental strategy based on electronic monitoring

- To evaluate patients' experiences with electronic monitoring

- To develop and validate a questionnaire aimed at identifying barriers of compliance with antihypertensive drugs

\section{Outline of the thesis}

- In chapter 2, recent studies in which electronic monitoring was used for assessing patient compliance with antihypertensive medications, are reviewed. Furthermore, it was evaluated what is known about the relationship between the level of compliance and blood pressure control

- In chapter 3, a randomised controlled trial is described in which an intervention to improve compliance with antihypertensive medication is compared with a control group. The control group represented typical routine care (usual care). Primary endpoint was the percentage of patients with normalised blood pressure 
- In chapter 4 , long term follow-up (12 months) data are presented in order to evaluate to what extent effects persist for longer times after stopping the intervention

- In chapter 5, the cost-effectiveness analysis in which the experimental strategy (monitoring of compliance) is compared to a usual care strategy, is described

- In chapter 6, a qualitative study is described performed in order to explore patient's views about a specific intervention to improve compliance and to gather information about the acceptance of the intervention

- In chapter 7, the development and validation of a questionnaire aimed at identifying reasons for non-compliance are presented

- In chapter 8, electronic monitoring of compliance, a method nowadays considered to be the "gold standard", is compared with another often used method to determine compliance which is based on pharmacy records

- In chapter 9 the findings of this thesis concerning compliance with antihypertensive medication are placed in perspective and the current insights into compliance improving interventions, are discussed. An outlook for future developments and the clinical significance of the results, are provided

The research for this thesis was performed at the Department of Epidemiology at Maastricht University and Care and Public Health Research Institute (CAPHRI). The research was funded by the Dutch Health Care Insurance Board. 


\section{References}

1. Burt VL, Cutler JA, Higgins M, Horan MJ, Labarthe D, Whelton P, Brown C, and Roccella EJ. Trends in the prevalence, awareness, treatment, and control of hypertension in the adult US population. Data from the health examination surveys, 1960 to 1991. Hypertension, 1995. 26(1): p. 60-9.

2. Ezzati M, Lopez AD, Rodgers A, Vander Hoorn S, and Murray CJ. Selected major risk factors and global and regonal burden of disease. Lancet, 2002. 360: p. 1347-1369.

3. Joint National Committee on prevention, evaluation, and treatment of high blood pressure. The sixth report of the Joint National Committee on prevention, detection, evaluation, and treatment of high blood pressure. Arch Intern Med, 1997. 157(21): p. 2413-46.

4. Chobanian AV, Bakris GL, Black HR, Cushman WC, Green LW, Izzo JL, Jones DW, Materson BJ, Oparil S, Wright JT, Jr., and Roccella EJ. The seventh report of the Joint National Committee on Prevention, Detection, Evaluation, and Treatment of High Blood Pressure: the JNC 7 report. JAMA, 2003. 289: p. 2560-2572.

5. Waeber B, Leonetti G, Kolloch R, and McInnes GT. Compliance with aspirin or placebo in the Hypertension Optimal Treatment (HOT) study. J Hypertens, 1999. 17(7): p. 1041-5.

6. Urquhart J. The odds of the three nons when an aptly prescribed medicine isn't working: noncompliance, non-absorption, non-response. Br J Clin Pharmacol, 2002. 54(2): p. 212-20.

7. Kastrissios $\mathrm{H}$ and Blaschke TF. Medication compliance as a feature in drug development. Ann Rev Pharmacol Toxicol, 1997. 37: p. 451-475.

8. Haynes RB, Taylor DW, and Sackett DL. Compliance in health care. 1979, Baltimore: The John Hopkins University Press.

9. Trostle JA. Medical compliance as an ideology. Soc Sci Med, 1988. 27(12): p. 1299-308.

10. Caldwell JR. Drug regimens for long-term therapy of hypertension. Geriatrics, 1976. 1: p. 115119.

11. Bovet P, Burnier M, Madeleine G, Waeber B, and Paccaud F. Monitoring one-year compliance to antihypertension medication in the Seychelles. Bull World Health Organ, 2002. 80(1): p. 33-9.

12. Burnier M, Schneider MP, Chiolero A, Stubi CL, and Brunner HR. Electronic compliance monitoring in resistant hypertension: the basis for rational therapeutic decisions. $J$ Hypertens, 2001. 19(2): p. 335-41.

13. Choo PW, Rand CS, Inui TS, Lee ML, Cain E, Cordeiro-Breault M, Canning C, and Platt R. Validation of patient reports, automated pharmacy records, and pill counts with electronic monitoring of adherence to antihypertensive therapy. Med Care, 1999. 37(9): p. 846-57.

14. Cook CL, Wade WE, Martin BC, and Perri M. Concordance among three self-reported measures of medication adherence and pharmacy refill records. Journal of the American Pharmacists Association, 2005. 45(2).

15. Cramer JA, Mattson RH, Prevey ML, Scheyer RD, and Ouellette VL. How often is medication taken as prescribed? A novel assessment technique. JAMA, 1989. 261(22): p. 3273-7.

16. DiMatteo MR, Giordani P, Lepper HS, and Croghan TW. Patient adherence and medical treatment outcomes: a meta-analysis. Med Care, 2002. 40(9): p. 749-811.

17. Girvin B, McDermott BJ, and Johnston GD. A comparison of enalapril $20 \mathrm{mg}$ once daily versus $10 \mathrm{mg}$ twice daily in terms of blood pressure lowering and patient compliance. J Hypertens, 1999. 17(11): p. 1627-31.

18. Guerrero D, Rudd P, Bryant-Kosling C, Middleton B, and Middleton BF. Antihypertensive medication-taking. Investigation of a simple regimen. Am J Hypertens, 1993. 6(7 Pt 1): p. 586-92.

19. Hamilton GA. Measuring adherence in a hypertension clinical trial. Eur J Cardiovasc Nurs, 2003. 2(3): p. 219-28.

20. Iskedjian M, Einarson TR, MacKeigan LD, Shear N, Addis A, Mittmann N, and Ilersich AL. Relationship between daily dose frequency and adherence to antihypertensive pharmacotherapy: evidence from a meta-analysis. Clin Ther, 2002. 24(2): p. 302-16. 
21. Kruse W, Rampmaier J, Ullrich G, and Weber E. Patterns of drug compliance with medications to be taken once and twice daily assessed by continuous electronic monitoring in primary care. Int J Clin Pharmacol Ther, 1994. 32(9): p. 452-7.

22. Leenen FH, Wilson TW, Bolli P, Larochelle P, Myers M, Handa SP, Boileau G, and Tanner J. Patterns of compliance with once versus twice daily antihypertensive drug therapy in primary care: a randomized clinical trial using electronic monitoring. Can J Cardiol, 1997. 13(10): p. 914 20.

23. Mallion JM, Meilhac B, Tremel F, Calvez R, and Bertholom N. Use of a microprocessorequipped tablet box in monitoring compliance with antihypertensive treatment. $J$ Cardiovasc Pharmacol, 1992. 19 Suppl 2: p. S41-8.

24. Nuesch R, Schroeder K, Dieterle T, Martina B, and Battegay E. Relation between insufficient response to antihypertensive treatment and poor compliance with treatment: a prospective casecontrol study. BMJ, 2001. 323(7305): p. 142-6.

25. Rudd P, Ahmed S, Zachary V, Barton C, and Bonduelle D. Compliance with medication timing: Implications from a medication trial for drug development and clinical practice. Journal of Clinical Research and Pharmacoepidemiology, 1992. 6: p. 15-27.

26. Waeber B, Brunner HR, and Metry JM. Compliance with antihypertensive treatment: implications for practice. Blood Press, 1997. 6(6): p. 326-31.

27. Sabate E. Adherence to long-term therapies: evidence for action. WHO, 2003(Geneva).

28. McGavock H. A review of the literature on drug adherence. 1996, Queen's University: Belfast.

29. Cramer JA. Practical issues in medication compliance. Transplant Proc, 1999. 31(4A): p. 7S-9S.

30. Roter DL, Hall JA, Merisca R, Nordstrom B, Cretin D, and Svarstad B. Effectiveness of interventions to improve patient compliance: a meta-analysis. Med Care, 1998. 36(8): p. 1138-61.

31. DiMatteo MR and DiNicola DD. Achieving patient compliance. 1982, New York: Pergamon Press.

32. Donovan JL and Blake DR. Patient noncompliance: Deviance or reasoned decision-making. Soc Sci Med, 1992. 34: p. 507

33. McDonald HP, Garg AX, and Haynes RB. Interventions to enhance patient adherence to medication prescriptions: scientific review. JAMA, 2002. 288(22): p. 2868-79.

34. Krousel-Wood M, Thomas S, Munther P, and Morisky D. Medication adherence: a key factor in achieving blood pressure control and good clinical outcomes in hypertensive patients. Curr Opin Cardiol, 2004. 19: p. 357-362.

35. Urquhart J. Erratic patient compliance with prescribed drug regimens: target for drug delivery systems. Clin Pharmacol Ther, 2000. 67(4): p. 331-4.

36. Urquhart J. The electronic medication event monitor. Lessons for pharmacotherapy. Clin Pharmacokinet, 1997. 32(5): p. 345-56.

37. Burnier M. Long-term compliance with antihypertensive therapy: another facet of chronotherapeutics in hypertension. Blood Press Monit, 2000.5 (suppl 1): p. S31-S34.

38. Rudd P. In search of the gold standard for compliance measurement. Arch Intern Med, 1979. 139(6): p. 627-629.

39. Pullar T and Feely M. Problems of compliance with drug treatment: new solutions? Pharm J, 1990. 245: p. 213-215.

40. De Klerk E. Measurement of patient compliance on drug therapy: an overview. Advances in behavioral medicine assesment, ed. A. Vingerhoets. 2001: Harwood academic Publishers.

41. Urquhart J. Patient compliance with prescribed drug regimens: overview of the past 30 years of research. Clinical measurement in Drug Evaluation, 1995: p. 213-227.

42. Turner BJ and Hecht FM. Improving on a coin toss to predict patient adherence to medications. Ann Intern Med, 2001. 134(10): p. 1004-6.

43. Cramer JA. Microelectronic systems for monitoring and enhancing patient compliance with medication regimens. Drugs, 1995. 49(3): p. 321-7. 
44. Urquhart J. Role of patient compliance in clinical pharmacokinetics. A review of recent research. Clin Pharmacokinet, 1994. 27(3): p. 202-15.

45. Mushlin AI and Apple FA. Diagnosing potential noncompliance. Physicians' ability in a behavioral dimension of medical care. Arch Intern Med, 1977. 137(3): p. 318-321.

46. Steiner JF and Prochazka AV. The assessment of refill compliance using pharmacy records: methods, validity, and applications. J Clin Epidemiol, 1997. 50(1): p. 105-16.

47. Rudd P, Byyny RL, Zachary V, LoVerde ME, Titus C, Mitchell WD, and Marshall G. The natural history of medication compliance in a drug trial: limitations of pill counts. Clin Pharmacol Ther, 1989. 46(2): p. 169-76.

48. Waterhouse DM, Calzone KA, Mele C, and Brenner DE. Adherence to oral tamoxifen: a comparison of patient self-report, pill counts, and microelectronic monitoring. J Clin Oncol, 1993. 11(6): p. 1189-97.

49. Pullar T, Kumar S, Tindall H, and Feely M. Time to stop counting the tablets? Clin Pharmacol Ther, 1989. 46(2): p. 163-8.

50. Bertholet N, Favrat B, Fallab-Stubi CL, Brunner HR, and Burnier M. Why Objective Monitoring of Compliance is Important in the Management of Hypertension. J Clin Hypertens (Greenwich), 2000. 2(4): p. 258-262.

51. Waeber B, Vetter W, Darioli R, Keller U, and Brunner HR. Improved blood pressure control by monitoring compliance with antihypertensive therapy. Int J Clin Pract, 1999. 53(1): p. 37-8.

52. Urquhart J. Partial compliance in cardiovascular disease: risk implications. Br J Clin Pract Suppl, 1994. 73: p. 2-12.

53. Urquhart J. Ascertaining how much compliance is enough with outpatient antibiotic regimens. Postgrad Med J, 1992. 68 Suppl 3: p. S49-58; discussion S59.

54. Sackett DL, Haynes RB, Gibson ES, Taylor DW, Roberts RS, and Johnson AL. Patient compliance with antihypertensive regimens. Patient Couns Health Educ, 1978. 1(1): p. 18-21.

55. Krall RL. Interactions of compliance and patient safety, in Patient compliance in medical practice and clinical trials, J.A. Cramer and B. Spilker, Editors. 1991, Raven Press: New York. p. $19-25$.

56. Luscher TF, Vetter H, Siegenthaler W, and Vetter W. Compliance in hypertension: facts and concepts. J Hypertens Suppl, 1985. 3(1): p. S3-9.

57. Schroeder K, Fahey T, Ebrahim S, and Peters TJ. Adherence to long-term therapies: recent WHO report provides some answers but poses even more questions. J Clin Epidemiol, 2004. 57: p. 2-3.

58. Schroeder K, Fahey T, and Ebrahim S. Interventions for improving adherence to treatment in patients with high blood pressure in ambulatory settings. The Cochrane Database of Systematic Reviews 2004, 2004(3).

59. Schroeder K, Fahey T, and Ebrahim S. How can we improve adherence to blood pressurelowering medication in ambulatory care. Arch Intern Med, 2004. 164: p. 722-732. 


\section{Chapter 2}

Facts and fiction of poor compliance as a cause of inadequate blood pressure control:

a systematic review

Gwenn E.C. Wetzels, Patricia J. Nelemans, Jan

S.A.G. Schouten and Martin H. Prins

Journal of Hypertension 2004, 22: 1849-1855 


\begin{abstract}

\section{Objectives}

(1) To obtain an overview of measured compliance with antihypertensive medication; (2) to explore sources of variation in measured compliance percentages between studies and; (3) to investigate whether studies can establish a relationship between compliance and achieved blood pressure.
\end{abstract}

\title{
Study selection
}

MEDLINE, PubMed and EMBASE databases were searched for studies, published between 1985 and 2003, in which patient compliance with antihypertensive medication was measured with electronic monitors.

\section{Data extraction}

A standard form was used to extract relevant data from the included articles. Two investigators extracted all data independently.

\section{Results}

Thirty studies were identified. The studies included were highly varied in their methods used to quantify compliance. Taking compliance and/or correct dosing were used in 20 studies. Mean taking compliance for a once-daily regimen was $94.0 \pm 4.4 \%$ and $88.2 \pm 6.5 \%$ for a twice-daily regimen. Mean correct dosing was $85.0 \pm 8.7 \%$ for a once daily regimen and $75.3 \pm 6.5 \%$ for a twice-daily regimen. Proportions of patients with taking compliance or correct dosing $\leq 80 \%$ were provided by only five studies and ranged from 9 to $37 \%$. Studies with a monitoring period exceeding six months showed a distinct decrease in compliance over time. Studies on the association between achieved blood pressure and compliance gave inconsistent results.

\section{Conclusions}

Although poor compliance is assumed to be an important explanation for inadequate blood pressure control, any convincing empirical evidence to support this hypothesis is currently lacking. The relationship between patient compliance and blood pressure control has not yet been properly established. 


\section{Introduction}

It is generally agreed upon that pharmacological treatment of hypertension makes it possible to achieve substantial blood pressure reductions. ${ }^{1}$ However, only $30 \%$ of patients who use antihypertensive medication achieve adequate blood pressure control.2,3 Poor compliance with prescribed antihypertensive drug regimens is assumed to be the most important reason for unsatisfactory control of blood pressure. . $^{4-6}$ According to a recent report of the World Health Organization it is estimated that at least $50 \%$ of the patients in a general hypertensive population do not take their antihypertensive medication as prescribed. ${ }^{7}$ Similarly, in a recent study, $870 \%$ of the treating physicians indicated that poor compliance is the main reason for treatment failures.

Poor compliance with medication is difficult to recognize in clinical practice because its evaluation relies on subjective and therefore invalid methods, such as self-report by patients and pill counts. Less frequently, blood or urine samples are obtained to measure plasma drug concentrations, but this method is impracticable and not suitable for continuous monitoring of compliance. In 1986 electronic monitoring systems became available as a tool for objective registration of patient compliance. ${ }^{9}$ The electronic monitoring device exists of a medication bottle, with a cap that includes a microprocessor, which records the time and date of actual dosing events. Electronic monitoring is now considered as the "gold standard" for compliance measurements.

A systematic review was performed to investigate whether the assumption that lack of compliance with antihypertensive drugs is a common problem and an important cause of inadequate blood pressure control is medical lore or a fact supported by good quality evidence from literature. This review aims: 1) to give an overview of measured compliance with antihypertensive medication in studies using electronic monitoring 2) to explore sources of variation in measured compliance percentages between these studies and 3) to investigate whether these studies could establish a relationship between compliance percentages and blood pressure levels.

\section{Methods}

\section{Data sources}

Studies were identified through MEDLINE, PubMed and EMBASE searches using the following terms: patient compliance, patient adherence, hypertension, electronic monitoring and medication event monitoring system (MEMS). The reference lists of the obtained articles were screened to identify other eligible references, which were then retrieved. Letters to the editor, commentaries, review articles, editorials and abstracts were not included. Only English-language studies were considered. The search was updated until December 2003. 


\section{Study selection}

Studies were included in the review if they met the following criteria: 1) inclusion of a cohort of patients to be treated with antihypertensive drugs 2) assessment of compliance with electronic monitoring and 3) a monitoring period of at least 4 weeks.

Studies that did not present exact compliance percentages, or information about sample-size and duration of monitoring, were excluded. Similar data based on the same patient sample were included only once. Two investigators screened the full text of potentially relevant articles using the inclusion criteria. In all cases of disagreement, the investigators reached consensus.

\section{Compliance measurements}

Compliance can be defined according to several definitions, which are not always clearly specified in literature. The following definitions are most often used in literature:

- Taking compliance:

the percentage of prescribed doses taken, calculated as:

(total number of recorded medication events / total number of prescribed doses) X 100\%

- Correct dosing:

the percentage of days on which the correct number of doses was taken, calculated as:

(the total number of days with recorded medication events as prescribed/total number of monitored days) X $100 \%$

Variations on these measures, for example timing compliance which specifies timeintervals (for example $24 \pm 6$ hours) within which doses should be taken and compliance expressed as medication taken on at least six days a week, are also used. In addition, specific cut-off points to differentiate between patients considered compliant or noncompliant with treatment are used.

\section{Data extraction}

A standard form was used to extract relevant data from the included articles. Extracted data consisted of compliance measures and medication and study characteristics (Table 1 and 2). When reported, taking compliance and correct dosing were extracted (Table 1). Only when a study reported neither taking compliance nor correct dosing an alternative compliance measure was recorded (Table 2).

\section{Data synthesis}

The two most frequently reported measures of compliance, taking compliance and correct dosing, were pooled to determine mean compliance. 
Since in many of the included studies standard errors were not given and there appeared to be no relation between mean compliance and sample size, data were calculated without weighing. Sources of variation in measured compliance percentages were explored by comparing studies with and without a specific study characteristic with respect to mean compliance percentages. Differences were tested using Student's t-test $(\alpha=0.05)$.

\section{Results}

\section{Included studies}

We identified 3010-39 studies that electronically measured compliance with antihypertensive drugs in hypertensive patients. Two studies were excluded due to incomplete information about measured compliance rates, sample-size or duration of the monitoring period. 22,35 Three articles were not used for calculating average compliance percentages because the results were partly11,18 or completely ${ }^{30}$ published in more than one publication. In part of the included studies compliance was measured within the context of a randomised controlled trial. Most frequently, the primary objective of these trials was comparison of once- versus twice-daily dosing or comparison of two types of antihypertensive drugs. 


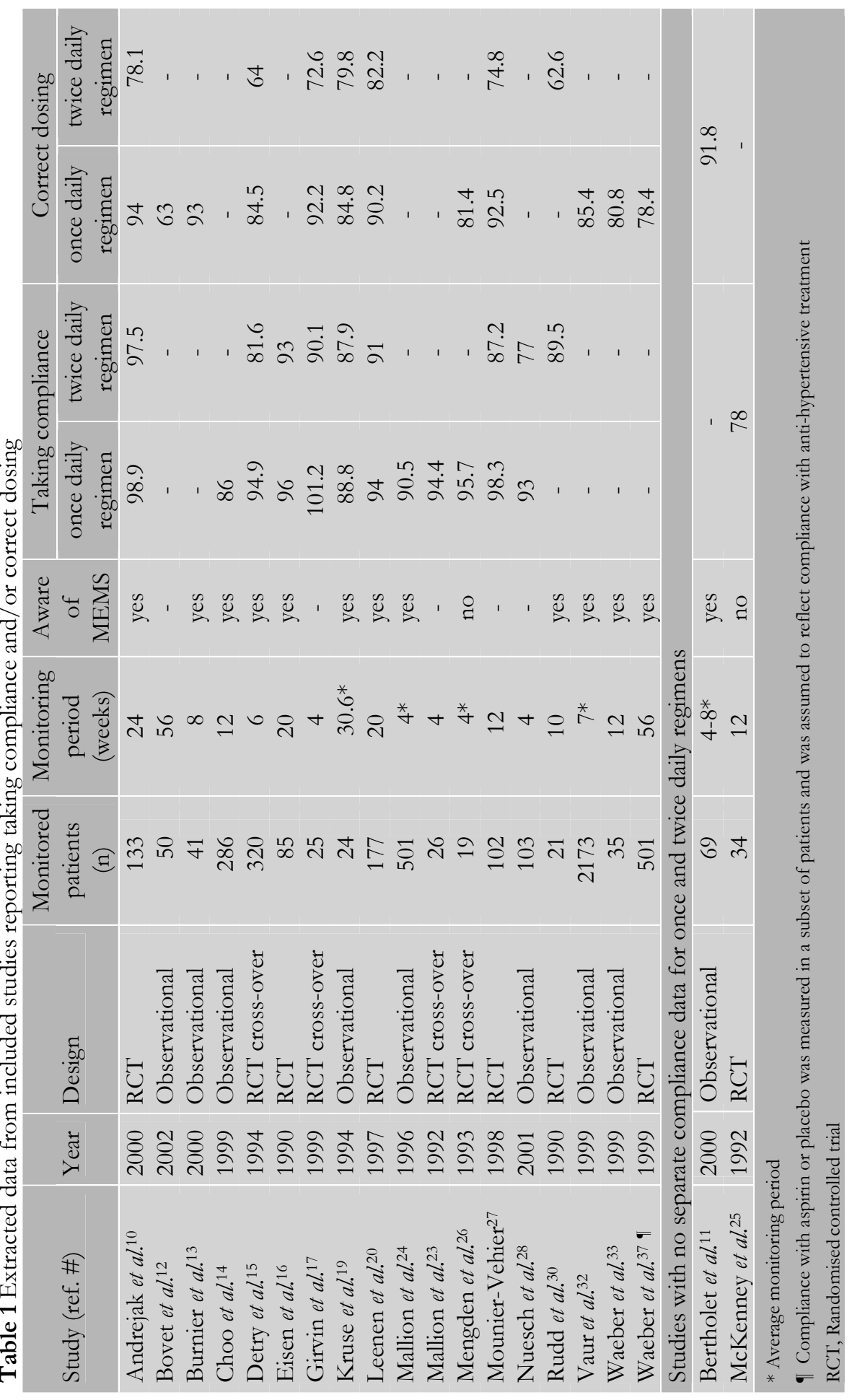




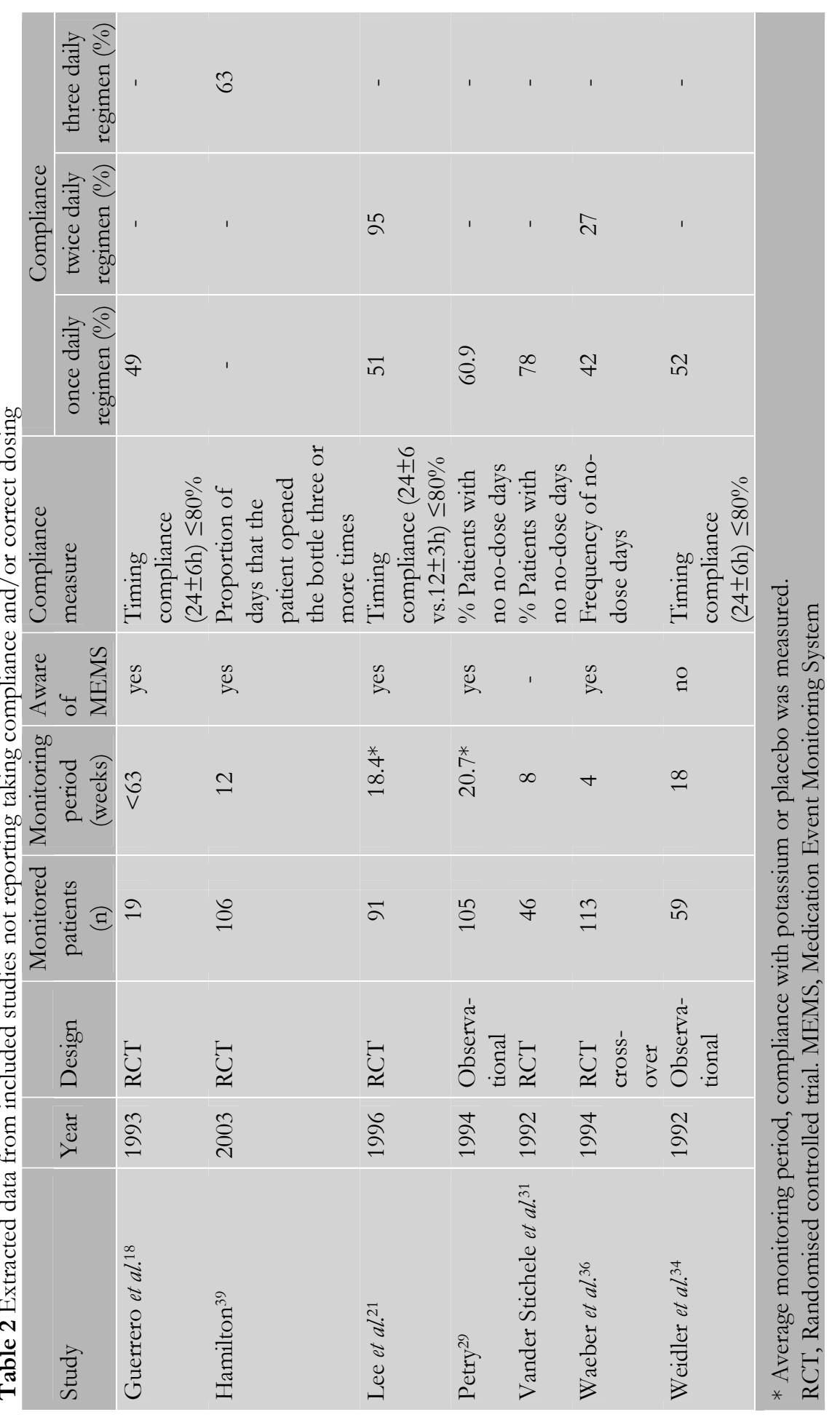




\section{Estimates of compliance}

The included studies varied highly in methods to quantify compliance (Table 1 and 2). Taking compliance and/or correct dosing were used in 20 studies. Mean taking compliance for a once-daily regimen was $94.0 \pm 4.4 \%(n=12)$ and $88.2 \pm 6.5 \%$ for a twice-daily regimen $(\mathrm{n}=9)$. Mean correct dosing was $85.0 \pm 8.7 \%$ for a once daily regimen $(n=12)$ and $75.3 \pm 6.5 \%$ for a twice-daily regimen $(n=7)$, respectively. Taking compliance and correct dosing were significantly higher for a once-daily regimen compared to a twice-daily regimen ( $\mathrm{p}=0.02$ and $\mathrm{p}=0.01$, respectively).

In a subset of 15 studies a specific cut-off point below which compliance was assumed unsatisfactory, was defined (Table 3). The data illustrate a large variation in compliance measures, cut-off points and medication regimens. Five studies on compliance with a once- daily regimen reported the percentage of patients with a taking compliance or correct dosing $\leq 80 \%$. According to these studies, the proportion of patients with inadequate compliance ranges from 9 to $37 \%$.

\section{Determinants of compliance}

In approximately $60 \%$ of the reviewed studies, compliance was measured within the context of a randomised controlled trial; the other studies were nonrandomised observational studies (Table 1 and 2). Taking compliance and correct dosing for a once- daily regimen was $96.7 \pm 2.5(\mathrm{n}=8)$ and $87.6 \pm 6(\mathrm{n}=7)$, respectively, in randomised controlled trials compared to $89.3 \pm 3.5(\mathrm{n}=4)$ and $81.4 \pm 11.2(\mathrm{n}=5)$ in observational studies, suggesting that measured compliance rates are somewhat higher in randomised controlled trials.

The length of the monitored period varied between 4 and 56 weeks (Table 1). Only three studies ${ }^{12,19,37}$ had monitoring periods exceeding six months. Average compliance was not higher in studies with shorter monitoring periods.

However, within some studies with a monitoring period exceeding six months, a distinct decrease in compliance over time could be shown. In the study by Bovet et al. ${ }^{12}$ the percentage of patients who took their medication at at least six days a week dropped from $73.9 \%$ in the first month to $54.6 \%$ after one year and, in the HOTstudy, ${ }^{37}$ compliance was significantly better in the first six months than during the second six-month period ( $84.1 \%$ vs. $72.3 \%)$.

Other studies, ${ }^{10,21}$ with shorter monitoring periods, fail to demonstrate a decrease in compliance rates in time. In only two studies, ${ }^{25,26}$ patients were not informed that their compliance was being monitored. In these studies, the measured compliance percentages (taking compliance; $96 \%$ and $78 \%$ ) were not lower than in the studies, wherein patients were aware of monitoring. 
Table 3 Extracted data from included studies that used specific cut-off points

\begin{tabular}{|c|c|c|c|c|c|}
\hline Study (ref.\#) & $\begin{array}{l}\text { Compliance } \\
\text { measure }\end{array}$ & $\begin{array}{c}\text { Monitoring } \\
\text { period } \\
\text { (weeks) }\end{array}$ & $\begin{array}{l}\text { Medication } \\
\text { regimen }\end{array}$ & $\begin{array}{c}\text { Cut-off } \\
\text { point } \\
(\%)\end{array}$ & $\begin{array}{c}\% \text { below } \\
\text { cut-off } \\
\text { point }\end{array}$ \\
\hline \multirow[t]{2}{*}{ Mallion et al..$^{24}$} & Taking compliance & 4 & 1 & $<80$ & 17 \\
\hline & Taking compliance & 4 & 1 & $<100$ & 80 \\
\hline \multirow[t]{3}{*}{ Waeber et al. ${ }^{33}$} & Taking compliance & 12 & 1 & $<80$ & 34 \\
\hline & Taking compliance & 12 & 1 & $<70$ & 20 \\
\hline & Taking compliance & 12 & 1 & $<50$ & 9 \\
\hline \multirow[t]{2}{*}{ Weidler et al. ${ }^{34}$} & Taking compliance & 18 & 1 & $<95$ & 35 \\
\hline & Taking compliance & 18 & 1 & $<80$ & 29 \\
\hline Burnier et al. ${ }^{13}$ & Correct dosing & 8 & 1 & $\leq 90$ & 20 \\
\hline Eisen et al. ${ }^{16}$ & Correct dosing & 20 & 1 & $<100$ & 13 \\
\hline Waeber et al. ${ }^{36}$ & Correct dosing & 4 & 1 & $\leq 80$ & 9 \\
\hline Vaur et al. ${ }^{32}$ & Correct dosing & $4-6$ & 1 & $\leq 80$ & 37 \\
\hline Guerrero et al..$^{18}$ & Timing compliance & $\leq 63$ & 1 & $\leq 80$ & 49 \\
\hline Lee $e t a .^{21}$ & Timing compliance & 18 & 1 & $<80$ & 51 \\
\hline Leenen et al. ${ }^{20}$ & Timing compliance & 20 & 1 & $\leq 80$ & 18 \\
\hline Weidler et al. ${ }^{34}$ & Timing compliance & 18 & 1 & $\leq 80$ & 52 \\
\hline Bovet et al. ${ }^{12}$ & $\begin{array}{l}\text { Medication taken } \\
6 / 7 \text { days a week }\end{array}$ & 4 & 1 & $\leq 85$ & 54 \\
\hline Petry ${ }^{29}$ & $\begin{array}{l}\% \text { of days with } \\
\text { correct dosing }\end{array}$ & $20.7^{*}$ & 1 & $<80$ & 4.6 \\
\hline Eisen et al. ${ }^{15}$ & Correct dosing & 20 & 2 & $<100$ & 19.2 \\
\hline Waeber ${ }^{36}$ & Correct dosing & 4 & 2 & $\leq 80$ & 34 \\
\hline Lee $e t a l .21$ & Timing compliance & 18 & 2 & $<80$ & 95 \\
\hline Leenen et al. ${ }^{20}$ & Timing compliance & 20 & 2 & $\leq 80$ & 46 \\
\hline Rudd et al. ${ }^{38}$ & $\begin{array}{l}\text { Monitored days } \\
\text { with no opening }\end{array}$ & 10 & 2 & $<100$ & 27 \\
\hline McKenney et al. ${ }^{25}$ & Taking compliance & 12 & $\operatorname{mix}$ & $\leq 80$ & 50 \\
\hline Neusch et al..$^{28}$ & Taking compliance & 4 & mix & $<80$ & 17 \\
\hline
\end{tabular}




\section{Blood pressure versus compliance}

Eight studies $11-13,21,24,28,32,37$ investigated the relationship between compliance percentage and blood pressure (Tables 4-6). Three approaches were used. Four studies $11,13,28,37$ compared compliance in subgroups of patients categorized according to achieved blood pressure (Table 4).

In all four studies, compliance in patients who achieved the target blood pressure was not statistically different from compliance in patients who did not.

Table 4 Comparison of compliance in subgroups categorized according to achieved blood pressure

\begin{tabular}{|c|c|c|c|c|}
\hline Study reference & Blood pressure subgroups & $\mathrm{n}$ & Compliance & $\begin{array}{l}\text { Significant } \\
\text { relation }\end{array}$ \\
\hline \multirow{4}{*}{ Bertholet et al. ${ }^{11}$} & & & Mean & \multirow{3}{*}{ No } \\
\hline & $\mathrm{BP}<140 / 90 \mathrm{mmHg}$ & 23 & $91 \%$ & \\
\hline & BP improved & 23 & $93 \%$ & \\
\hline & No change & 13 & $92 \%$ & \multirow{5}{*}{ No } \\
\hline \multirow{4}{*}{ Burnier et al. ${ }^{13}$} & & & Mean & \\
\hline & $\mathrm{DBP}<90 \mathrm{mmHg}$ & 14 & $97 \%$ & \\
\hline & DBP $91-100 \mathrm{mmHg}$ & 6 & $94 \%$ & \\
\hline & \multirow[t]{2}{*}{$\mathrm{DBP}>100 \mathrm{mmHg}$} & \multirow[t]{2}{*}{21} & $89 \%$ & \\
\hline \multirow{3}{*}{ Nuesch et al..$^{28}$} & & & Inadequate $(\leq 80 \%)$ & \multirow{3}{*}{ No } \\
\hline & Responsive to treatment & 54 & $15 \%$ & \\
\hline & Treatment resistant & \multirow[t]{2}{*}{49} & $18 \%$ & \\
\hline Waeber et al. ${ }^{37}$ & Exact numbers not given & & Exact numbers not given & No \\
\hline
\end{tabular}

Five studies ${ }^{12,13,21,24,32}$ used an opposite approach. In these studies the efficacy of antihypertensive treatment in subgroups of patients categorized according to compliance were compared (Table 5).

Four of these studies $12,13,21,32$ did demonstrate that better compliance was associated with significantly higher reduction in systolic and/or diastolic blood pressure or significantly higher percentages of patients with normalized blood pressure.

Finally, three studies $13,33,37$ evaluated the effect of compliance monitoring itself on blood pressure (Table 6). At the end of the monitoring period, diastolic blood pressure had normalized in $34 \%, 57 \%$ and $86 \%$ of patients, respectively. However, only in the HOT study ${ }^{37}$ a control group was used. In this study the percentage of patients achieving target diastolic blood pressure $\leq 90 \mathrm{mmHg}$ did not differ between the group with and without compliance monitoring ( $86 \%$ versus $85 \%$ ). 
Table 5 Comparison of efficacy of treatment in subgroups categorized according to compliance

\begin{tabular}{|c|c|c|c|c|c|}
\hline & $\begin{array}{l}\text { Compliance } \\
\text { Subgroups (n) }\end{array}$ & $\mathrm{n}$ & $\begin{array}{l}\text { Mean decrease } \\
\text { SBP/ } \\
\text { Mean decrease } \\
\text { DBP }\end{array}$ & $\begin{array}{l}\text { Target blood } \\
\text { pressure } \\
\text { achieved }\end{array}$ & $\begin{array}{l}\text { Significant } \\
\text { relation }\end{array}$ \\
\hline Bovet et al. ${ }^{12}$ & $\begin{array}{l}\text { 0-3 days/week } \\
\text { 4-5 days/week } \\
\text { 6-7 days/week }\end{array}$ & $\begin{array}{l}- \\
- \\
-\end{array}$ & $\begin{array}{r}7 \pm 13 / 5 \pm 6 \\
13 \pm 5 / 9 \pm 8 \\
16 \pm 12 / 9 \pm 6\end{array}$ & & $\begin{array}{l}\text { Yes } \\
\mathrm{p}=0.034 \\
\mathrm{p}<0.001\end{array}$ \\
\hline Burnier et al. ${ }^{13}$ & $\begin{array}{l}51-92 \% \\
93-99 \% \\
99-100 \%\end{array}$ & $\begin{array}{l}13 \\
14 \\
14\end{array}$ & & $\begin{array}{l}\text { Achieved } \\
\text { DBP higher } \\
\text { in lowest } \\
\text { tertile }\end{array}$ & $\begin{array}{l}\text { Yes } \\
p=0.044\end{array}$ \\
\hline Lee $e t a .^{21}$ & $\begin{array}{l}\text { Adherent } \\
\text { Non-adherent }\end{array}$ & $\begin{array}{l}18 \\
17\end{array}$ & & $\begin{array}{l}50 \% \\
14 \%\end{array}$ & $\begin{array}{l}\text { Yes } \\
p=0.001\end{array}$ \\
\hline Mallion et al. ${ }^{24}$ & $\begin{array}{l}0-50 \% \\
50-80 \% \\
80-100 \% \\
>100 \%\end{array}$ & $\begin{array}{r}19 \\
50 \\
297 \\
86\end{array}$ & $\begin{array}{l}14 \pm 21 / 11 \pm 9 \\
21 \pm 15 / 15 \pm 6 \\
18 \pm 16 / 11 \pm 9 \\
24 \pm 18 / 14 \pm 9\end{array}$ & & No \\
\hline Vaur et al. ${ }^{32}$ & $\begin{array}{l}0-49 \% \\
50-79 \% \\
80-100 \%\end{array}$ & $\begin{array}{r}120 \\
638 \\
1293\end{array}$ & $\begin{array}{l}21 \pm 13 / 14 \pm 9 \\
23 \pm 14 / 16 \pm 9 \\
23 \pm 15 / 16 \pm 8\end{array}$ & $\begin{array}{l}72 \% \\
82 \% \\
85 \%\end{array}$ & $\begin{array}{l}\text { Yes } \\
p=0.002\end{array}$ \\
\hline
\end{tabular}

Table 6 Effect of compliance monitoring on percentage of patients achieving target blood pressure

\begin{tabular}{l|c|r|c|c|} 
& Monitoring period & $\mathrm{n}$ & $\begin{array}{l}\text { Normalized DBP } \\
(\leq 90 \mathrm{mmHg})\end{array}$ & $\begin{array}{l}\text { Normalized SBP } \\
(\leq 140 \mathrm{mmHg})\end{array}$ \\
\hline Burnier et al. ${ }^{13}$ & 2 months & 41 & $34 \%$ & $32 \%$ \\
Waeber et al. ${ }^{33}$ & 3 months & 35 & $57 \%$ & $37 \%$ \\
Waeber et al. ${ }^{37}$ & 12 months & 501 & $86 \%(85 \%$ in total group $)$ & \\
\hline SBP, Systolic blood pressure. DBP, diastolic blood pressure &
\end{tabular}

\section{Discussion}

This review indicates that compliance with antihypertensive medication is suboptimal in most studies. However, due to the large variation in methods to quantify compliance and the inconsistency of study results, it is difficult to estimate the magnitude of the problem and its impact on blood pressure control. Does this mean that the often mentioned problem of non-compliance is exaggerated, or do alternative explanations account for the discrepancy between the observed 
compliance data and the assumed magnitude of the problem? To address this question, it is important to discuss a few issues that relate to the measurement of compliance.

To quantify compliance, many different measures are used. This lack of agreement is a serious limitation in comparing compliance studies. Correct dosing better reflects deviations in the dosing history from the prescribed regimen than taking compliance. It is therefore not surprising that studies using taking compliance as an outcome measure report higher compliance percentages than studies using the more stringent correct dosing. Moreover, it is important to realize that average compliance rates give no information about the group of patients that are most interesting to both investigators and clinicians, namely the poor compliers.

In this respect, the studies that defined a specific cut-off point below which compliance is considered to be inadequate were more informative, but only few studies used this approach.

Although the studies in this review used electronic monitoring, which is considered an objective method for compliance measurement, bias toward overestimation of compliance cannot be excluded. First, patients that participate in a trial do get specific attention, which may increase compliance. The finding that mean compliance percentages were higher in clinical randomised trials compared with observational studies corroborates this hypothesis. Second, it is conceivable that the informed consent procedure leads to selection of patients who do not have compliance problems, because they are expected to be more willing to participate in a study in which compliance is monitored. Third, in most studies patients were informed about the purpose of monitoring and the monitoring itself might have resulted in higher compliance, because the patient is aware of the fact that compliance is being monitored.

It is often hypothesized that this effect wears off as the monitoring period becomes longer. However, no evident trend can be seen between compliance rates and monitoring length. On the other hand, while studies with short monitoring periods ${ }^{10,21}$ fail to demonstrate a decrease in compliance rates in time, studies with a monitoring period of at least six months were able to demonstrate a clear-cut decrease in compliance over time.

This review also shows that, in agreement with other studies that demonstrate an inverse association between dose regimen and compliance, ${ }^{40,41}$ mean compliance percentages are higher on a once daily regimen (85-94\%) compared to a twice daily regimen (75-88\%). However this superiority of a once daily regimen has to be balanced with the drug duration of action, which is another critical determinant of effectiveness. Compliance in studies wherein patients were unaware of being monitored was not higher than in the other studies. However, in this review there were only two such studies. ${ }^{25} 26 \mathrm{~A}$ few studies studied the influence of monitoring itself on compliance. A study by Cramer et al. ${ }^{42}$ concluded that, although patients were aware that their compliance with anti-epileptic drugs was being monitored, this fact did not influence compliance. Kruse and Weber ${ }^{43}$ found a compliance of 
$91 \%$ in informed individuals compared with $78 \%$ in a group who did not understand the value of the electronic pillbox.

The lack of control of hypertension is often attributed to poor compliance. In several studies it has been demonstrated that blood pressure rises quickly when a dose is omitted. ${ }^{20}$ The eight studies ${ }^{11-13,21,24,28,32,37}$ on the association between compliance and blood pressure gave inconsistent results.

A methodological problem is that, in most of the studies, it was not clearly mentioned whether blood pressure measurements were performed by persons who were unaware of the compliance status of patients. Such lack of blinding could have introduced bias towards a positive association.

The most convincing, although indirect, evidence that increased compliance results in more adequate blood pressure control comes from the studies by Burnier et al. ${ }^{13}$ and Waeber et al. ${ }^{33}$ These studies demonstrated that blood pressure normalized or decreased after a period of monitoring. However, these studies did not use a control group.

Based on our observations, several recommendations can be made.

First, a serious limitation in comparing results of compliance studies is the lack of agreement in definitions of compliance. To facilitate such comparisons, measures to quantify compliance should be standardized.

Correct dosing seems to be preferable to taking compliance because it better reflects deviations in the dosing history from the prescribed regimen.

Second, the presentation of the proportion of patients who have a compliance percentage below a specific cut-off point provides more insight into the magnitude of the problem of poor compliance than average compliance rates. Because of lack of knowledge on how much compliance is enough, it would be useful to present multiple cut-off points.

Third, some study results suggest that monitoring itself increases compliance because the patient is aware of the fact that compliance is being monitored. If this is true, monitoring periods longer than six months seem necessary to obtain valid compliance data.

Finally, the fact that monitoring itself increases compliance can provide information to what extent monitoring can be used to manage the problem of non-compliance. Therefore, there is a need for randomised trials that are designed to evaluate whether normalization of blood pressure occurs more often in patients who are monitored than in patients without monitoring.

Such a finding would provide indirect evidence that lack of compliance is a cause of inadequate blood pressure control.

Accordingly, although many research groups are already focusing on interventions to improve compliance, many questions regarding the magnitude of the noncompliance problem remain to be answered. How much compliance is enough? What is the exact magnitude of the problem? What is the impact of noncompliance on patient outcome? All these questions are essential in clinical practice but remain to be answered. 


\section{References}

1. Knight EL, Bohn RL, Wang PS, Glynn RJ, Mogun H, and Avorn J. Predictors of uncontrolled hypertension in ambulatory patients. Hypertension, 2001. 38(4): p. 809-14.

2. Burt VL, Cutler JA, Higgins M, Horan MJ, Labarthe D, Whelton P, Brown C, and Roccella EJ. Trends in the prevalence, awareness, treatment, and control of hypertension in the adult US population. Data from the health examination surveys, 1960 to 1991. Hypertension, 1995. 26(1): p. 60-9.

3. Joint National Committee on prevention, evaluation, and treatment of high blood pressure. The sixth report of the Joint National Committee on prevention, detection, evaluation, and treatment of high blood pressure. Arch Intern Med, 1997. 157(21): p. 2413-46.

4. O'Rorke JE and Richardson WS. Evidence based management of hypertension: What to do when blood pressure is difficult to control. BMJ, 2001. 322(7296): p. 1229-32.

5. Urquhart J. Partial compliance in cardiovascular disease: risk implications. Br J Clin Pract Suppl, 1994. 73: p. 2-12.

6. Mar J and Rodriguez-Artalejo F. Which is more important for the efficiency of hypertension treatment: hypertension stage, type of drug or therapeutic compliance? J Hypertens, 2001. 19(1): p. $149-55$.

7. Sabate E. Adherence to long-term therapies: evidence for action. WHO, 2003(Geneva).

8. Menard J and Chatellier G. Limiting factors in the control of BP: why is there a gap between theory and practice? J Hum Hypertens, 1995. 9 Suppl 2: p. S19-23.

9. Cramer JA. Microelectronic systems for monitoring and enhancing patient compliance with medication regimens. Drugs, 1995. 49(3): p. 321-7.

10. Andrejak M, Genes N, Vaur L, Poncelet P, Clerson P, and Carre A. Electronic pill-boxes in the evaluation of antihypertensive treatment compliance: comparison of once daily versus twice daily regimen. Am J Hypertens, 2000. 13(2): p. 184-90.

11. Bertholet N, Favrat B, Fallab-Stubi CL, Brunner HR, and Burnier M. Why Objective Monitoring of Compliance is Important in the Management of Hypertension. J Clin Hypertens (Greenwich), 2000. 2(4): p. 258-262.

12. Bovet P, Burnier M, Madeleine G, Waeber B, and Paccaud F. Monitoring one-year compliance to antihypertension medication in the Seychelles. Bull World Health Organ, 2002. 80(1): p. 33-9.

13. Burnier M, Schneider MP, Chiolero A, Stubi CL, and Brunner HR. Electronic compliance monitoring in resistant hypertension: the basis for rational therapeutic decisions. J Hypertens, 2001. 19(2): p. 335-41.

14. Choo PW, Rand CS, Inui TS, Lee ML, Cain E, Cordeiro-Breault M, Canning C, and Platt R. Validation of patient reports, automated pharmacy records, and pill counts with electronic monitoring of adherence to antihypertensive therapy. Med Care, 1999. 37(9): p. 846-57.

15. Detry JM, Block P, De Backer G, and Degaute JP. Patient compliance and therapeutic coverage: comparison of amlodipine and slow release nifedipine in the treatment of hypertension. The Belgian Collaborative Study Group. Eur J Clin Pharmacol, 1995. 47(6): p. 477-81.

16. Eisen SA, Miller DK, Woodward RS, Spitznagel E, and Przybeck TR. The effect of prescribed daily dose frequency on patient medication compliance. Arch Intern Med, 1990. 150(9): p. 1881-4.

17. Girvin B, McDermott BJ, and Johnston GD. A comparison of enalapril $20 \mathrm{mg}$ once daily versus $10 \mathrm{mg}$ twice daily in terms of blood pressure lowering and patient compliance. J Hypertens, 1999. 17(11): p. 1627-31.

18. Guerrero D, Rudd P, Bryant-Kosling C, Middleton B, and Middleton BF. Antihypertensive medication-taking. Investigation of a simple regimen. Am J Hypertens, 1993. 6(7 Pt 1): p. 586-92.

19. Kruse W, Rampmaier J, Ullrich G, and Weber E. Patterns of drug compliance with medications to be taken once and twice daily assessed by continuous electronic monitoring in primary care. Int J Clin Pharmacol Ther, 1994. 32(9): p. 452-7. 
20. Leenen FH, Wilson TW, Bolli P, Larochelle P, Myers M, Handa SP, Boileau G, and Tanner J. Patterns of compliance with once versus twice daily antihypertensive drug therapy in primary care: a randomized clinical trial using electronic monitoring. Can J Cardiol, 1997. 13(10): p. 914-20.

21. Lee JY, Kusek JW, Greene PG, Bernhard S, Norris K, Smith D, Wilkening B, and Wright JT, Jr. Assessing medication adherence by pill count and electronic monitoring in the African American Study of Kidney Disease and Hypertension (AASK) Pilot Study. Am J Hypertens, 1996. 9(8): p. 719-25.

22. Lueg MC, Herron J, and Zellner S. Transdermal clonidine as an adjunct to sustained-release diltiazem in the treatment of mild-to-moderate hypertension. Clin Ther, 1991. 13(4): p. 471-81.

23. Mallion JM, Meilhac B, Tremel F, Calvez R, and Bertholom N. Use of a microprocessorequipped tablet box in monitoring compliance with antihypertensive treatment. J Cardiovasc Pharmacol, 1992. 19 Suppl 2: p. S41-8.

24. Mallion JM, Dutrey-Dupagne C, Vaur L, Genes N, Renault M, Elkik F, Baguet P, and Boutelant $\mathrm{S}$. Benefits of electronic pillboxes in evaluating treatment compliance of patients with mild to moderate hypertension. J Hypertens, 1996. 14(1): p. 137-44.

25. McKenney JM, Munroe WP, and Wright JT, Jr. Impact of an electronic medication compliance aid on long-term blood pressure control. J Clin Pharmacol, 1992. 32(3): p. 277-83.

26. Mengden T, Binswanger B, Spuhler T, Weisser B, and Vetter W. The use of self-measured blood pressure determinations in assessing dynamics of drug compliance in a study with amlodipine once a day, morning versus evening. J Hypertens, 1993. 11(12): p. 1403-11.

27. Mounier-Vehier C, Bernaud C, Carre A, Lequeuche B, Hotton JM, and Charpentier JC. Compliance and antihypertensive efficacy of amlodipine compared with nifedipine slow-release. Am J Hypertens, 1998. 11(4 Pt 1): p. 478-86.

28. Nuesch R, Schroeder K, Dieterle T, Martina B, and Battegay E. Relation between insufficient response to antihypertensive treatment and poor compliance with treatment: a prospective casecontrol study. BMJ, 2001. 323(7305): p. 142-6.

29. Petri JUH. Patient compliance with Beta-blocker medication in general practice. Pharmacoepidemiology and drug safety, 1994. 3: p. 251-256.

30. Rudd P, Ahmed S, Zachary V, Barton C, and Bonduelle D. Improved compliance measures: applications in an ambulatory hypertensive drug trial. Clin Pharmacol Ther, 1990. 48(6): p. 676-85.

31. Vander Stichele R. Measurement of patient compliance and the interpretation of randomized clinical trials. Eur J Clin Pharmacol, 1991. 41(1): p. 27-35.

32. Vaur L, Vaisse B, Genes N, Elkik F, Legrand C, and Poggi L. Use of electronic pill boxes to assess risk of poor treatment compliance: results of a large-scale trial. Am J Hypertens, 1999. 12(4 Pt 1): p. 374-80.

33. Waeber B, Vetter W, Darioli R, Keller U, and Brunner HR. Improved blood pressure control by monitoring compliance with antihypertensive therapy. Int J Clin Pract, 1999. 53(1): p. 37-8.

34. Weidler D, Wallin JD, Cook E, Dillard D, and Lewin A. Transdermal clonidine as an adjunct to enalapril: an evaluation of efficacy and patient compliance. J Clin Pharmacol, 1992. 32(5): p. 444-9.

35. Wurzner G, Gerster JC, Chiolero A, Maillard M, Fallab-Stubi CL, Brunner HR, and Burnier M. Comparative effects of losartan and irbesartan on serum uric acid in hypertensive patients with hyperuricaemia and gout. J Hypertens, 2001. 19(10): p. 1855-60.

36. Waeber B, Erne P, Saxenhofer H, and Heyen G. Use of drugs with a more than a twenty-fourhour duration of action. Journal of hypertension, 1994. 12 (suppl. 8): p. S67-S71.

37. Waeber B, Leonetti G, Kolloch R, and McInnes GT. Compliance with aspirin or placebo in the Hypertension Optimal Treatment (HOT) study. J Hypertens, 1999. 17(7): p. 1041-5.

38. Rudd P, Ahmed S, Zachary V, Barton C, and Bonduelle D. Compliance with medication timing: Implications from a medication trial for drug development and clinical practice. Journal of Clinical Research and Pharmacoepidemiology, 1992. 6: p. 15-27.

39. Hamilton GA. Measuring adherence in a hypertension clinical trial. Eur J Cardiovasc Nurs, 2003. 2(3): p. 219-28. 
40. Claxton AJ, Cramer J, and Pierce C. A systematic review of the associations between dose regimens and medication compliance. Clin Ther, 2001. 23(8): p. 1296-310.

41. Iskedjian M, Einarson TR, MacKeigan LD, Shear N, Addis A, Mittmann N, and Ilersich AL. Relationship between daily dose frequency and adherence to antihypertensive pharmacotherapy: evidence from a meta-analysis. Clin Ther, 2002. 24(2): p. 302-16.

42. Cramer JA, Quelette VL, and Mattson RH. The effect of microelectronic observation on compliance. Epilepsia, 1990. 31: p. 617-618.

43. Kruse W and Weber E. Dynamics of drug regimen compliance-its assessment by microprocessor-based monitoring. European Journal of Clinical Pharmacology, 1990. 38: p. 561-565. 


\section{Chapter 3}

Electronic monitoring of adherence as a tool to improve blood pressure control: a randomised controlled trial

Gwenn E.C. Wetzels, Patricia J. Nelemans, Jan S.A.G. Schouten, Carmen D. Dirksen, Trudy van der Weijden, Henri E.J.H. Stoffers, Rob Janknegt, Peter W. de Leeuw and Martin H. Prins

American Journal of Hypertension. In press. 


\begin{abstract}
Background

Poor adherence with antihypertensive drug regimens is believed to be a major contributor to treatment failure. Electronic monitoring of adherence may improve adherence and allow differentiation between those who are nonadherent and those who are pharmacologically nonresponsive. This pragmatic study is designed to evaluate the effectiveness of electronic monitoring of adherence in lowering blood pressure in comparison with usual care.
\end{abstract}

\title{
Methods
}

258 patients with high blood pressure despite use of antihypertensive medication were randomly assigned to either 1) continuation of usual care; if necessary, antihypertensive medication was adjusted or 2) introduction of electronic monitoring; adherence with antihypertensive medication was monitored for two months without medication changes. The primary outcome measure was the proportion of patients who reached target blood pressure levels after a five-month follow-up period.

\section{Results}

At five months, 50.6\% of the patients in the usual care group reached adequate blood pressure versus $53.7 \%$ in the electronic monitoring group $(p=0.73)$. The percentages of patients with drug additions and/or increases in dosage were higher in the usual care group compared with those in whom adherence was monitored $(\mathrm{p}<0.01)$.

\section{Conclusion}

These data show that electronic monitoring in comparison to usual care results in similar blood pressure control but leads to less drug changes and drug use. This result is likely to be achieved through improving adherence. Hence, a strategy that includes electronic monitoring has the potential to avoid the pitfall of unnecessary treatment escalation in patients with poor adherence. 


\section{Introduction}

Poor adherence with antihypertensive treatment is likely to be a major contributor to treatment failure which may result in more visits to health professionals, unnecessary medication-switches, dose escalations and even hospitalization. ${ }^{1}$ It is estimated that at least $50 \%$ of the patients in a general hypertensive population do not take their antihypertensive medication as prescribed. ${ }^{2}$ Therefore, improving adherence with prescribed drug regimens in this population remains a major challenge to the treating physician.

Over the last decades, several studies assessing adherence with antihypertensive drugs have used pillboxes that electronically record every opening. ${ }^{3}$ Mean adherence rates in these studies ranged between 75 and $95 \%$ depending on the definitions used. ${ }^{4-11} \mathrm{~A}$ few studies have assessed the effect of the use of electronic monitors on blood pressure. ${ }^{12-14}$ Interestingly, even without treatment adjustment, electronic monitoring of adherence may lead to lower blood pressure levels or even a normalization of blood pressure in a substantial part of the patients as illustrated, for instance, by a study of Burnier et al. ${ }^{12}$ Comparable results were obtained by Waeber et al., ${ }^{14}$ who found that diastolic blood pressure normalized in $57 \%$ of patients after a three-month monitoring period. These studies indicate that inadequate adherence may be responsible for a lack of response to the prescribed medication, at least in part of the hypertensive population, and that the problem can be managed to a certain degree by monitoring adherence. Unfortunately, both studies did not use a control group. This is important because the very fact that patients are being monitored under experimental conditions may already reduce blood pressure, irrespective of changes in adherence within patients. Therefore we performed a pragmatic randomised controlled trial, in which we compared an experimental strategy using electronic monitoring of adherence with usual clinical care in patients who had uncontrolled hypertension despite antihypertensive treatment. This design allows us to ascertain in these patients whether electronic monitoring is an effective alternative to routine clinical practice, which would imply increasing the intensity of pharmacological treatment.

\section{Methods}

\section{Study population}

Patients were recruited by 43 physicians in the Netherlands in the period from September 2002 to March 2004. Five-month follow-up was completed in September 2004.

Patients were eligible if they met all of the following criteria: a) diagnosis of hypertension, b) inadequate blood pressure control despite the use of antihypertensive drugs and c) indication for treatment escalation.

Patients were excluded if they changed therapy because of adverse effects of current medication, insisted on using dose organizers, were not managing their 
drug intake themselves, or were institutionalised. Treatment escalation was defined as increase in dosage of existing medication and/or addition of other antihypertensive drugs. Hypertension was defined as a systolic blood pressure $(\mathrm{SBP}) \geq 160 \mathrm{mmHg}$ and/or diastolic blood pressure (DBP) $\geq 95 \mathrm{mmHg}^{15}$ according to the national guideline of the family physicians which were in force at the start of the study.

In the Dutch health care system all citizens are enlisted with a family physician. This family physician functions as a gatekeeper to secondary care. All included patients gave written informed consent.

\section{Study design}

In the first phase of the study, which lasted two months, patients were randomly assigned to either of two strategies: 1) continuation of usual care; with adjustment of antihypertensive medication if necessary or 2) introduction of electronic monitoring and no medication changes.

Randomisation was performed centrally through the Trial Coordinating Centre by telephone. For each physician a random allocation scheme was generated by the study coordinator using computer-generated random permuted blocks with a block size of 6 . The treating physician phoned the Trial Coordinating Center in order to randomise the patient to its treatment group. Within the first phase, adherence in patients who were assigned to electronic monitoring was monitored electronically for two months without medication changes. Patients in the monitoring group received, for each antihypertensive drug they used, a pillbox equipped with a microchip in its lid that registered the date and time of each opening (Medication Event Monitoring System (MEMS), Aardex corp., Geneve). MEMS monitors were provided to the patients by their local pharmacists. Although neither the treating physician nor the pharmacist did address the issues of adherence with the included patients, patients were aware that the MEMS monitor recorded the date and time of each opening of the medication bottle. This information was mentioned in the patient information in order to meet the requirements of the medical ethical committee. Each opening was considered as being a single dose intake. After the two-month monitoring period, adherence data were downloaded to a personal computer using dedicated software (PowerView version 2 software (Aardex corp., Geneve) and the adherence data were discussed with the patients (feedback). Adherence was defined as the percentage of days with number of doses taken as prescribed, i.e. correct dosing. Patients were, arbitrarily, considered to be compliant when the percentage of days with correct dosing was $\geq 85 \%$ for all prescribed antihypertensive medications. At the end of the first phase, patients from the monitoring group were referred to the treating physician. The physician was informed about blood pressure and adherence and could then decide whether to change the medication. 
During the second phase of the trial which lasted three months, patients from both experimental arms received usual care. This design allowed us to evaluate whether a short-term intervention with a monitor is sufficient to maintain the bloodpressure lowering effect of monitoring over time.

The study was approved by the Medical Ethical Committee of Maastricht University.

\section{Baseline and follow-up measurements}

\section{Adherence measurements}

In addition to the measurements by the electronic monitors, adherence based on pharmacy records was estimated for a period of twelve months prior to the start of electronic monitoring. Furthermore, to assess the occurrence of selection bias, we also determined refill adherence from 40 patients who chose not to participate in the trial.

Refill adherence during the interval between two prescription fills was calculated as the number of days for which pills were prescribed divided by the total number of days in this interval. Mean percentage refill adherence for the period of 12 months preceding the trial was computed by adding the percentages of each interval and dividing the sum by the number of intervals. Satisfactory refill adherence was, as is the case with correct dosing, defined as an average refill adherence $\geq 85 \%$.

\section{Blood pressure measurements}

At inclusion, office blood pressure was measured by the physician using conventional sphygmomanometry. Further blood pressure measurements were carried out at the end of the first and second phase of the trial ( 2 and 5 months after inclusion). To avoid assessment bias due to the fact that the treating physician was aware of the treatment allocation, all these measurements ( 2 and 5 months) were performed by a research nurse using the Omron 705 CP automated blood pressure monitor with printed output. At each follow-up visit, blood pressure was measured three times in a sitting position after five minutes of rest. Mean SBP and DBP were used for analysis.

\section{Statistical analysis}

We applied a randomisation ratio of electronic monitoring versus usual care of 2:1. This asymmetric allocation schema was chosen to provide a reliable estimate of the percentage non-adherence in the electronic monitoring group. It was assumed that normalization of blood pressure would occur in $50 \%$ of the patients in the usual care group. In order to reject the hypothesis of a difference in proportions with normalized blood pressure of $20 \%$ or more with a significance level of $5 \%$ (twosided) and a power of 85\%, 164 and 89 patients were needed in the monitoring and usual care group, respectively. With this sample size, the power to demonstrate with $95 \%$ confidence (two-sided) a difference of $15 \%$ or more is 60 . 
Relevant baseline characteristics were collected to assess the comparability of the randomised groups.

Results were analysed according to an intention-to-treat analysis. The primary outcome measure was the proportion of patients with normalized blood pressure $(\mathrm{SBP}<160 \mathrm{mmHg}$ and $\mathrm{DBP}<95 \mathrm{mmHg}$ ) at 5 months after inclusion. Secondary endpoints were a) the proportion of patients with non-normalized but improved blood pressure (SBP reduction $\geq 10 \mathrm{mmHg}$ and DBP reduction $\geq 5 \mathrm{mmHg}$ ) b) the mean reduction in systolic and diastolic blood pressure as compared with the blood pressure which was measured by the physician at inclusion, and c) the proportion of patients with escalation of medication. Differences between proportions were tested using the Chi square test, differences between means were tested by unpaired Student's t-tests $(\alpha=0.05)$.

Logistic multivariate regression models were used to adjust for small imbalances in baseline characteristics between groups.

\section{Results}

\section{Patients}

Between September 2002 and March 2004, a total of 258 patients were recruited. Two of them were lost to follow up because they refused further participation because of illness. One patient died of stroke and two patients refused further cooperation after inclusion without giving a specific reason. Therefore, complete outcome measures were available for 253 patients (98\%), 164 patients in the electronic monitoring group and 89 patients in the usual care group (Fig. 1). The patients' characteristics are shown in Table 1. Percentages of patients with satisfactory adherence based on pharmacy data were comparable in both groups ( $81 \%$ versus $77 \%$ in the electronic monitoring and usual care group, respectively). The percentage of patients with adequate adherence in a random sample of patients that did not participate in the study was $87 \%$. 
Figure 1 Flow of participants through the study

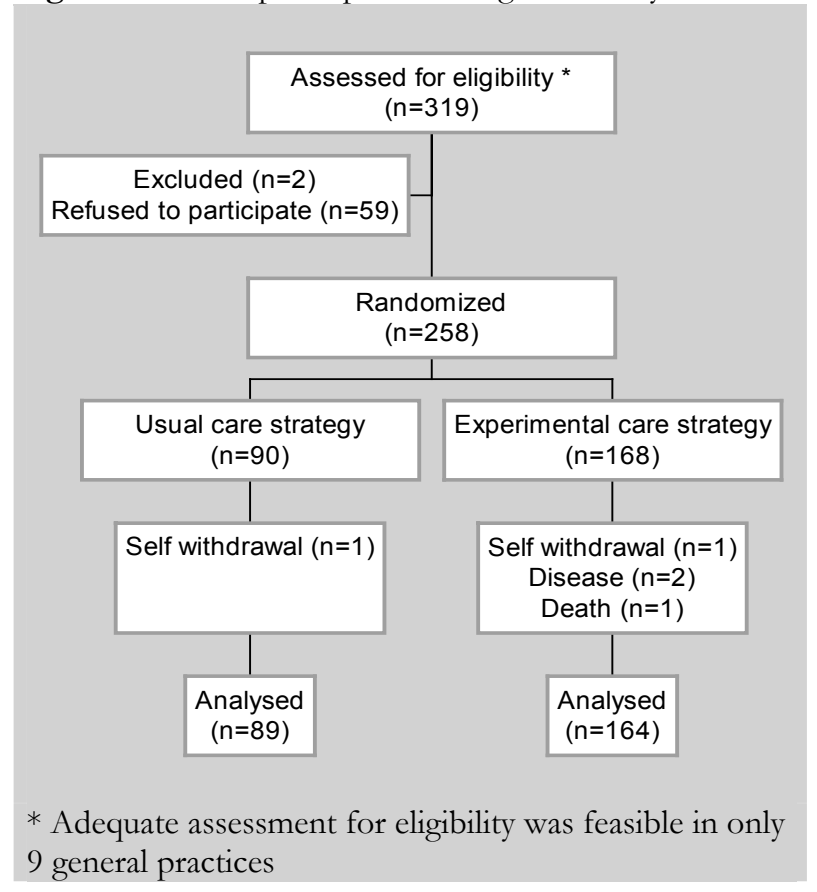

\section{First phase}

At the end of the first phase of the trial, at 2 months after inclusion, $38.6 \%$ in the electronic monitoring group versus $57.8 \%$ of the patients in the usual care group reached adequate blood pressure $(\mathrm{p}<0.01)$.

After two months of monitoring, average adherence, expressed as percentage of days with correct dosing, was $95.3 \pm 10 \%$ in the electronic monitoring group. Percentage of correct dosing was $\geq 85 \%$ in $95.8 \%$ of the patients randomised to electronic monitoring group. Monitoring adherence was better than refill adherence as determined before inclusion. Refill adherence, also with a cut-off point of $\geq 85 \%$, showed that adherence was satisfactory in only $81 \%$ of these patients (Table 1). 
Table 1 Baseline characteristics of included patients ( $n=258)$

\begin{tabular}{|c|c|c|}
\hline Demographic characteristics (\%) \# & $\begin{array}{l}\text { Usual care group } \\
\qquad(\mathrm{n}=90)\end{array}$ & $\begin{array}{c}\text { Electronic } \\
\text { monitoring group } \\
(n=168)\end{array}$ \\
\hline \multicolumn{3}{|l|}{ Age (y) } \\
\hline$\leq 55$ & 23 & 20 \\
\hline $56-65$ & 32 & 43 \\
\hline $66-75$ & 43 & 29 \\
\hline$\geq 75$ & 1 & 8 \\
\hline \multicolumn{3}{|l|}{ Gender } \\
\hline Male & 59 & 49 \\
\hline \multicolumn{3}{|l|}{ Education } \\
\hline Low & 27 & 26 \\
\hline Middle & 33 & 32 \\
\hline High & 27 & 32 \\
\hline Very high & 13 & 10 \\
\hline \multicolumn{3}{|l|}{ Employed } \\
\hline Yes & 30 & 29 \\
\hline No & 70 & 71 \\
\hline \multicolumn{3}{|l|}{ Civil status } \\
\hline Married & 78 & 75 \\
\hline Widow/widower & 13 & 14 \\
\hline \multicolumn{3}{|l|}{ Clinical characteristics (Mean (SD)) } \\
\hline Years with hypertension & $9 \quad(9)$ & $10(9)$ \\
\hline BMI $(\mathrm{kg} / \mathrm{m} 2)$ & 28 (4) & $29(5)$ \\
\hline Smoking $(\%)$ & 21 & 21 \\
\hline Cardiovascular diseases family (\%) & 44 & 40 \\
\hline Cholesterol $>5 \mathrm{mmol}(\%)$ & 46 & 53 \\
\hline Diabetes Mellitus (\%) & 19 & 24 \\
\hline Left ventricle hypertrophy $(\%)$ & 2 & 3 \\
\hline Congestive heart failure $(\%)$ & 1 & 1 \\
\hline Angina Pectoris $(\%)$ & 9 & 7 \\
\hline Myocardial infarction (\%) & 1 & 5 \\
\hline TIA $(\%)$ & 6 & 3 \\
\hline Stroke $(\%)$ & 5 & 3 \\
\hline Peripheral arterial disease $(\%)$ & 4 & 9 \\
\hline \multicolumn{3}{|l|}{ Baseline treatment $(\%)$} \\
\hline Diuretics & 3 & 4 \\
\hline ß-blockers & 10 & 11 \\
\hline Calcium antagonists & 1 & 3 \\
\hline ACE inhibitors & 9 & 9 \\
\hline Others & 9 & 10 \\
\hline Combination of different drugs & 68 & 63 \\
\hline \multicolumn{3}{|l|}{ Total number of antihypertensive tablets (\%) } \\
\hline$\leq 2$ tablets & 67 & 78 \\
\hline$>2$ tablets & 33 & 22 \\
\hline$\%$ Adherers (based on pharmacy records) & 77 & 81 \\
\hline
\end{tabular}

46 | Electronic monitoring as a tool to improve blood pressure control 
Immediately upon monitoring, patients from the experimental group were referred to their physician. Medication was escalated (drug additions and/or dose escalations) in $47.6 \%$ of the patients with no improvement in blood pressure in comparison with $16.3 \%$ in the patients with improved or normalized blood pressure in the electronic monitoring group.

\section{Second phase}

Whereas there were clear differences in blood pressure control between the usual care and electronic monitoring group at 2 months, this difference disappeared at 5 months. At 5 months after inclusion, $50.6 \%$ of the patients in the usual care group reached adequate blood pressure versus $53.7 \%$ in the electronic monitoring group $(\mathrm{p}=0.73)$. In addition, blood pressure had not normalized but substantially decreased in $11.2 \%$ versus $16.5 \%$ of the patients $(\mathrm{p}=0.35$ ). Average blood pressure reductions were similar $(10 \mathrm{mmHg}$ for $\mathrm{DBP}$ and $15 \mathrm{mmHg}$ for SBP in both groups, respectively) (Table 2).

The percentages of drug additions and/or dose escalations were higher in the usual care group compared to the electronic monitoring group $(\mathrm{p}<0.01)$. Initially, in the usual care group medication was changed in $72.3 \%$ of the patients shortly after enrolment. In $12.2 \%$ of the patients in the usual care group, medication was readjusted again resulting in a net result of no change at five months. Eventually, the net percentage of patients with a dose increase and/or drug addition was $61.1 \%$ in the usual care group (Table 3). In the monitoring group, at 5 months medication had been changed in $33.5 \%$, and readjusted in $4.6 \%$, resulting in a net increase in $28.9 \%$ of the patients. The difference in proportions between the groups with a net change in medication $(-32.2 \%)$ was statistically significant $(\mathrm{p}<0.01)$ (Table 3).

Table 1 showed that there were small imbalances in baseline characteristics between groups. None of the differences were statistically significant, but we incorporated baseline variables with a difference exceeding 3\% in a multivariate logistic model in order to check whether the small differences affected the result. This was not the case. Monitoring was associated with an OR=1.12 (95\% CI: 0.671.88) for normalization at 5 months before adjustment, and an OR $=1.11$ ( $95 \%$ CI: $0.59-2.08$ ) after adjustment (for age ( $\leq 65$ vs. $>65$ ), gender, cholesterol $\geq 5 \mathrm{mmol} / \mathrm{l}$, diabetes mellitus, myocardial infarction, peripheral arterial disease (and number of antihypertensive tablets per day $(\leq 2$ vs. $>2)$. 


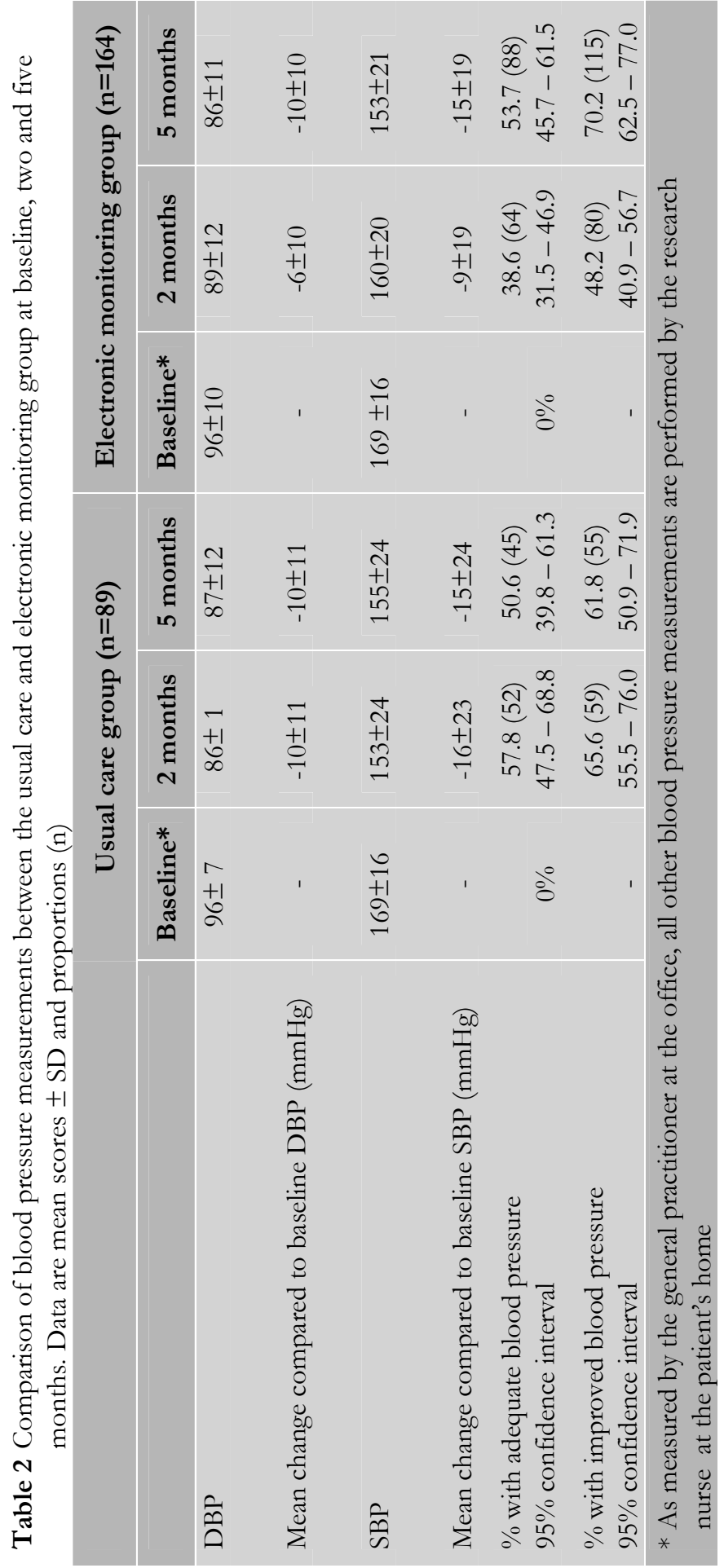


Table 3 Comparison of the number of dose increase or addition of drugs after five months between the usual care and electronic monitoring group

\begin{tabular}{|c|c|c|}
\hline \multirow{2}{*}{$\begin{array}{c}\text { Number of dose } \\
\text { increases or additions }\end{array}$} & \multicolumn{2}{|c|}{$\begin{array}{c}\text { Percentage of patients with a dose increase and/or } \\
\text { addition of (a) } \operatorname{drug}(\mathrm{s}) \#\end{array}$} \\
\hline & $\begin{array}{l}\text { Usual care group } \\
\qquad(n=89)\end{array}$ & $\begin{array}{l}\text { Electronic monitoring group } \\
\qquad(n=164)\end{array}$ \\
\hline-1 & 1.1 & 0.6 \\
\hline $0^{*}$ & 37.8 & 70.5 \\
\hline 1 & 52.2 & 26.5 \\
\hline 2 & 7.8 & 1.8 \\
\hline 3 & 1.1 & 0.6 \\
\hline \multicolumn{3}{|c|}{$\begin{array}{l}\text { \# Differences in proportions between the groups: } \mathrm{p}<0.01 \\
\text { * Includes both patients with no medication change during the follow up period and } \\
\text { patients with an initial increase in medication followed by a decrease resulting in a net } \\
\text { change of zero. }\end{array}$} \\
\hline
\end{tabular}

\section{Discussion}

An important observation in our study was that electronic monitoring of adherence resulted in a normalization of blood pressure in $53.7 \%$ of the patients whereas the need for treatment escalations was strongly reduced.

These data support the assumption that poor adherence is a common cause of treatment resistant hypertension and provide evidence that in many patients persisting hypertension has its origin in poor adherence. ${ }^{16}$

An obvious explanation for our findings is that patients were aware of the fact that they were being monitored, because this was explained to them in the patient information. This probably encouraged them to be more compliant with treatment than they used to be. This assumption also explains the low prevalence of poor adherence during electronic monitoring whereas pharmacy records revealed that the prevalence of poor adherence before the start of the study was $19 \%$ in the electronic monitoring group.

An important question when applying electronic monitoring in clinical practice is whether a short-term intervention with a monitor is sufficient to maintain the blood-pressure lowering effect of monitoring over time. From our results it can be concluded that a relatively short monitoring period is sufficient to sustain blood pressure reductions for at least 5 months.

Possibly these results reflect a patient's learning process in which daily medication intake eventually becomes incorporated as a habit.

The results of this study are in agreement with other studies, which also point in this direction. In contrast with the general assumption that adherence is inadequate in about $40 \%$ to $50 \%$ of patients, ${ }^{2}$ recent studies using electronic monitoring often report lower proportions of patients with poor adherence. $4,7,9,17$ This discrepancy suggests that electronic monitoring itself improves adherence. 
More direct evidence comes from studies of Burnier ${ }^{12}$ and Waeber, ${ }^{14}$ which demonstrated that a two or three-month period of monitoring of adherence was associated with a significant improvement of blood pressure.

According to recent reviews most interventions are complex, labour-intensive and not predictably effective. ${ }^{18,19}$ Electronic monitoring would be an easy to use intervention in contrast to other interventions that have been evaluated in randomised controlled trials.

Certain methodological issues in the present study deserve attention. Patients were informed about the study and gave written consent to participate in the study. Theoretically this could lead to a selection of patients who have fewer problems with taking their medication as prescribed. Such a selection could explain the overall high percentage of adherence as measured with electronic monitoring. Therefore, refill adherence from all participants was compared with that of forty patients that chose not to participate in the study. In $13 \%$ of the patients who did not participate adherence was poor, compared to $20 \%$ in the group of participants. This finding indicates that patients with adherence problems, as defined by refill adherence, were more inclined to participate, making selection bias towards patients with good adherence less likely.

Baseline blood pressure measurements were office based and made by the physician, whereas blood pressure measurements at the end of the first phase and second phase were performed by the research nurse using the Omron $705 \mathrm{CP}$ automated blood pressure monitor. Part of the decrease in blood pressure in both groups might be explained by different measurement methods during inclusion and follow-up (measurement bias). However, given the fact that the effectiveness of antihypertensive medication is well accepted, the decrease in blood pressure in the usual care group cannot be explained by measurement bias solely. Likewise, it can be expected that part of the decrease in blood pressure in the electronic monitoring group can be attributed to electronic monitoring.

According to the protocol, medication should have been escalated in all patients who were assigned to the usual care strategy. However, in the usual care group medication was not changed in $27.7 \%$ of the patients. A common reason for this was that the treating physician preferred to await the effects of life-style changes on blood pressure.

It can be argued that the fact that medication was not changed in some patients resulted in underestimation of the five-month blood pressure reductions that can be achieved by medication change. However, lack of adjustment also occurred in the electronic monitoring group in those patients, who after monitoring still had high blood pressure (40 out of 84 patients). Assuming that these patients had an indication for medication adjustment, non-adherence to the national guidelines occurred in a similar proportion as in the usual care group, namely in $24.4 \%$ $(40 / 164)$ of patients. Therefore, it is unlikely that the similar effectiveness in both strategies can be attributed to differences in protocol deviations between the groups. 
Implementation of electronic monitoring in general practice could be recommended in situations where patients do not reach blood pressure targets and both patient and physician are reluctant to increase the dose or number of antihypertensive drugs. In consensus with the patient, it is possible to explore whether dosing errors may be a cause of inadequate response to antihypertensive medication. Thus, in the group of patients with adherence problems the use of an electronic monitor can offer an escape from further escalation of antihypertensive medication or further diagnostic work-up.

To our knowledge this is the first randomised study on the effect of electronic monitoring on blood pressure regulation. Further randomised trials with longer follow-up are needed to confirm the effectiveness of this approach and to evaluate whether blood pressure control can be sustained over a longer period of time.

\section{Conclusion}

It can be concluded that electronic monitoring that electronic monitoring in comparison to usual care results in similar blood pressure control, but leads to less drug changes and drug use.

This result is likely to be achieved through improving adherence. According to these results, electronic monitoring expands the therapeutic possibilities to treat hypertension.

\section{Acknowledgements}

The authors gratefully acknowledge the Health Care Insurance Board for funding this project. We would like to thank Professor John Urquhart for his helpful suggestions regarding the design and execution of the trial. Furthermore we thank Claudia Gulikers, our research nurse who visited all patients and performed the majority of measurements. Finally we would like to thank all participating physicians. 


\section{References}

1. O'Rorke JE and Richardson WS. Evidence based management of hypertension: What to do when blood pressure is difficult to control. BMJ, 2001. 322(7296): p. 1229-32.

2. Sabate E. Adherence to long-term therapies: evidence for action. WHO, 2003(Geneva).

3. Urquhart J. Partial compliance in cardiovascular disease: risk implications. Br J Clin Pract Suppl, 1994. 73: p. 2-12.

4. Eisen SA, Miller DK, Woodward RS, Spitznagel E, and Przybeck TR. The effect of prescribed daily dose frequency on patient medication compliance. Arch Intern Med, 1990. 150(9): p. 1881-4.

5. Girvin B, McDermott BJ, and Johnston GD. A comparison of enalapril $20 \mathrm{mg}$ once daily versus $10 \mathrm{mg}$ twice daily in terms of blood pressure lowering and patient compliance. J Hypertens, 1999. 17(11): p. 1627-31.

6. Kruse W, Rampmaier J, Ullrich G, and Weber E. Patterns of drug compliance with medications to be taken once and twice daily assessed by continuous electronic monitoring in primary care. Int J Clin Pharmacol Ther, 1994. 32(9): p. 452-7.

7. Leenen FH, Wilson TW, Bolli P, Larochelle P, Myers M, Handa SP, Boileau G, and Tanner J. Patterns of compliance with once versus twice daily antihypertensive drug therapy in primary care: a randomized clinical trial using electronic monitoring. Can J Cardiol, 1997. 13(10): p. 914-20.

8. Mallion JM, Meilhac B, Tremel F, Calvez R, and Bertholom N. Use of a microprocessorequipped tablet box in monitoring compliance with antihypertensive treatment. J Cardiovasc Pharmacol, 1992. 19 Suppl 2: p. S41-8.

9. Nuesch R, Schroeder K, Dieterle T, Martina B, and Battegay E. Relation between insufficient response to antihypertensive treatment and poor compliance with treatment: a prospective casecontrol study. BMJ, 2001. 323(7305): p. 142-6.

10. Rudd P, Ahmed S, Zachary V, Barton C, and Bonduelle D. Improved compliance measures: applications in an ambulatory hypertensive drug trial. Clin Pharmacol Ther, 1990. 48(6): p. 676-85.

11. Wetzels GEC, Nelemans P, Schouten JS, and Prins MH. Facts and fiction of poor compliance as a cause of inadequate blood pressure control: a systematic review. J Hypertens, 2004. 22(10): p. 1849-55.

12. Burnier M, Schneider MP, Chiolero A, Stubi CL, and Brunner HR. Electronic compliance monitoring in resistant hypertension: the basis for rational therapeutic decisions. J Hypertens, 2001. 19(2): p. 335-41.

13. Bertholet N, Favrat B, Fallab-Stubi CL, Brunner HR, and Burnier M. Why Objective Monitoring of Compliance is Important in the Management of Hypertension. J Clin Hypertens (Greenwich), 2000. 2(4): p. 258-262.

14. Waeber B, Vetter W, Darioli R, Keller U, and Brunner HR. Improved blood pressure control by monitoring compliance with antihypertensive therapy. Int J Clin Pract, 1999. 53(1): p. 37-8.

15. Geijer RMM, Burgers JS, Van der Laan JR, Wiersma T, Rosmalen CFH, and Thomas S. NHGStandaard Hypertensie, tweede herziening, in NHG-standaarden voor de huisarts, deel 1. 1999, Elsevier/Bunge: Maarssen. p. 187-205.

16. Wright EC. Non-compliance--or how many aunts has Matilda? Lancet, 1993. 342(8876): p. 90913.

17. Mallion JM, Dutrey-Dupagne C, Vaur L, Genes N, Renault M, Elkik F, Baguet P, and Boutelant $\mathrm{S}$. Benefits of electronic pillboxes in evaluating treatment compliance of patients with mild to moderate hypertension. J Hypertens, 1996. 14(1): p. 137-44.

18. McDonald HP, Garg AX, and Haynes RB. Interventions to enhance patient adherence to medication prescriptions: scientific review. JAMA, 2002. 288(22): p. 2868-79.

52 | Electronic monitoring as a tool to improve blood pressure control 


\section{Chapter 4}

Electronic monitoring of compliance as a tool to improve blood pressure control: long term follow-up

Gwenn E.C. Wetzels, Patricia J. Nelemans, Jan S.A.G. Schouten and Martin H. Prins 


\section{Abstract}

\section{Background}

In a previous randomised study, it was shown that a two-month period of monitoring compliance was sufficient to sustain blood pressure reductions for the next three months. In this study the effects of electronic monitoring on blood pressure and medication use are studied ten months after stopping with monitoring.

\section{Methods}

Data on blood pressure measurements and use of antihypertensive medication were collected for a period of 12 months after inclusion. The required data for the period between 5 and 12 months were derived from pharmacy records and blood pressure readings from the general practitioner's office.

\section{Results}

Twelve months after inclusion, blood pressure was normal in $52.9 \%$ of the patients in the electronic monitoring group versus $66.0 \%$ of patients in the usual care group $(p=0.13)$. The percentages of drug additions and/or dose escalations were still significantly lower in the electronic monitoring group compared to the usual care group ( $\mathrm{p}=0.015)$.

\section{Discussion}

This study demonstrates that the positive effects of a short period of monitoring are still present at 10 months after stopping with the electronic monitoring. However, the results also seem to indicate that the effect on blood pressure wanes over time. 


\section{Introduction}

In spite of an increased awareness of hypertension and the availability of a wide variety of highly effective drugs, only $30 \%$ of the patients who use antihypertensive medication achieve adequate blood pressure control.1,2 One of the major contributors to the large number of uncontrolled hypertensive patients appears to be non-compliance with prescribed regimens. ${ }^{3}$ Many studies have been conducted to assess the effects of interventions to improve compliance with medication with often contradictory results. ${ }^{4-7}$

When studying the effects of an intervention to improve compliance two main issues have to be considered. First, an important question is whether a short-term intervention is sufficient to maintain the favourable clinical outcome for longer times. Many studies do not evaluate how long the effect of a complianceimproving intervention sustains after the intervention has stopped. The duration of the follow-up of most studies is usually only a few months.

Second, the outcome measure of many studies designed to evaluate the effect of a compliance-improving intervention is only compliance. However, increasing compliance is only a means to achieve an end, not an end in itself. The goal of antihypertensive therapy is to help patients control their blood pressure and to reduce cardiovascular events. Hence, it is important to evaluate the effects of an intervention to improve compliance on clinical outcome, in this case blood pressure.

This study describes the effects of an intervention to improve compliance with antihypertensive medication over a prolonged period of time. In a previous study, it was shown that a two-month period of monitoring compliance with an electronic monitor, existing of a medication bottle with a cap containing microcircuitry that registered time and date of the openings of the bottle, was sufficient to sustain blood pressure reductions for the next three months. In this study the effects of electronic monitoring on blood pressure and medication use are studied at ten months after stopping with monitoring.

\section{Methods}

\section{Short description of the original trial}

Data were derived from patients who participated in a randomised controlled trial. The objective of this trial was to compare the effects of electronic monitoring as a compliance improving intervention with usual care. The outcome measure of primary interest was the proportion of patients with blood pressure control (defined as $\mathrm{SBP} / \mathrm{DBP}<160 / 95 \mathrm{mmHg}$ ) at five months after inclusion. Another relevant outcome measure was the proportion of patients with drug additions and/or dose escalations within this follow-up period.

Eligible were patients who used antihypertensive medication but still had too high blood pressure (SBP/DBP $\geq 160 / 95 \mathrm{mmHg}$ ). 
These patients were randomly assigned (in a ratio of 2:1) to one of two strategies: 1) introduction of electronic monitoring; adherence with antihypertensive medication was monitored for eight weeks without medication changes, or 2) continuation of usual care; if necessary, antihypertensive medication was adjusted. Patients in the electronic monitoring group received, for each antihypertensive drug they used, a pillbox equipped with a microchip in its lid that registered the date and time of each opening (Medication Event Monitoring System (MEMS), Aardex corp., Geneve). Follow-up measurements of blood pressure were carried out at 2 and 5 months after inclusion. Mean SBP and DBP were used for analysis. Results were analysed according to an intention-to-treat-analysis. Methods are described in more detail in chapter 3 .

\section{Long term follow-up}

In order to evaluate the long term effectiveness of both treatments at 12 months after inclusion, data were collected on the proportion of patients who still had normalized blood pressure and on the proportion of patients who had received antihypertensive drug additions and/or dose escalations. The required data were derived from pharmacy records and blood pressure readings from the general practitioner's office. Pharmacy records included the names of the prescribed antihypertensive drug(s), dosage, the quantity dispensed at each pharmacy fill and the dates of prescription fills. The collected data covered the period of 12 months after inclusion.

To determine blood pressure at 12 months after inclusion, all office blood pressure readings that were performed by the general practitioner between 10 and 14 months (12 \pm 2 months) were averaged. If more than three blood pressure readings were available for the defined period, only the three measurements closest to the 12-month time-point were taken into account.

Differences between proportions were tested using the Chi square test, differences between means were tested by unpaired Student's t-tests $(\alpha=0.05)$.

\section{Results}

Both Data from pharmacy records and blood pressure readings from the general practitioner's office could be collected for 53 patients (of 89 patients) in the usual care group and 104 patients (of 164 patients) in the experimental group.

\section{Blood pressure measurements}

Twelve months after inclusion, blood pressure was normal in $52.9 \%$ of the patients in the electronic monitoring group versus $66.0 \%$ of patients in the usual care group.

This difference was not statistically significant $(\mathrm{p}=0.13)$ although in the monitoring group the probability of retaining a normal blood pressure was somewhat lower $(\mathrm{RR}=0.80,95 \%$ CI: 0.63-1.06). 
It seems that the effects of electronic monitoring are waning over time, resulting in a smaller proportion of patients with adequate blood pressure in comparison to usual care (Table 1).

The percentage of patients with adequate or substantially improved blood pressure (SBP reduction $\geq 10 \mathrm{mmHg}$ and DBP reduction $\geq 5 \mathrm{mmHg}$ ) was $60.6 \%$ in the monitoring group compared to $73.6 \%$ in the usual care group $(\mathrm{p}=0.12)$ (Table 1). The relative risk of retaining normal or improved blood pressure (monitoring versus usual care) is 0.82 (95\% CI: 0.68-1.05).

Twelve months after inclusion, the percentages of drug additions and/or dose escalations were still significantly lower in the monitoring group compared to the usual care group $(\mathrm{p}=0.015)$.

The percentage of patients with a dose increase and/or drug addition increased from $28.9 \%$ after five months to $36.1 \%$ after twelve months in the electronic monitoring group. In the usual care group, the percentage of patients with a dose increases and/or drug addition slightly decreased from $61.1 \%$ to $57 \%$ (95\% CI of difference between proportions: $-33.9 \%$ to $-7.1 \%$ ) (Table 2). 


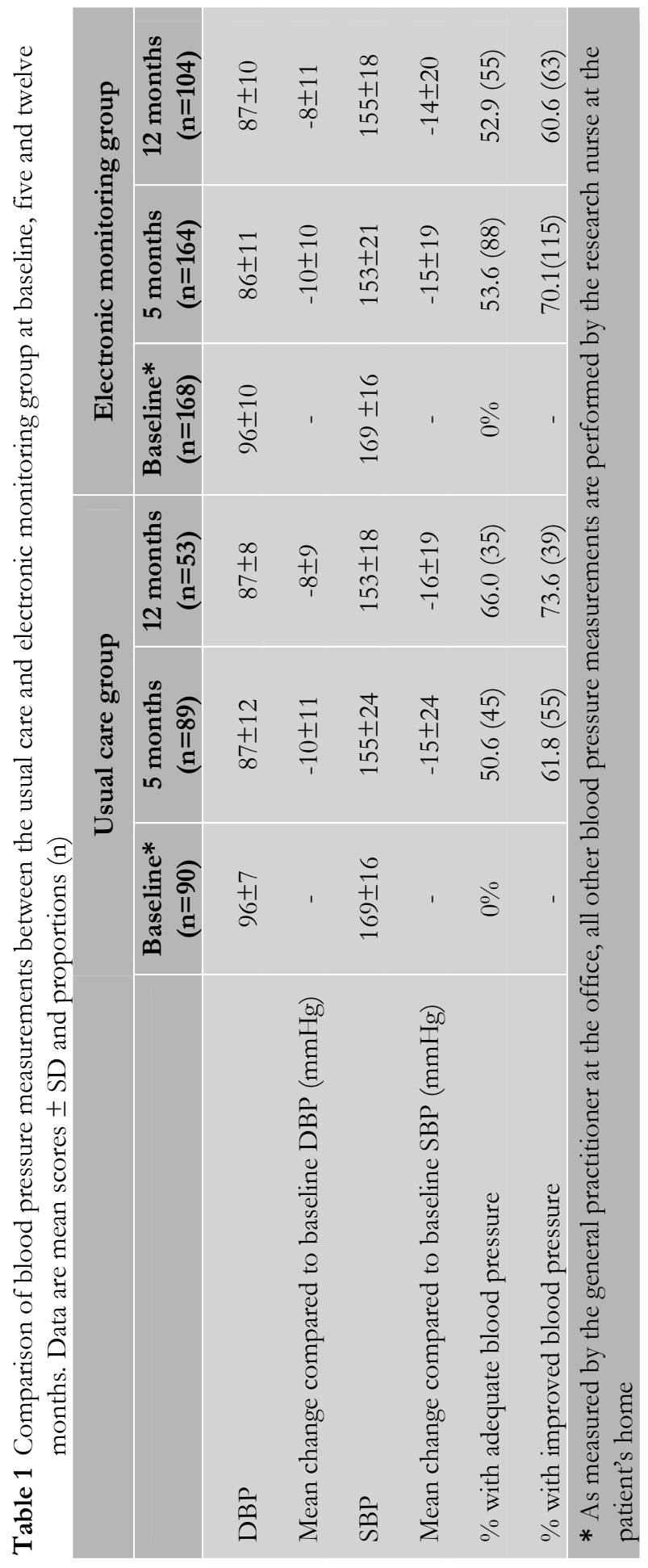


Table 2 Comparison of the number of dose increase or addition of drugs after twelve months between the usual care and experimental group

\begin{tabular}{|c|c|c|}
\hline & $\begin{array}{c}\text { Percentage of patients with a dose increase and/or } \\
\text { addition of (a) drug(s) }\end{array}$ \\
\hline $\begin{array}{c}\text { Number of dose } \\
\text { increases or additions }\end{array}$ & $\begin{array}{c}\text { Usual care group } \\
(\mathbf{n = 8 9 )}\end{array}$ & $\begin{array}{c}\text { Electronic monitoring group } \\
(\mathbf{n}=\mathbf{1 6 4 )}\end{array}$ \\
\hline-2 & 2.3 & 1.3 \\
-1 & 3.5 & 7.1 \\
0 & 37.2 & 55.5 \\
1 & 37.2 & 27.7 \\
2 & 14.0 & 4.5 \\
3 & 5.8 & 3.9 \\
* Includes both patients with no medication change during the follow up period and
\end{tabular}

\section{Discussion}

The objective of this study is to evaluate whether a short-term intervention with an electronic monitor is sufficient to sustain blood pressure control and reductions in medication for a longer time (10 months) after stopping with electronic monitoring. Three months after stopping with electronic monitoring (five months after inclusion), it was shown that in the electronic monitoring group a considerable proportion of patients still had normalized blood pressure without the need for drug additions or dose escalations.

From the data collected in this study, it can be concluded that 10 months after stopping with monitoring, the percentage of patients with normalized blood pressure does not significantly differ between the experimental and usual care strategy. On the other hand, it was shown that frequency of retaining normal blood pressure was lower in the monitoring group indicating that there is a tendency for better blood pressure control in the usual care strategy. However, the number of patients with dose increases or addition of drugs since inclusion was still much lower in the monitoring group compared to the usual care group.

These results seem to indicate that the effects of electronic monitoring are waning over time and eventually will fade away. Probably, this observation points to the need for repeated interventions in order to maintain optimal compliance and adequate blood pressure control for a longer period. The findings from this longterm evaluation take away the concern that it was the design of the original study that for the most part prevented increase of the dose or addition of another class of antihypertensive medication in the first 5 months after inclusion.

The data support the hypothesis that electronic monitoring not merely delays adjustment of medication, but really takes away the need for intensification of 
medication for a certain period of time. At the same time this study also clearly demonstrates the need for repeated interventions.

Some issues regarding the data collection in this study have to be considered. In the original trial, a research nurse performed all blood pressure measurements after inclusion at the patients' home. Due to practical limitations, it was decided to collect the 12 -month blood pressure readings from the databases of the treating general practitioners. This brings up two possible problems: a less standardized method of blood pressure measurements and the possible occurrence of selection bias. In the usual care group, the blood pressure readings could be retrieved from $60 \%$ of the patients versus $63 \%$ in the experimental group. This considerable lossto-follow up is mainly due to the fact that there simply were no blood pressure readings available in the defined time frame. These missing data may have caused selection bias. It is possible that patients, who frequently visit their general practitioner and have regular check-ups, have a higher chance to reach adequate blood pressure. Such a selection is expected to bias the result towards overestimation of blood pressure control. The other way around, it can be argued that missing data pertain to patients whose blood pressure is already regulated and who therefore are not going to their general practitioner and order their prescriptions for their antihypertensive medication by phone. In this case, the bias would be in the other direction, towards underestimation of blood pressure control. However, loss of follow up was similar in both groups and if selection bias occurred to the same extent in both groups, it is not to be expected that it affected the comparison between electronic monitoring and usual care.

\section{Conclusion}

From the original trial it was concluded that electronic monitoring in comparison to usual care resulted in similar blood pressure control, but led to less drug changes and drug use. Electronic monitoring was considered as an easy-to-use and effective tool to improve compliance. This study demonstrates that the positive effects of a short period of monitoring are still present at 10 months after stopping with the electronic monitoring. However, the results also seem to indicate that the effect on blood pressure wanes over time and point to the need for repeated intervention in order to maintain optimal compliance and adequate blood pressure control for a longer period. 


\section{References}

1. Burt VL, Cutler JA, Higgins M, Horan MJ, Labarthe D, Whelton P, Brown C, and Roccella EJ. Trends in the prevalence, awareness, treatment, and control of hypertension in the adult US population. Data from the health examination surveys, 1960 to 1991. Hypertension, 1995. 26(1): p. 60-9.

2. Joint National Committee on prevention, evaluation, and treatment of high blood pressure. The sixth report of the Joint National Committee on prevention, detection, evaluation, and treatment of high blood pressure. Arch Intern Med, 1997. 157(21): p. 2413-46.

3. Sabate E. Adherence to long-term therapies: evidence for action. WHO, 2003(Geneva).

4. Haynes RB, McKibbon KA, and Kanani R. Systematic review of randomised trials of interventions to assist patients to follow prescriptions for medications. Lancet, 1996. 348(9024): p. 383-6.

5. Haynes RB, McDonald HP, and Garg AX. Helping patients follow prescribed treatment: clinical applications. JAMA, 2002. 288(22): p. 2880-3.

6. McDonald HP, Garg AX, and Haynes RB. Interventions to enhance patient adherence to medication prescriptions: scientific review. JAMA, 2002. 288(22): p. 2868-79.

7. Schroeder K, Fahey T, and Ebrahim S. Interventions for improving adherence to treatment in patients with high blood pressure in ambulatory settings. The Cocbrane Database of Systematic Reviens 2004, 2004(3). 
62 Electronic monitoring as a tool to improve blood pressure: long term follow-up 


\section{Chapter 5}

Costs and cost-effectiveness of an adherence improving program in hypertensive patients

Danielle E.M. Brunenberg, Gwenn E.C. Wetzels, Patricia J. Nelemans, Carmen D. Dirksen, Henri E.J.H. Stoffers, Jan S.A.G. Schouten, Martin H. Prins, Johan L. Severens, Peter W. de Leeuw, Manuela A. Joore

Pharmacoeconomics. Submitted 


\section{Abstract}

\section{Background}

Non-adherence to anti-hypertensive drugs is high, and economic consequences of non-adherence may be substantial. The Medication Events Monitoring System (MEMS), which is a method to improve adherence, proved to be a useful tool for the management of adherence problems.

\section{Objective}

To assess the cost-effectiveness of MEMS in a population of hypertensive patients compared to usual care. The program consisted of provision of electronic monitors and (if indicated) a training to improve adherence in patients with unsatisfactory adherence.

\section{Methods}

In a randomised controlled trial 164 patients in the experimental strategy and 89 patients in the usual care strategy were followed for five months. Eligible were patients who still had too high blood pressure despite the use of antihypertensive drugs. Patients were recruited by a general practitioner, and treatment took place in general practice. In the experimental strategy electronic monitoring of the intake of antihypertensive drugs was introduced without change of medication. Unsatisfactory adherence, was defined as $<85 \%$ of days with number of doses taken as prescribed. In the usual care strategy, antihypertensive treatment was intensified by addition or change of antihypertensive drugs, if necessary, without provision of an electronic monitor. Outcome parameters included the proportion of patients with normalized blood pressure (NBP) at five months and Quality Adjusted Life Years (QALYs). Costs were quantified from the healthcare and societal perspective.

\section{Results}

At five months 3.1\% (95\% UI: minus $9.7 \%$ to $15.8 \%$ ) more patients had NBP, and 0.003 (95\% UI: minus 0.005 to 0.010 ) more QALYs were generated in the experimental strategy. A statistically significant lower percentage of patients had a dose escalation in the experimental strategy. Irrespective of the ceiling ratio for cost-effectiveness, the cost-effectiveness probability was between $75-80 \%$ for the analysis from the healthcare perspective using proportion patients with NBP as outcome parameter. For the analysis from the societal perspective using QALY as outcome parameter, this probability was between $45-51 \%$.

\section{Conclusion}

For a time horizon of 5 months a difference in both cost and effect could not be detected between an adherence improving program compared to usual care for hypertensive patients. 
However, since electronic monitoring costs are relatively low, and the probability of cost-effectiveness was reasonable, this adherence enhancing program may be a cost-effective intervention. Although no effect on quality of life was demonstrated, patients may benefit from this program, as it is associated with a decrease in use of anti-hypertensive drugs. Therefore, implementation of this intervention in general practice would be recommended. 
66| Cost-effectiveness of an adherence improving program 


\section{Introduction}

For pharmacological treatment to be beneficial, it is of utmost importance that patients adhere to prescribed medication. Failure to adhere to prescribed medication regimens increases the risk of illness, ${ }^{1}$ and also increases total healthcare costs. ${ }^{2}$ Non-adherence is common and has been identified as a major public health problem. ${ }^{3}$ The proportion of patients that not adheres to treatment is considerable to high and depends on the class of drug. It is estimated to vary between 33\% for cholesterol lowering agents and $87 \%$ for inhalation corticosteroids. ${ }^{4}$ Hypertension is one of the chronic conditions, where nonadherence needs attention. It has been estimated that only approximately $50 \%$ to $70 \%$ of patients with hypertension take their medication. 5,6 Because of the high prevalence of hypertension, which has been estimated to be on average $44 \%$ in six European countries and 28\% in North America, ${ }^{7}$ economic consequences may be substantial. In the Netherlands, superfluous expenses associated with treatment non-adherence in total, are estimated to amount to 234 million euro, which is $0.7 \%$ of the total healthcare budget in the year 1998.4 Development of patient management strategies which are targeted at increasing patients' own role in improving blood pressure control, may lead to cost containments and therefore deserve interest.

Several methods to monitor and improve adherence have been used; e.g. selfreported adherence, prescription renewal, counting pills, or biological markers. All these methods have their limitations, ${ }^{8,9}$ and a number of systematic reviews have demonstrated that no single intervention has emerged as superior to others. ${ }^{10-12}$ Recently, the Medication Event Monitoring System (MEMS; Aardex Corp., Geneva), which is a drug container that electronically records the date and time of each opening of the box, has become available. ${ }^{13}$ It seems to be an effective tool to identify non-adherent patients. ${ }^{14-21}$ Moreover, electronic monitoring has been shown to improve adherence in hypertensive patients, ${ }^{14-15}$ in psychiatric patients, ${ }^{22,23}$ in patients with obstructive lung disease, ${ }^{24}$ and in women participating in a smoking cessation trial. ${ }^{25}$ The consequences of non-adherence with pharmacotherapy's have been largely neglected in the medical and health economic literature. ${ }^{27}$ Although the cost-effectiveness of a number of adherence enhancing interventions in hypertension has been assessed, ${ }^{28-32}$ the cost-effectiveness of electronic monitoring as a tool to improve adherence remains to be elucidated. The objective of the present study was to assess the cost-effectiveness of an adherence improving program using MEMS in hypertensive patients in the primary care setting, compared to usual care. Differences in healthcare and societal costs were related to the difference in effects in terms of normalised blood pressure and generic quality of life, respectively. 


\section{Research design and methods}

\section{Study design}

This economic evaluation has been performed alongside The Utrecht Limburg Initiative on Patient adherence with Antihypertensives (TULIPA) study, a randomised clinical trial with two parallel groups. Patients were randomly assigned to either the experimental strategy or the usual care strategy, according to a randomization ratio of 2:1. This ratio was employed in order to allow for a reliable estimation of the proportion of poor adherers in the experimental care strategy. Patients were followed for five months. The Institutional Review Board granted ethical approval for the study. From each enrolled patient a written informed consent form was obtained.

\section{Patients and methods}

Patients were recruited by 43 general practitioners (GPs) in the South of the Netherlands. Patients were eligible if they had a diagnosis of hypertension, which was inadequately controlled despite the use of antihypertensive drugs. Uncontrolled blood pressure was defined as a systolic blood pressure (SBP) $\geq 160$ $\mathrm{mmHg}$ and/or diastolic blood pressure (DBP) $\geq 95 \mathrm{mmHg} .{ }^{33} \mathrm{In}$ diabetic patients high blood pressure (BP) was defined as $\geq 150 \mathrm{mmHg}$ SBP and $\geq 85 \mathrm{mmHg}$ DBP. Furthermore, there had to be an indication for treatment escalation, defined as increase in dosage, addition or change of antihypertensive drugs. Patients were excluded when treatment was adjusted because of adverse effects of current medication, or when patients insisted on using dose organisers. Patients who were not managing their drug intake themselves and institutionalised patients were also not eligible for the study.

The power calculation was based on the proportion of patients with a normalised BP (NBP). With a power of $85 \%$, a significance level of 0.05 , an expected reduction of the proportion of patients with NBP of $20 \%$, and a drop-out rate of $15 \%, 167$ patients were needed in the experimental care strategy and 83 patients in the usual care strategy.

\section{Intervention}

The intervention provided to the patients in the experimental strategy consisted of adherence monitoring and an adherence improving training for patients with unsatisfactory adherence. In the experimental strategy, antihypertensive medication was monitored for eight weeks without medication changes. For each prescribed drug patients received a MEMS monitor, which is a container equipped with a microchip in its cap that registered the date and time of each opening. Patients were informed that the MEMS monitor recorded the date and time of each opening of the container. After the first evaluation period of two months, adherence data were downloaded to a personal computer using dedicated software and medication adherence was determined by a GP assistant. 
Adherence was defined as the proportion of days with number of doses taken as prescribed, e.g. correct dosing. A proportion correct dosing $\geq 85 \%$ for all prescribed medication, was considered satisfactory. In patients with unsatisfactory adherence no dose escalation or medication adjustment took place, and irrespective of their BP, electronic monitoring was continued for another three months. Patients with satisfactory adherence who still had uncontrolled blood pressure after two months of electronic monitoring, were referred to their general practitioner who decided whether or not adjustment of medication was indicated.

Additionally, these patients received training to manage adherence, provided by a GP assistant in three sessions of 15 minutes. The training consisted of a review of the adherence report with the patient. The goal was to give insight into their own dosing history, to identify periods of suboptimal adherence, to explore reasons for suboptimal adherence, and to define "cues" linked to drug taking. In the usual care strategy, antihypertensive medication was intensified and regular drug containers were used.

\section{Costs}

Costs were quantified from both the healthcare perspective and the societal perspective. The healthcare perspective takes only medical costs into account (either paid for by an insurance company or the patients themselves). The societal perspective incorporates medical and non-medical costs and health effects regardless of who incurs the costs and who obtains the effects. ${ }^{33,34}$

Data on healthcare utilisation, paid house assistance and productivity loss was collected using cost diaries, which were completed prospectively three times for (during) four weeks prospectively; during month 1, during month 3 and during month 5. All resource use was collected, irrespective of its reason. Cost data were interpolated under the assumption that costs in month 1 were representative for costs in month 2 and costs in month 3 and 5 were representative for costs in month 4. Information on the volume and type of the drugs obtained by each patient was derived from the patient's pharmacist. We distinguished between direct healthcare costs, direct non healthcare costs and indirect costs. Details concerning these cost categories are presented in Table 1.

The intervention costs consisted of costs of instruction, electronic monitoring costs and a training aimed at improving adherence. These costs were determined based on the following assumptions. Patients were given instructions on how to use the monitor by the GP assistant during the first visit for 15 minutes. Relevant to the electronic monitoring costs are the costs of the MEMS monitor, the communicator and software for reading out of the monitor, as well as personnel costs for packaging the drug in the electronic monitor and reading out of the monitors. Patients were assumed to have one GP consultation, during which the monitor was handed out. Subsequently, the pharmacist assistant filled caps with electronic monitors for every prescribed drug. 
It was assumed that re-use of the monitor cap was allowed; but that monitor containers were for single use only and that every practice was equipped with one communicator and a software program for reading out the monitors. Electronic monitor caps, the communicator and the software program were depreciated in three years using the annuity method, and an interest rate of $4.5 \% .35$ The costs of the communicator and software program were calculated by dividing the total depreciation costs per year $(€ 242)$ by the mean number of anti-hypertensive medication prescriptions for patients without adequate BP control in a usual GP practice (459). The mean number of anti-hypertensive medication prescriptions was determined by multiplying the average number of patients without adequate BP control per usual GP practice $(255)^{36}$ by the mean number of anti-hypertensive medication prescriptions per patient (1.8), as observed in this study. The costs of the training were calculated by multiplying the personnel costs per minute $(€ 0.44)$ by the mean duration of the training (45 minutes).

The direct costs were estimated according to the Dutch guidelines for cost analysis. ${ }^{35}$ The most recent drug prices (25-05-05) were obtained from an online database on medication $\operatorname{costs}^{37}$ and included the pharmacist dispensing fee. Productivity loss costs for paid labour were calculated according to the friction cost method, based on a mean income of the Dutch population according to age and gender for employees. ${ }^{38}$

The healthcare costs per patient were calculated by combining the resource utilisation data with the corresponding unit cost-estimates and are reported in 2002 euros.

\section{Effects}

The effectiveness of the adherence improving program was assessed in terms of the proportion of patients with normalised BP (NBP) at five months and generic quality of life. NBP was defined as a systolic BP below $160 \mathrm{mmHg}$ and a diastolic BP below $95 \mathrm{mmHg}$.

Generic quality of life was measured using the EQ-5D ${ }^{39}$ at baseline and at 5 months. This questionnaire contains items to measure five different dimensions of quality of life: mobility, self-care, daily activities, pain and complaints and feeling. Based on the scores on the items of the EQ-5D a population health state utility estimate was calculated. ${ }^{40}$ The obtained utility estimates were used to compute Quality Adjusted Life Years (QALYs). The QALY is a measure of health outcome that assigns a weight ranging from 0 (worst imaginable health state) to 1 (best imaginable health state) for each period of time. ${ }^{41}$ One year in perfect health yields one QALY. Since the time horizon in this study was five months, and extrapolation in time was considered not to be valid, a maximum of 0.417 QALYs could be generated. BP and other measurements were carried out by a research nurse in the first week, 2 months and 5 months after inclusion. 


\section{Cost-effectiveness}

The cost-effectiveness of electronic monitoring of medication adherence was assessed in two ways: 1) by relating the difference in healthcare costs between the two strategies to the difference in the proportion of patients with normalised BP (NBP) and 2) by relating the difference in societal costs between the two strategies to the difference in QALYs. The resulting point estimates, the incremental costeffectiveness ratios (ICERs), reflect the healthcare costs per patient with NBP and the societal costs per QALY, respectively. Results were not extrapolated beyond the 5 month follow up and therefore discounting was not relevant. 33,34

\section{Analysis}

Data were analysed according to the intention-to-treat principle. The mean substitution method ${ }^{42}$ was applied in case of missing values due to incompleteness. Statistical significance was indicated by a p-value smaller than 0.05 . The QALY was estimated using regression analysis adjusting for baseline utility. ${ }^{43}$

In order to get insight into the uncertainty around the incremental costs, incremental effects, and incremental cost-effectiveness ratios, bootstrap simulations were conducted. ${ }^{44}$ These simulations yield information concerning the joint distribution of the cost and effect differences. From these data 95\% uncertainty intervals (UI) for cost and effect differences were calculated based on the $2.5^{\text {th }}$ and $97.5^{\text {th }}$ percentiles. The cost-effect pairs per bootstrap sample $(\mathrm{N}=1000)$ are presented in a cost-effectiveness plane.

Decision uncertainty (the relation between a given ceiling ratio and the probability of cost-effectiveness) is graphically presented in a so-called cost-effectiveness acceptability curve (CEAcc). ${ }^{45}$ A CEAcc is constructed under the assumption that the willingness to pay for health gain (WTP) is identical to the willingness to accept compensation for health loss (WTA). However, it has been shown in economics that individuals do not consider these situations identical. The amount of saving that will be required to accept losing health is generally larger than the extra money people are prepared to pay for gaining health. ${ }^{46}$ To take this disparity into account, a CEAcc was constructed with addition of the situation that society is not prepared to accept compensation for health loss (WTA is infinite). ${ }^{47}$ All analyses were performed using SPSS 12.0.

\section{Sensitivity analysis}

One-way sensitivity analyses were conducted on deterministic variables to provide information on the robustness of the results of the economic evaluation. Costs were assumed to be fixed and therefore were not varied. In the first analysis, the electronic monitors were provided for only one drug for three months, instead of for each drug for a maximum of five months. In the second analysis it was assumed that both the cap and the container were used only once, instead of re-use of the cap and single use of the container. The sensitivity analyses were performed under the assumption that WTP and WTA are identical. 


\section{Results}

In total, 258 patients were included in the study between September 2002 and March 2004. Of five patients no follow-up data were available. Four patients refused to participate (two due to illness, and two without giving a specific reason), and one patient died of stroke. Of the 253 patients (98\%) with complete follow-up, 164 patients were randomised to the experimental strategy and 89 patients to the usual care strategy. Mean age of the participants was 62 years (sd:10) in both groups, $59 \%$ was male in the experimental strategy and $49 \%$ was male in the usual care strategy. On average $70 \%$ of the participants had paid employment and $77 \%$ was married in both groups.

First, third and fifth month cost data were available for 139, 136 and 127 patients respectively $(85 \%, 83 \%$ and $77 \%)$ in the experimental strategy and for 84,82 , and 76 patients $(94 \%, 92 \%$ and $85 \%)$ in the usual care strategy. EQ-5D data were obtained in the experimental strategy from 160 patients (98\%) at baseline, and from 156 patients (95\%) at 5 months. In the usual care strategy from $85(95 \%)$ and 86 patients (95\%) respectively.

\section{Costs}

Electronic monitoring for five months led to a saving of $€ 40$ in medication costs (95\% UI: €90 saved to €8 extra; Table 1). Reduction in drug costs is achieved as a result of the statistically significant $(\mathrm{p}<0.01)$ lower percentage of patients with drug additions and/or dose escalations in the experimental care strategy. The average costs of electronic monitoring were $€ 26$ per patient. The communicator and software costs amounted to $€ 242$ per year per GP practice and $€ 0.04$ per prescription per month. The costs of the adherence improving training amounted to $€ 19.80$ per patient. In total, mean costs directly related to the intervention were $€ 367$ in the experimental strategy and to $€ 374$ in the usual care strategy.

The mean total healthcare costs per patient amounted to $€ 827$ in the experimental strategy and to $€ 927$ in the usual care strategy (incremental costs: $€ 100$ saved; $95 \%$ UI: $€ 415$ saved to $€ 189$ extra). This cost difference is mainly caused by a longer hospital stay (not related to hypertension) of patients in the usual care strategy, which resulted in higher admission costs compared to the experimental care group. The mean total five months societal costs per patient were slightly higher in the experimental strategy (€1,573) than in the usual care strategy $(€ 1,526)$; incremental costs: $€ 47$ (95\% UI: $€ 873$ saved to $€ 867$ extra). This cost difference is mainly due to longer health related work absenteeism in the experimental care strategy, which resulted in higher productivity loss costs for paid work compared to the usual care strategy. 


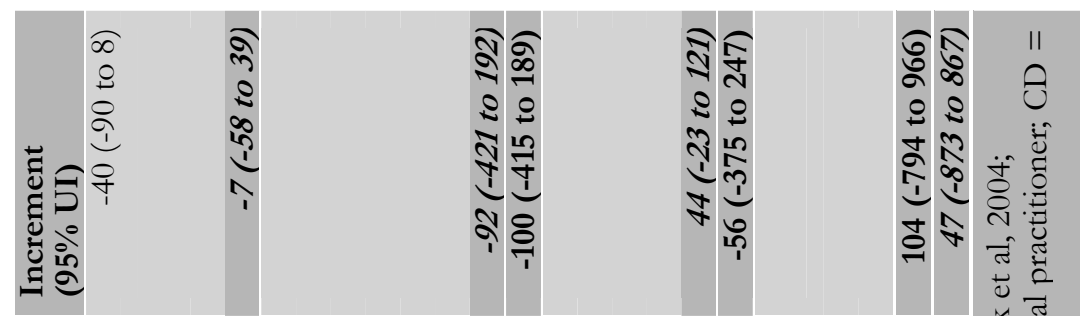

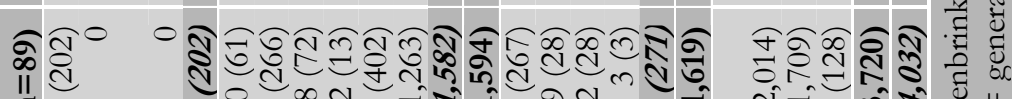

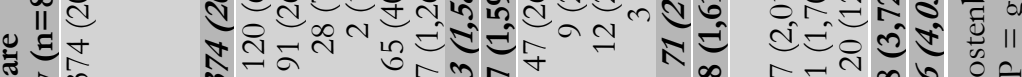

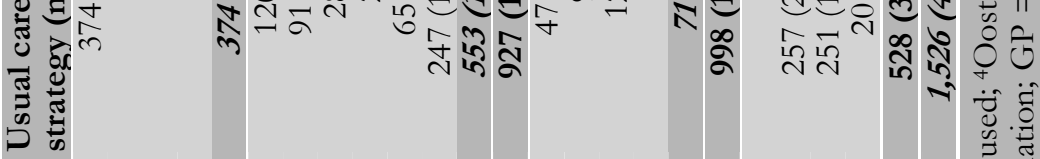

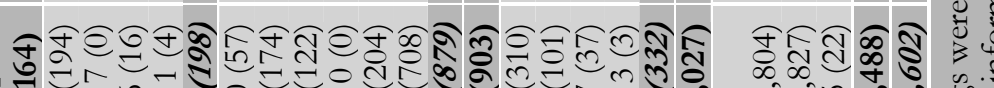

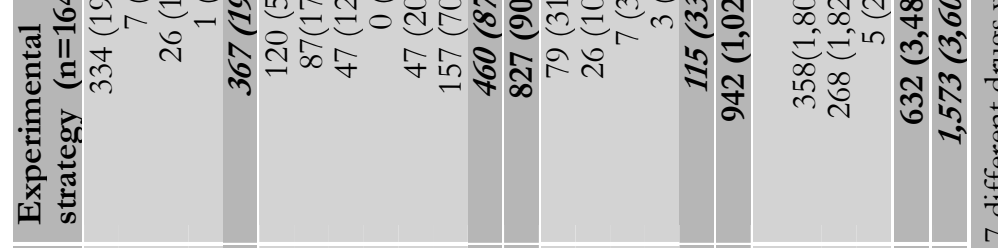
¿

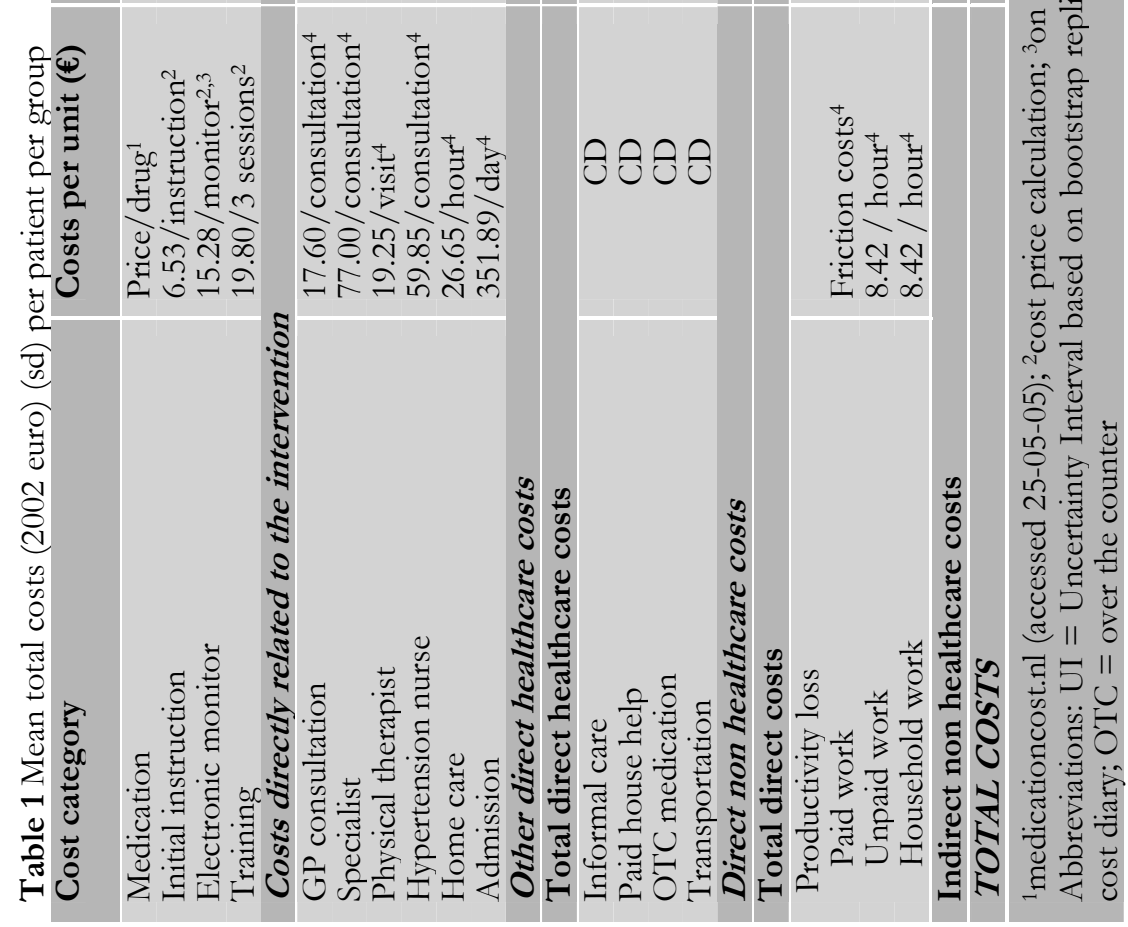




\section{Effects}

The effects are displayed in Table 2. At the end of the follow-up period, $53.7 \%$ of the patients in the experimental strategy achieved NBP, compared to $50.6 \%$ in the usual care strategy. This resulted in an increment of $3.1 \%$ in favour of the experimental strategy (95\% UI: minus $9.7 \%$ to $15.8 \%$ ).

The mean population health state utility estimate at baseline was 0.757 in the experimental strategy and 0.808 in the usual care strategy. Without adjustment for the baseline utility difference, less QALYs were generated in the experimental strategy compared to the usual care strategy. Adjusting for the baseline difference ${ }^{43}$ 0.330 QALY was yielded in the experimental care strategy, and the mean QALY was 0.327 in the usual care group. As a result the incremental QALY was 0.003 (95\% UI: minus 0.005 to 0.010 ) in favour of the experimental care strategy.

Table 2 Mean effects (sd)

\begin{tabular}{|c|c|c|c|}
\hline $\begin{array}{l}\text { Outcome parameter } \\
\text { and moment }\end{array}$ & $\begin{array}{l}\text { Experimental } \\
\text { strategy }(n=164)\end{array}$ & $\begin{array}{l}\text { Usual care } \\
\text { strategy }(n=89)\end{array}$ & $\begin{array}{l}\text { Increment } \\
(95 \% \mathrm{UI})\end{array}$ \\
\hline $\begin{array}{l}\text { Normalised BP at } 5 \\
\text { months ( } \% \text { patients) }\end{array}$ & 53.7 & 50.6 & $\begin{array}{l}3.1 \\
(-9.7 \text { to } 15.8)\end{array}$ \\
\hline \multicolumn{4}{|l|}{ Utility } \\
\hline Baseline & $0.757(0.252)$ & $0.808(0.184)$ & $\begin{array}{l}-0.052 \\
(-0.103 \text { to } 0.000)\end{array}$ \\
\hline 5 months & $0.794(0.224)$ & $0.813(0.198)$ & $\begin{array}{l}-0.019 \\
(-0.067 \text { to } 0.030)\end{array}$ \\
\hline QALY\# & $0.323(0.092)$ & $0.338(0.075)$ & $\begin{array}{l}-0.015 \\
(-0.035 \text { to } 0.005)\end{array}$ \\
\hline $\begin{array}{l}\text { QALY, baseline utility } \\
\text { adjustment }\end{array}$ & $0.330(0.033)$ & $0.327(0.026)$ & $\begin{array}{l}0.003 \\
(-0.005 \text { to } 0.010)\end{array}$ \\
\hline \multicolumn{4}{|c|}{$\begin{array}{l}\text { \# range: } 0 \text { to } 0.417 \\
\text { Abbreviations: UI = uncertainty interval based on bootstrap replications; } \\
\text { QALY=Quality Adjusted Life Year }\end{array}$} \\
\hline
\end{tabular}

\section{Cost-effectiveness}

The economic evaluation from the healthcare perspective has shown that electronic monitoring led to a cost saving of $€ 100$, and $3.1 \%$ more patients with NBP compared to usual care. As a result, the ICER point estimate indicated a dominance situation for this outcome parameter. The uncertainty around this outcome is visualised in the cost-effectiveness plane in Figure 1. In total 55\% of the cost-effectiveness replicates were situated in the South-east (dominance) quadrant. Note that the uncertainty around the ICER was considerable and that the replicates were scattered over the origin.

From the societal perspective, electronic monitoring resulted in extra costs of $€ 47$. This means that electronic monitoring for a period of five months costs $€ 15,667$ per QALY gained. 
Figure 1 Cost-effectiveness plane of 1,000 replications showing ICER of healthcare costs per patient with normalised $\mathrm{BP}$

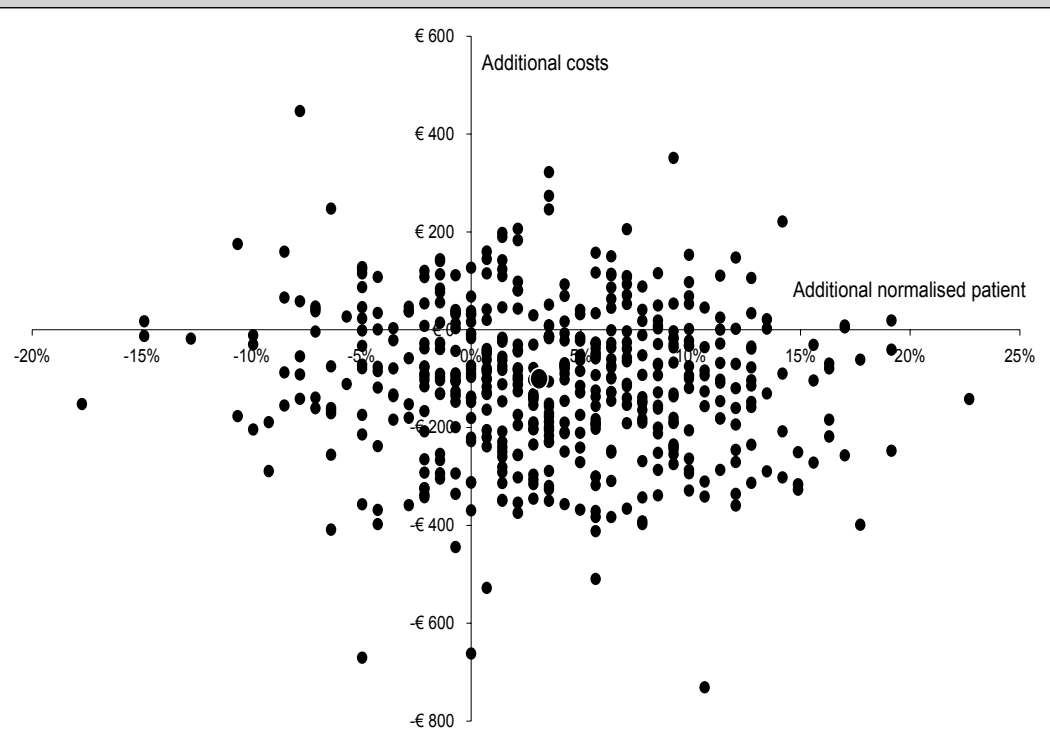

South-east quadrant: the new intervention is less costly and more effective: dominant. North-west quadrant: the new intervention is more costly and less effective: inferior. South-west quadrant: the new intervention is less costly and less effective: costeffectiveness depends on what society is prepared to invest per gain in effectiveness. North-east quadrant: the new intervention is more costly and more effective: costeffectiveness depends on what society is prepared to invest per gain in effectiveness.

The uncertainty around the ICER point estimate showed the same pattern as for the clinical effectiveness measure, as is shown in Figure 2. In total $42 \%$ of the pairs was located in the North-east quadrant, 35\% in the South-east quadrant and 18\% in the North-west quadrant. Again the uncertainty was considerable and the pairs covered the origin. 
Figure 2 Cost-effectiveness plane of 1,000 replications showing ICER of societal costs per QALY

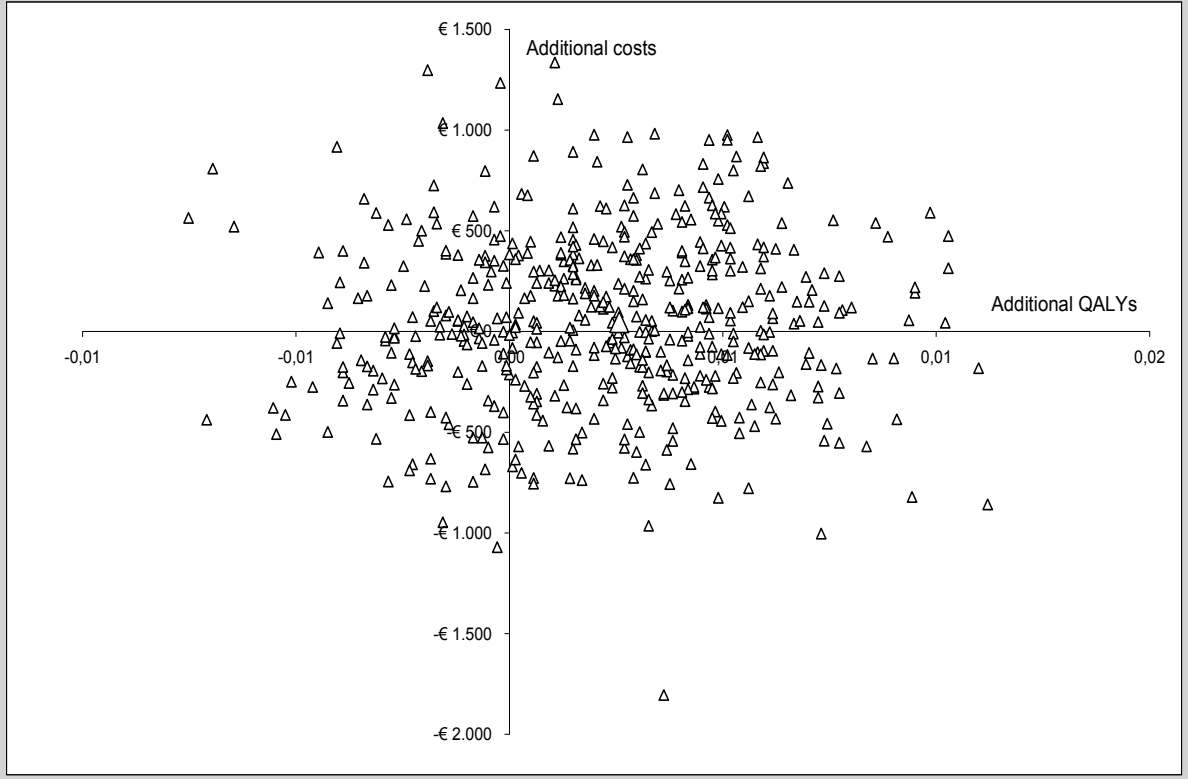

South-east quadrant: the new intervention is less costly and more effective: dominant. North-west quadrant: the new intervention is more costly and less effective: inferior. South-west quadrant: the new intervention is less costly and less effective: costeffectiveness depends on what society is prepared to invest per gain in effectiveness. North-east quadrant: the new intervention is more costly and more effective: costeffectiveness depends on what society is prepared to invest per gain in effectiveness

The cost-effectiveness acceptability curve is presented in Figure 3. Concerning the healthcare costs per patient with NBP, the probability that the experimental strategy is the most cost-effective alternative ranged between 75 and $80 \%$ for all ceiling ratios, assuming W'TP to be identical to W'TA. When assuming that society is not willing to accept health loss, the probability ranged between $57 \%$ and $72 \%$. For the societal costs per QALY analysis, the probability of cost-effectiveness ranged from $45 \%$ to $51 \%$, depending on the ceiling ratio and presuming WTP and WTA to be equal. This probability dropped $10 \%$ over the whole range of ceiling ratios when no compensation for health loss is accepted by society. 
Figure 3 Cost-effectiveness acceptability curve

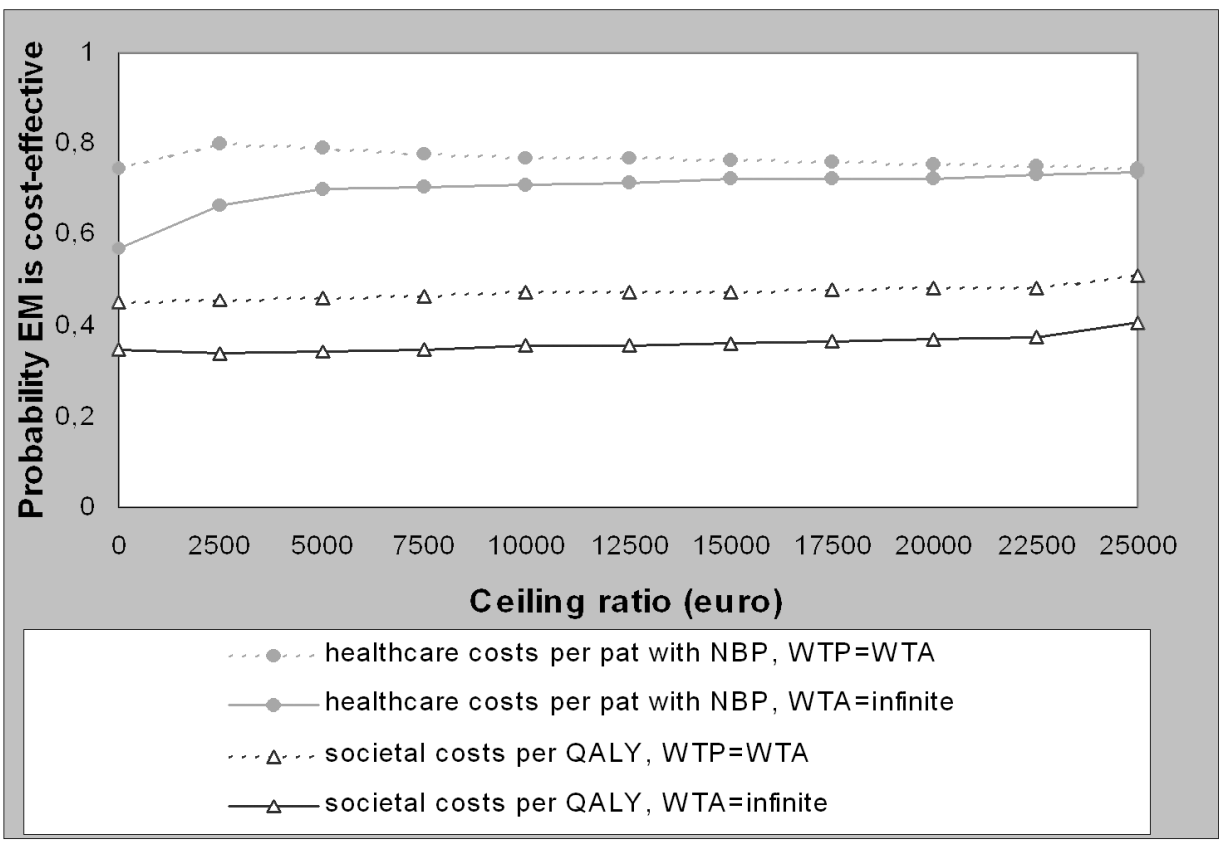

\section{Sensitivity analysis}

In the first sensitivity analysis it was assumed that in patients who use more than one antihypertensive drug, an electronic monitor was provided for only one drug. As this obviously results in lower costs in the experimental care group, the point estimate of the ICER remained to indicate a dominance situation (lower costs and lower effects) from the healthcare perspective. From the societal perspective as a result of the decreasing costs, the extra costs decreased and the probability that electronic monitoring is cost-effective is $53 \%$ at a ceiling ratio of $€ 25,000$ per QALY instead of $51 \%$.

In the second sensitivity analysis, it was assumed that the electronic monitor cap is not re-used. From the healthcare perspective, as a result of the increasing electronic monitoring costs the probability that electronic monitoring is costeffective at a ceiling ratio of $€ 25,000$ decreased from $74 \%$ to $69 \%$ for the proportion of patients with NBP as outcome parameter. From the societal perspective the probability dropped from $51 \%$ to $43 \%$ for the costs per QALY analysis at the maximum ceiling ratio. 


\section{Discussion}

The cost-effectiveness of an adherence improving program was evaluated in a randomised controlled trial.

We observed that healthcare costs were lower (€100, UI: €415 saved to €189 extra) and that societal costs were slightly higher (€47, UI: €873 saved to €867 extra) in the experimental strategy compared with usual care.

The cost-effectiveness acceptability curve showed that the probability of costeffectiveness from the societal perspective (cost per QALY analysis) was rather low (on average 47\%). It must be noted that inclusion of non healthcare costs and use of generic quality of life as outcome parameter is especially appropriate in studies evaluating interventions in which these parameters are likely to be influenced. In this study on medication adherence in a population of patients with mild to moderate hypertension this was not the case: the intervention had only a small impact on non healthcare costs and generic quality of life.

In this respect, the societal perspective might not be the most appropriate perspective. Therefore, also an analysis from the healthcare perspective has been conducted. Taking into account only the healthcare costs and the proportion of patients with NBP, a reasonable cost-effectiveness probability (on average $77 \%$ ) was observed. A cost-minimization analysis, whereby the less costly treatment is the preferred one, was not performed because Briggs ${ }^{48}$ recommended focussing on the joint density of costs and effect differences, rather than separate and sequential hypothesis testing in costs and effects.

The sensitivity analyses demonstrated that the results were insensitive for the number of drugs per patient that are electronically monitored, but that the costs of the electronic monitor strongly depended on re-use of the monitor cap. Only when the cap can be used multiple times in different patients, it seemed to be a reasonable cost-effective adjustment in the usual management of patients with hypertension. (the probability of cost-effectiveness was on average $77 \%$ ).

We chose for the relative short time horizon of five months as we expected to capture all effects within this period of time. Moreover, since the observed effect in both outcome parameters was rather small, extension of the time horizon beyond one year using a modelling technique would be very difficult.

The cost-effectiveness of several adherence enhancing interventions has been assessed by others. ${ }^{28-32}$ The majority of these studies were performed from the patient or healthcare perspective, only one trial took also the societal perspective. ${ }^{28}$ Like in our study, this study related costs to proportion patients with BP control, whereas in the other studies a specific reduction in $\mathrm{mmHg}, 30,31$ and medication adherence improvement ${ }^{31}$ were used as outcome parameters.

Because of the diversity of interventions and use of different outcome parameters, the studies are difficult to compare. In the study by Friedman et $\mathrm{al}^{31}$ an automated telephone patient monitoring and counselling system was found to be a costeffective tool to improve adherence compared to usual care. 
In the study by Logan et al. ${ }^{30}$ a worksite hypertension program proved to be substantially more cost-effective than regular care. Cantor et al. ${ }^{28}$ demonstrated that multiple educational intervention combinations are not more cost-effective than single interventions.

The results of Eastaugh et al. ${ }^{29}$ showed that only in a sub sample of highly depressed patients the benefits of the triage method outweigh its costs. Finally, Zarnke et al. ${ }^{32}$ found that a patient directed hypertension management strategy, in which patients measured their own blood pressure at home, did not prove to result in a lower frequency of physician visits or a difference in quality of life. It may be evident that results of these studies are not univocal.

The present study was the first economic evaluation of electronic monitoring. The results strongly depend on the taken perspective (healthcare or societal) and outcome parameter (proportion of patient with NBP or QALY). It should be emphasized that the adherence improving program was not more expensive than the usual care strategy and that from the health care perspective it even resulted in cost savings. The observed costs were not statistically significantly different between the groups. Although no effect on quality of life was demonstrated, patients may benefit from this program, as it is associated with a decrease in use of anti-hypertensive drugs.

Therefore, implementation of this intervention in general practice could be recommended, for instance in situations where patients do not reach blood pressure targets and both patient and general practitioner are reluctant to increase the dose or number of antihypertensive drugs.

Given a drug cost containment of $€ 40$ per five months, and assuming unchanged drug use over one year, a yearly drug cost containment of $€ 96$ per patient can be obtained. As the costs directly related to electronic monitoring are relatively low (€26 per patient), this would result in a net cost reduction of $€ 70$ per patient. Taken into account that over 2 million patients are prescribed with antihypertensive drugs in the Netherlands ${ }^{4}$, and that in only $36 \%$ of these patients adequate BP control is not reached ${ }^{36}$ this could lead to a substantial cost saving.

\section{Conclusion}

In conclusion, we state that since electronic monitoring costs are relatively low, and the probability of cost-effectiveness was reasonable and policy decisions concerning the allocation of finite resource use in healthcare are warranted, this adherence enhancing program may be a cost-effective intervention. 


\section{Acknowledgements}

This study was funded by a unconditional grant from the Health Care Insurance Board.

The authors would like to thank Claudia Gulikers for data collection and data management, and all participating general practitioners and patients for their cooperation and effort. 


\section{References}

1. Hunt JS, Siemienczuk J, Touchette D, et al. Impact of educational mailing on the BP of primary care patients with mild hypertension. J Gen Intern Med 2004; 19: 925-930

2. Urquhart J. Patient non-compliance with drug regimens: measurement, clinical correlates, economic impact. Eur Heart J 1996; 17 Suppl. A: 8-15

3. Gascón JJ, Sánchez-Ortuno M, Llor B, et al for the Treatment Compliance in Hypertension Study Group. Why hypertensive patients do not comply with the treatment. Results from a qualitative study. Fam Pract 2004 21; 125-130

4. Herings RMC, Leufkens HGM, Heerdink ER, Klungel et al. Chronic pharmacotherapy continued. Pharmo report 2002. CIP data Royal Library, The Hague [in Dutch]

5. Psaty BM, Koepsell TD, Yanez ND, et al. Temporal patterns of antihypertensive medication use among older adults, 1989 through 1992: an effect of the major clinical trials on clinical practice? JAMA 1995; 273: 1436-1438

6. Caro JJ, Speckman Jl, Salas, et al. Effect of initial drug choice on the persistence with antihypertensive treatment: the importance of actual practice data. Can Med Assoc J 1999; 16: $41-$ 46

7. Wolf-Maier K, Cooper RS, Banegas JR, et al. Hypertension prevalence and BP levels in 6 European countries, Canada, and the United States. JAMA 2003; 289: 2363-2369

8. Rudd P, Byyny RL, Zachary V, et al. Pill count measures of compliance in a drug trial: variability and suitability. Am J Hypertens 1988; 1: 309-312

9. Maenpaa H, Manninen V, Heinonen OP. Comparison of the digoxin marker with capsule counting and compliance questionnaire methods for measuring compliance to medication in a clinical trial. Eur J Clin Pharmacol 1990;38:561-565

10. Roter DL. Hall JA, Merisca R, et al. Effectiveness of interventions to improve patient compliance: a meta-analysis. Med Care 1998; 36: 1138-1161

11. Schroeder K, Fahey T, Ebrahim S. How can we improve adherence to BP lowering medication in ambulatory care? Systematic review of randomized controlled trials. Arch Intern Med 2004; 164: $722-732$

12. Takiya LN, Peterson AM, Finley RS. Meta-analysis of interventions for medication adherence to antihypertensives. Ann Pharmacother 2004; 38: 1617-1624

13. Urquhart J. The electronic medication event monitoring. Lessons for pharmacotherapy. Clin Pharmacokinet 1997; 32: 245-256

14. Burnier M, Schneider MP, Chiolero A, et al. Electronic adherence monitoring in resistant hypertension: the basis for rational therapeutic decisions. J Hypertens 2001; 19; 335-341

15. Waeber B, Vetter W, Darioli R, et al. Improved BP control by monitoring adherence with antihypertensive treatment. Int J Clin Pract 1999; 53; 37-38.

16. Cramer JA, Ouelette VL, Mattson RH. Effect of microelectronic observation on compliance. Epilepsia 1990; 31: 617-618

17. Bertholet N, Favrat B, Fallab-Studbi CL, et al. Why objective monitoring of compliance is important in the management of hypertension. J Clin Hypertens 2000; 2 (4): 258-262

18. Bovet P, Burnier M, Madelaine $G$, et al. Monitoring one-year compliance to antihypertension medication in the Seychelles. Bull World Health Organ 2002; 80:33-39

19. Leenen FHH, Wilson TW, Bolli P, et al. Patterns of compliance with once versus twice daily antihypertensive drug therapy in primary care: a randomized clinical trial using electronic monitoring. Can J Cardiol 1997; 13(10): 914-920

20. Schwed A, Fallab C-L, Burnier M, et al. Electronic monitoring of compliance to lipid-lowering therapy in clinical practice. J of Clin Pharmacol 1999; 39: 402-409.

21. Mallion JM, Dutrey-Dupagne C, Vaur L, et al. Benefits of electronic pillboxes in evaluating treatment compliance of patients with mild to moderate hypertension. J Hypertens, 1996; 14: $137-$ 144 
22. Cramer JA \& Rosenbeck R. Enhancing medication compliance for people with serious mental illness. J Nerv Ment Dis 1999; 187: 53-55

23. Elixhauser A, Eisen SA, Romeis JC, et al. The effects of monitoring and feedback on compliance. Med Care 1990; 28: 882-893

24. Nides MA, Tadhkin DP, Simmons MS, et al. Improving inhaler adherence in a clinical trail trough the use of the nebulizer chronology. Chest 1993; 104: 501-507

25. Schmitz JM, Sayre SL, Stotts AL, et al. Medication compliance during a smoking cessation trial: a brief intervention using MEMS feedback. J Behav Med 2005; 28(2): 139-147

26. Hughes DA, Bagust A, Haycox A, et al. The impact of non-compliance on the cost-effectiveness of pharmaceuticals: a review of the literature. Health Economics 2001; 10: 601-615

27. Cantor JC, Morisky DE, Green LW, et al. Cost-effectiveness of educational interventions to improve patient outcomes in BP control. Prevent Med 1985; 14: 782-800

28. Eastaugh SR, Hatcher ME. Improving compliance among hypertensives: a triage criterion with cost-benefit implications. Medical Care 1982; 20: 1001-7

29. Logan AG, Milne BJ, Achber C, et al. Cost-effectiveness of a worksite hypertension treatment program. Hypertension 1981; 3: 211-8

30. Friedman Rh, Kazis L, Jette A, et al. A telecommunications system for monitoring and counseling patients with hypertension. Impact on medication adherence and BP control. Am J Hypertens 1996; 9: 285-92

31. Zarnke KB, Feagen BG, Mahon J, et al. A randomized study comparing a patient-directed hypertension management strategy with usual office-based care. Am J Hypertens 1997; 10: 58-57

32. Chobanian AV, Bakris GL, Black HR, et al. The seventh report of the Joint National Committee on Prevention, Detection, Evaluation and Treatment of High Blood Pressure: The JNC 7 report. JAMA 2003; 289: 2560-2572.

33. Gold MR, Siegel JE, Russell LB, Weinstein MC. Cost-effectiveness in health and medicine. Oxford: Oxford University Press; 1996

34. Drummond MF, O'Brien B, Stoddart GL, Torrance GW. Methods for the Economic Evaluation of Health Care Programs. $3^{\text {nd }}$ ed. Toronto: Oxford Univ Press; 2005

35. Oostenbrink JB, Koopmanschap MA, Rutten FF. Standardisation of costs: the Dutch Manual for Costing in economic evaluations. Pharmacoeconomics 2002; 20(7): 443-454

36. Klungel $\mathrm{OH}$, de Boer A, Paes AHP, et al. Undertreatment of hypertension in a population-based study in The Netherlands. J Hypertens 1998; 16: 1371-1378

37. Health Insurance Board. Http://www.medicijnkosten.nl. [in Dutch\}. Accessed: 25-05-05

38. Koopmanschap MA, Rutten FF. A practical guide for calculating indirect costs of disease. Pharmacoeconomics 1996; 10 (5): 460-466

39. EuroQol-Group. EuroQol--a new facility for the measurement of health-related quality of life. The EuroQol Group. Health Policy 1990; 16(3): 199-208.

40. Dolan P. A social tariff for EuroQol: results from a UK population survey. York: University of York; 1995

41. Russell LB, Gold MR, Siegel JE, et al. The role of cost-effectiveness analysis in health and medicine. Panel on Cost-Effectiveness in Health and Medicine. JAMA 1996; 276: 1172 -7

42. Little R, Rubin D. Statistical Analysis with missing data. Wiley: New York, 1987

43. Manca A, Hawkins N, Sculpher MJ. Estimating mean QALYs in trial-based cost-effectiveness analysis: the importance of controlling for baseline utility. Health Econ 2005; 14(5): 487-96

44. Briggs AH, Wonderling DE, Mooney CZ. Pulling cost-effectiveness analysis up by its bootstraps: a non-parametric approach to confidence interval estimation. Health Econ 1997; 6(4): 327-40

45. van Hout BA, Al MJ, Gordon GS, et al. Costs, effects and C/E-ratios alongside a clinical trial. Health Econ 1994: 3(5): 309-319

46. O'Brien BJ, Gertsen K, Willan AR, Faulkner A. Is there a kink in consumer's threshold value for cost-effectiveness in health care? Health Econ 2002; 11: 175-180 
47. Severens JL, Brunenberg DEM, Fenwick EAL, O’Brien B, Joore MA. Cost-effectiveness acceptability curves and a reluctance to lose. Pharmacoeconomics 2005; (12): 1207-1214

48. Briggs AH, O'Brien BJ. The death of cost-minimization analysis? Health Econ 2001; 10(2): 179184 
84 Cost-effectiveness of an adherence improving program 


\section{Chapter 6}

Electronic monitoring of adherence as a tool to improve blood pressure control: a qualitative study

Gwenn Wetzels, Ben van Steenkiste, Claudia Gulikers, Trudy van der Weijden, Patricia Nelemans and Martin Prins

Patient Education and Counseling. Submitted 


\section{Abstract}

\section{Background}

Poor adherence with antihypertensive medication is regarded as a major contributor to treatment failure. Several studies suggest that an electronic drug monitoring system, although developed as a system to measure adherence, might be used as a tool to improve adherence.

\section{Objective}

To examine the usefulness of electronic medication monitors as a tool to improve the management of hypertension. Because related to this issue, also more general perceptions towards antihypertensive medication are examined.

\section{Design}

A qualitative study using in-depth interviews.

\section{Methods}

In-depth interviews with 17 patients with high blood pressure despite the use of antihypertensive medication. All patients were electronically monitored for five months.

\section{Results}

Half of the patients felt that they changed their medication behaviour during monitoring. Patients were highly motivated to improve their adherence and appreciated the value of the electronic monitor in this process. Most patients had ambivalent feelings about taking antihypertensive medication but balanced these feelings in favour of taking medication. Poor adherence often did not seem to be an active decision but merely a case of thoughtlessness and negligence.

\section{Conclusion}

Most patients appreciated electronic monitoring of their drug adherence as relevant, additional care. It was considered as a valuable tool in the management of hypertension. 


\section{Introduction}

Adherence can be defined as the patient's tendency to follow medical advice. ${ }^{1}$ It is claimed that half of the antihypertensive medication "failures" may be caused by poor adherence of the patient. ${ }^{2}$ Research in the area of adherence has been focused on methods to assess adherence as well as interventions to improve adherence. Methods to improve adherence have proven to be complex, labor-intensive and not predictably effective. ${ }^{3-6}$ Therefore innovative approaches to assist patients to follow prescriptions are still needed. ${ }^{3}$

Electronic monitors are often used to measure adherence. The system exists of a medication bottle with a cap that includes a microprocessor that records the time and date of actual dosing events (Medication Event Monitoring System, MEMS).7,8 Recently, we performed a study that randomised patients with persistent hypertension despite medical treatment to 1) dose increase or addition of antihypertensive medication or 2) electronic monitoring of adherence without changes of the medication regimen. After an eight-week monitoring period, blood pressure normalized or decreased substantially in about half of the patients in the monitor-group. Adherence as measured at the end of eight weeks was high in almost all patients. The improvement in blood pressure control was similar to that in the control group with medication changes. Therefore, it seems valid to assume that the improved blood pressure control in the monitored group resulted from improved adherence. It is possible that the patients, just by knowing that they were being monitored, improved their adherence behaviour. This implies that an electronic monitoring system may be used as a tool to improve adherence instead of a method to measure adherence. Since other authors have reported similar results, ${ }^{7-9}$ the question arises why patients who are being monitored change their behaviour. One possibility is that the patient is feeling "being watched" and tries to please the investigator or doctor. Another possibility, however, is that the insight in actual dosing pattern may be experienced by the patient as a valuable tool to improve adherence. The long-term effectiveness of electronic monitors as a tool to improve adherence largely depends upon the reason why medication behaviour has changed during monitoring.

We therefore undertook a qualitative study in a group of patients with a normalized or substantially decreased blood pressure at the end of an eight-week adherence monitoring period in order to explore whether and how the medication behaviour changed during the monitoring period and to assess the role of the electronic monitor in this process. Also the patient's acceptance of the monitors was examined. Finally, the usefulness of the electronic monitor as a tool to improve adherence also depends on the specific reasons for non-adherence. Therefore general perceptions of the patients towards antihypertensive medication were also investigated. 


\section{Methods}

\section{Design}

In-depth interviews with patients with high blood pressure (systolic blood pressure $\geq 160 \mathrm{mmHg}$ and/or diastolic blood pressure $\geq 95 \mathrm{mmHg}$ ) despite the use of antihypertensive medication.

\section{Sample}

In the randomised trial, 43 general practitioners in the South of the Netherlands included 258 patients with high blood pressure despite the use of antihypertensive medication. Adherence was monitored electronically in 164 patients. In 80 of these patients, blood pressure normalized or decreased substantially $(>10 \mathrm{mmHg}$ systolic and $>5 \mathrm{mmHg}$ diastolic). A random sub sample of 20 patients of the latter group was asked to participate in this qualitative study. Recruitment for the interview took place in the last three months of the trial. Patients were informed that participation in the interviews was strictly voluntary and that all information shared would be treated confidentially. Patients were asked for informed consent. The Ethical Committee of the Maastricht University approved of the study.

\section{Interviews}

The interviews were semi-structured, with predominantly open-ended questions. The patients were encouraged to talk freely about what they judged important. The interviewer used a topic guide that covered three domains: (1) the role of electronic monitoring as a tool to change medication behaviour, (2) the patient's acceptance of an electronic monitor as an aid to manage their hypertension, and (3) patients' general perceptions about antihypertensive medication. The topic guide was modified during five pilot interviews. These pilot interviews were not included in the analysis.

All interviews took place in the participants' homes and were conducted by one of the authors (CG or BvS). The patients already knew one interviewer (CG) because she was involved as a trial nurse in the execution of the main trial. The familiarity with the interviewer might have stimulated patients to be more open in answering the questions. BvS, who was not involved in the main trial, interviewed about one in four patients. Interviews typically lasted half an hour.

\section{Analysis}

Interviews were tape-recorded and fully transcribed. Interview contents were analysed by a constant comparative method using the software package Kwalitan version 5.0.9. Key issues and topics in relation to the main objectives of the study were identified and grouped into themes by GW and $\mathrm{BvS}$ independently. Then a coding scheme was generated in order to label transcript passages and different citations were labelled. By discussion, the process of categorization and coding of the data was further refined upon re-reading of the data. 
Interviews were performed until saturation of the data was experienced. After application of codes to the final dataset, themes within and between respondents were explored.

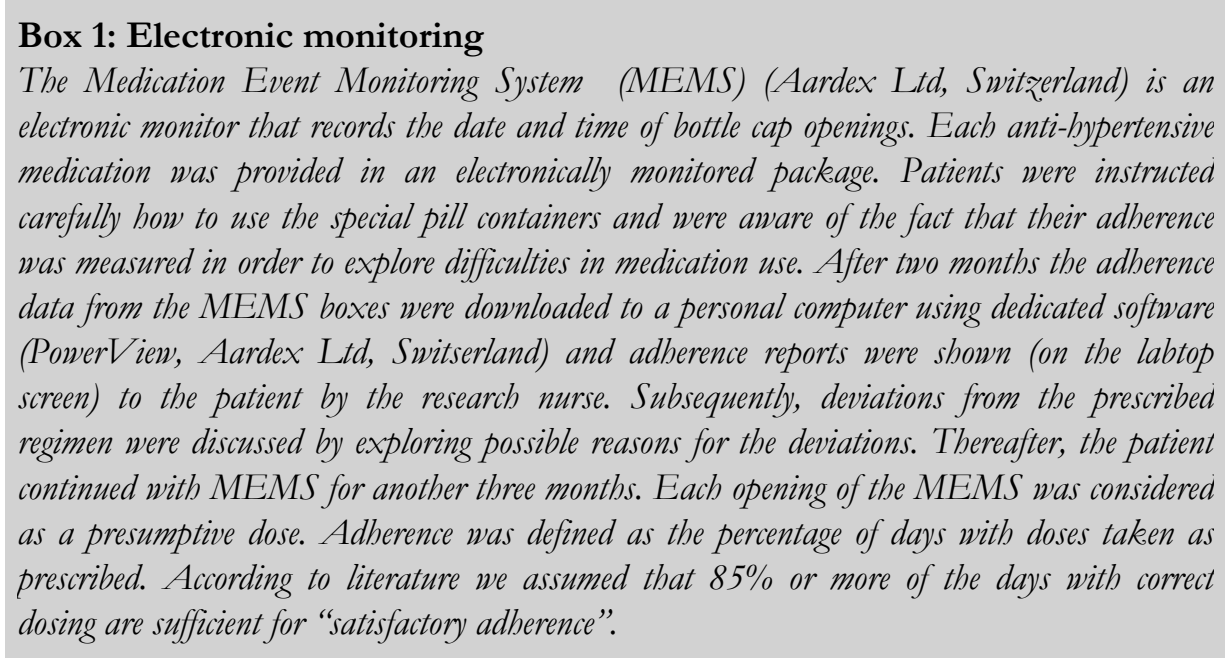

\section{Results}

Of the 20 patients invited for participation, one refused to be interviewed, one refused tape-recording and one interview could not be analysed due to technical problems. Therefore, the final data set consists of 17 interviews. It appeared that no new themes emerged after analysis of 11 interviews. The characteristics of the sample are listed in table 1. 
Table 1 Baseline characteristics of included patients $(n=19)$

\begin{tabular}{|c|c|c|}
\hline Demographic characteristics \# & $(\%)$ & \\
\hline \multicolumn{3}{|l|}{ Age } \\
\hline$\leq 55$ & 39 & \\
\hline $56-65$ & 25 & \\
\hline $66-75$ & 24 & \\
\hline$\geq 75$ & 12 & \\
\hline \multicolumn{3}{|l|}{ Gender } \\
\hline Male $(\%)$ & 88 & \\
\hline \multicolumn{3}{|l|}{ Education } \\
\hline Low & 12 & \\
\hline Middle & 36 & \\
\hline High & 42 & \\
\hline Very high & 12 & \\
\hline \multicolumn{3}{|l|}{ Employed } \\
\hline Yes & 47 & \\
\hline No & 53 & \\
\hline \multicolumn{3}{|l|}{ Civil status } \\
\hline Married & 82 & \\
\hline Widow/widower & 12 & \\
\hline Single & 6 & \\
\hline Clinical characteristics & Mean & $(\mathrm{SD})$ \\
\hline Systolic blood pressure at inclusion & 168 & $(18)$ \\
\hline Diastolic blood pressure at inclusion & 95 & (11) \\
\hline Years with hypertension & 9 & \\
\hline \multicolumn{3}{|l|}{ Baseline treatment $(\%)$} \\
\hline Diuretics & 6 & \\
\hline ß-blockers & 6 & \\
\hline Calcium antagonists & 6 & \\
\hline $\mathrm{ACE}$ inhibitors $/ \mathrm{AT}_{2}$-antagonists & 24 & \\
\hline Combination of different drugs & 59 & \\
\hline
\end{tabular}

\section{Electronic monitoring as a tool to change medication behaviour}

Adherence in all 17 interviewed patients was satisfactory $(>85 \%)$ during the eightweek monitoring period. Seven patients had a perfect adherence (100\%) while 10 patients omitted one or more doses. The mean percentage of days with correct dosing was $96 \pm 5 \%$.

During the monitoring period, all interviewed patients underwent a blood pressure improvement or reached adequate blood pressure without any change in medication.

Nine patients felt that they improved their medication intake during the monitoring period. Reasons for this improvement differed. Many patients claimed 
that the electronic monitor gave insight into actual dosing patterns thereby acting as a reminder to take the pills according to the prescribed regimen.

"With the special bottles you can really see which medication you've taken - and the GP can see it too. I've used strips before and have forgotten to take my pills without realizing that I'd forgotten them." (patient 4)

Although monitoring alone, without giving feedback on adherence (first eight week-period), resulted in substantial blood pressure reductions, it seemed that showing adherence reports (chronology plots downloaded from the monitor) to the patient and discussing possible reasons for the deviations from the prescribed regimen provided insight into dosing histories and corrected wrong perceptions about medication behaviour.

"The first time Claudia (research nurse) came, I took 85\% of my medication. I couldn't believe that I remembered only 85\% of the time! So I made a concerted effort and managed to remember 93\% of the time. I felt better. The fear of what the doctor thinks makes you more disciplined. But I think I really changed my habits. "(patient 11)

Besides effects of discussing the downloaded chronology plots with the patient, some patients specifically mentioned that they focussed better on the dosing schedule because they felt being watched.

"The electronic monitoring really works - just knowing that your behaviour is being watched helps a lot." (patient 10)

\section{Electronic monitoring: patient's acceptance}

Most patients appreciated electronic monitoring as relevant additional health care and valuable attention for their condition. None of the patients interviewed had negative feelings about their adherence being monitored. They did not experience the adherence measurements as an incursion on their privacy and the feeling prevailed that "it was for their own good". Patients were highly motivated to improve their adherence and appreciated the value of the electronic monitor in this process. Overall, patients thought that electronic monitoring could be a useful tool in the management of hypertension.

"A pretty cool system, especially when you get to see how your own behaviour has been registered." (patient 9)

In general, the electronic monitor was well accepted. A disadvantage that was mentioned by four patients was the incapability to check whether or not they had already taken their medication on the bottle itself. Several patients mentioned that it would be useful that the monitor would be equipped with a timepiece cap that displays the last time the cap was removed. 
'It's not that I minded to use the special bottles. It was just unnerving when you couldn't remember if you had taken the pills or not. That was the only negative aspect - sometimes I did not remember whether I had taken my pills." (patient 14)

\section{Patients' general perceptions about antihypertensive medication}

Respondents expressed ambivalent feelings towards the intake of anti-hypertensive medication. Although none of the patients experienced adverse effects of the antihypertensive medication, they perceived their medication as unnatural for their body and had concerns about the long-term use of antihypertensive medication. On the other hand, most patients were convinced of the benefits of their antihypertensive medication in achieving a good health outcome and believed that an effective alternative to lower blood pressure is not available. Patients felt strongly that it was best to do as the doctor said and anticipated on feelings of guilt in the future when imaging adverse events due to poor adherence. Furthermore, fear of complications of hypertension and improved blood pressure readings were the most important reasons to take medication.

'You have to take responsibility for your own actions. Be honest with yourself. You can't blame the doctor if you didn't follow his advice. If the doctor says that it's better to take the pills, then I do that. I don't think you have a choice." (patient 2)

"It's against my principles to take medicines; until five years ago I refused to take any. But now I think of the kids; they're still young. The risk of a heart attack or stroke is just too great - and I don't want to be a burden to them. And so I take what I need to." (patient 5)

Overall it seemed that most patients accepted their medication and were willing to take them according to the prescribed regimen. Patients often explained nonadherence as a case of simple thoughtlessness and no specific reasons for nonadherence were expressed.

During the monitoring period both the process of "insight in actual dosing patterns" and "the feeling of being watched" resulted in improved adherence in the majority of patients. Striking however was that "the feeling of being watched" was experienced as a positive encouragement to be adherent with the prescribed regimen.

\section{Discussion}

The main goal of this study was to examine the usefulness of the electronic monitor as a tool to improve the management of hypertension.

Coming from a population with uncontrolled hypertension, it was striking that patients seemed convinced that taking antihypertensive medication as prescribed by their doctor was the best option to control their blood pressure and to prevent 
long-term consequences of hypertension. Patients balanced their decision in favour of taking their medication and often non-adherence did not seem to be an active decision but merely a case of thoughtlessness and negligence. These results indicate that a tool that puts emphasis on exact timing of medication intake by giving detailed chronology plots might be very effective in improving adherence.

Electronic monitoring improves the involvement of the patient into their hypertension management by providing insight into actual dosing patterns. Patients clearly indicated that they considered electronic monitoring as valuable additional care and attention for their condition, which makes it unlikely that the improved adherence during monitoring can solely be explained by a short-term increase in adherence in order to please the investigator or doctor under trial conditions. Although the "feeling of being watched" did occur in some patients, this feeling encouraged the patient to focus on taking their medication on time. No negative feelings about adherence being monitored, were mentioned.

Our findings are in agreement with other studies that also concluded that patients balance positive and negative feelings about their medication in their ultimate decision to accept a certain medication regimen. ${ }^{10-12}$ However, while most studies explain non-adherence as an active decision of the patient as a result of aversion against taking medication, ${ }^{10,12,13}$ we found that non-adherence was merely a case of "simply forgotten". This finding is in agreement with a study of Cramer, ${ }^{14}$ who stated that "the adherence problem has it's origin in simple negligence, arising from the conflict between varying degrees of disorganization in daily life and the need for regular dosing". This finding indicates that adherence would improve drastically when patients are supported in a more disciplined behaviour towards taking their medication.

There may be some limitations to our study. All interviewed patients underwent substantial blood pressure reductions during monitoring and about half of the patients admitted that they improved their medication intake during monitoring. Whether better adherence was actually the cause of better blood pressure control, however, is not entirely clear. Blood pressure reductions can also be explained by random fluctuations and our assumption that improved adherence resulted in improved blood pressure readings may not be valid in all patients.

It may also be possible that only patients with no clear aversion against taking antihypertensive medication were willing to participate in the trial, which may have biased the results. However adherence-data based on pharmacy records in the year before inclusion showed no difference between participants and patients that refused to participate, making such a selection unlikely (data not shown). Finally, we used a random sample to perform the study. This resulted in a sample with more than $80 \%$ of the patients being male and married. This might have consequences for the external validity of our results. 


\section{Conclusion}

The effect of electronic monitoring on lowering blood pressure has already been described in other studies. ${ }^{7-9}$ This is however the first study that examines the effect of monitoring adherence on medication behaviour from the patients' point of view.

Electronic monitoring allows patients to get insight into their dosing history, which apparently improves the involvement of the patient into their hypertension management. Using a monitor equipped with a timepiece cap that displays the last time the cap was removed possibly further enhances these positive effects.

A practical problem may be that the adherence-improving effect of the monitor diminishes after time because patients are extra focussed on their medication regimen only in the first few months of monitoring. Therefore it would be useful that patients get feedback on their adherence reports at regular intervals by a health-professional who discusses possible adherence problems with the patient in a non-judgemental way.

It can be concluded that patients accept the electronic monitor as a valuable tool that supports the management of their blood pressure. Electronic monitoring therefore seems to be an effective and easy to use tool to improve adherence with the advantage of involving patients in the management of their high blood pressure. 


\section{References}

1. Urquhart J. Role of patient compliance in clinical pharmacokinetics. A review of recent research. Clin Pharmacokinet, 1994. 27(3): p. 202-15.

2. Stephenson J. Noncompliance may cause half of antihypertensive drug "failures". JAMA, 1999. 282(4): p. 313-4.

3. McDonald HP, Garg AX, and Haynes RB. Interventions to enhance patient adherence to medication prescriptions: scientific review. JAMA, 2002. 288(22): p. 2868-79.

4. Haynes RB, McKibbon KA, and Kanani R. Systematic review of randomised trials of interventions to assist patients to follow prescriptions for medications. Lancet, 1996. 348(9024): p. 383-6.

5. Haynes RB, McDonald HP, and Garg AX. Helping patients follow prescribed treatment: clinical applications. JAMA, 2002. 288(22): p. 2880-3.

6. Roter DL, Hall JA, Merisca R, Nordstrom B, Cretin D, and Svarstad B. Effectiveness of interventions to improve patient compliance: a meta-analysis. Med Care, 1998. 36(8): p. 1138-61.

7. Waeber B, Vetter W, Darioli R, Keller U, and Brunner HR. Improved blood pressure control by monitoring compliance with antihypertensive therapy. Int J Clin Pract, 1999. 53(1): p. 37-8.

8. Burnier M, Schneider MP, Chiolero A, Stubi CL, and Brunner HR. Electronic compliance monitoring in resistant hypertension: the basis for rational therapeutic decisions. J Hypertens, 2001. 19(2): p. 335-41.

9. Bertholet N, Favrat B, Fallab-Stubi CL, Brunner HR, and Burnier M. Why Objective Monitoring of Compliance is Important in the Management of Hypertension. J Clin Hypertens (Greenwich), 2000. 2(4): p. 258-262.

10. Benson J and Britten N. Patients' decisions about whether or not to take antihypertensive drugs: qualitative study. BMJ, 2002. 325(7369): p. 873.

11. Svensson S, Kjellgren KI, Ahlner J, and Saljo R. Reasons for adherence with antihypertensive medication. Int J Cardiol, 2000. 76(2-3): p. 157-63.

12. Townsend A, Hunt K, and Wyke S. Managing multiple morbidity in mid-life: a qualitative study of attitudes to drug use. BMJ, 2003. 327(7419): p. 837.

13. Gascon JJ, Sanchez-Ortuno M, Llor B, Skidmore D, and Saturno PJ. Why hypertensive patients do not comply with the treatment. Results from a qualitative study. Family Practice, 2004. 21(2): p. 125-130.

14. Cramer JA and Rosenheck R. Enhancing medication compliance for people with serious mental illness. J Nerv Ment Dis, 1999. 187(1): p. 53-5. 
$96 \mid$ Electronic monitoring and patient acceptance 


\section{Chapter 7}

Determinants of poor adherence in hypertensive patients: development and validation of the "Maastricht Utrecht Adherence in Hypertension (MUAH)questionnaire"

Gwenn E.C. Wetzels, Patricia J. Nelemans, Boris van Wijk, Nick Broers, Jan S.A.G. Schouten, Martin H. Prins

Patient Education and Counseling. In press. 


\begin{abstract}
Objectives

(1) To help identify patients with poor adherence and (2) to identify potential reasons that impede or facilitate adherence.
\end{abstract}

\title{
Methods
}

Seventeen patients who used antihypertensive drugs participated in semistandardized interviews. Interviews were recorded and reviewed by two investigators. Forty-four items were selected. An exploratory factor analysis was performed. Convergent validity was assessed by evaluating the association between sum scores on the identified subscales and three other adherence measures: 1) the Brief Medication Questionnaire (BMQ), 2) pharmacy refill records and 3) electronic monitoring. Regression analysis was used to evaluate the magnitude of associations.

\section{Results}

$255(90 \%)$ patients completed the questionnaire. Factor analysis resulted in a fourfactor solution, explaining $30 \%$ of cumulative variance among respondents. The factors (scales) were labelled: positive attitude towards health care and medication (I), lack of discipline (II), aversion towards medication (III) and active coping with health problems (IV). Chronbach's alpha coefficient was $0.75,0.80,0.63$ and 0.76 for scales I, II, III and IV, respectively. Convergent validity was partly supported by statistically significant associations that were found between sum scores of subscales 1 and II and the BMQ and electronic monitoring, respectively.

\section{Conclusion}

The MUAH-questionnaire has excellent psychometric properties and may be useful to identify factors that impede or facilitate adherence. However, it is not clear to what extent the questionnaire measures actual adherence.

\section{Practice implications}

Validation of the MUAH-questionnaire in other studies is needed. 


\section{Introduction}

Hypertension is a major cardiovascular risk factor. Although safe and effective drugs to lower blood pressure have become available, only $30 \%$ of the patients treated for hypertension achieve the target blood pressure of $140 / 90 \mathrm{mmHg} .{ }^{1,2}$ Despite the documented effectiveness of antihypertensive medication, it is estimated that about $50 \%$ of the patients with hypertension is not using antihypertensive medication as prescribed. ${ }^{3}$ Poor adherence with antihypertensive medication seems to be an important cause of lack of blood pressure control.4-7 Identification of patients whose adherence is inadequate remains a challenge. Patients often are reluctant to admit non-adherence and may not be aware of dosing errors. ${ }^{8,9}$ Findings revealed that physician estimates of adherence are not accurate either. ${ }^{10}$ Pill counts and self-reports of patients tend to overestimate patient adherence and measuring metabolites of drugs in blood and urine only provides adherence information for a certain point in time. ${ }^{11,12}$ Using pharmacy data is another method that enables measurement of adherence. By evaluating whether medication prescriptions are filled in time, it is possible to calculate refill adherence. However, it is expected that only a fraction of actual non-compliers will be identified because it only allows identification of patients that simply do not obtain enough medication to be compliant. In 1986 electronic monitoring systems became available as a tool for objective registration of patient adherence. ${ }^{13}$ It is claimed that electronic monitoring is more sensitive for detecting inadequate adherence than any other method.13-17 However, until now electronic monitoring has been used in a clinical research setting only. The costs of electronic monitors and other practical issues limit the use in routine clinical practice. Therefore, there is still a need for valid and easy-to-use tools for detecting adherence problems.

The last decades, several interventions to enhance adherence with antihypertensive medication have been performed with ambiguous results. ${ }^{18-21}$ The absence of individual tailoring of interventions might explain these results. Before starting an intervention to improve adherence, it would be helpful to have not only a tool to select patients that are likely to be poor adherers but also to understand the reasons why patients do not take medication as prescribed. For example, differentiation between intentional and unintentional non-adherence is essential to be able to select the optimal intervention.

It would be desirable to have a brief self-report questionnaire to enable targeting specific interventions in patients who are likely to have adherence problems.

A few questionnaires aimed at measuring adherence in patients who use antihypertensive drugs are available, but the sensitivity of these questionnaires is too low for use in clinical practice. ${ }^{22-26}$ Only the Brief Medication Questionnaire $(\mathrm{BMQ})^{25}$ claims to have a high accuracy with a sensitivity of detecting poor adherence of approximately $80 \%$. However, the ability of the BMQ to select specific adherence barriers is limited, because the questionnaire only focuses on the absence or presence of possible worries of patients in taking medication, and perceived efficacy of the medication. 
Therefore, the purpose of this study was 1) to help identify patients with poor adherence and 2) to identify potential reasons that impede or facilitate adherence.

\section{Methods}

\section{Development of the Maastricht-Utrecht Hypertension and Adherence (MUAH)-questionnaire}

The development procedure of the questionnaire comprised the following steps. Semi-structured interviews with 17 hypertensive patients were used to confirm that the selected items were covering all issues regarding non-adherence. During homeinterviews patients were encouraged to discuss all subjects related to drug-intake. Patients were asked about knowledge of hypertension, attitude toward their antihypertensive medication, reasons for not taking their medication and actual everyday execution of the regimen. The interviews were pursued until new ideas were exhausted. Patients expressing ideas that were too general or those talking about subjects not related to hypertension or adherence, were interrupted in order to refocus on relevant subjects. Each interview lasted 25 minutes on average. The interviews were taped and reviewed afterwards by two independent investigators using the software program Kwalitan, version 5.0 (University of Nijmegen, The Netherlands). All relevant topics that were mentioned by patients were categorized and items were generated from the verbatim statements. This resulted in a list of 44 items, which were included in the questionnaire. All items were scaled according to a seven point Likert scale ranging from "totally disagree" (1) to "totally agree" (7). The preliminary questionnaire was pre-tested in 7 patients to ensure that the questions were clear and not suggestive and to test the acceptance and the time required to complete the questionnaire. After some minor modifications, the questionnaire was administered to the patients. After one month, the questionnaire was sent again by mail in order to be able to determine test-retest reliability.

The patient had to complete the questionnaire within a week. If no response was available within ten days, the patient was contacted by phone.

\section{Subjects}

Eligible were hypertensive patients who were treated with antihypertensive medication. The patients were recruited within the framework of two studies, which were conducted by two research groups involved in the research on hypertension and adherence. Both studies were initiated as a randomised clinical trial to evaluate the effect of electronic monitoring on blood pressure control. Patients were included in two regions in the Netherlands: Utrecht (in the central part of the Netherlands) and Maastricht (in the southern part of the Netherlands). Eligibility and recruitment method differed between the two regions. 


\section{Maastricht region}

Patients were $(\mathrm{n}=168)$ were recruited through general practitioners (GP) at the moment they were scheduled for a follow-up visit. They were eligible if they had a) a diagnosis of hypertension for at least a year prior to inclusion, and b) inadequate blood pressure control despite the use of antihypertensive medication. Inadequate blood pressure control at inclusion was defined, according to the national guideline of the Dutch College of General Practitioners (update 1999), as a systolic blood pressure (SBP) $\geq 160 \mathrm{mmHg}$ and/or diastolic blood pressure (DBP) $\geq 95 \mathrm{mmHg} \cdot{ }^{27}$ Blood pressure was measured three times in sitting position after five minutes of rest. Mean SBP and DBP were used for analysis.

\section{Utrecht region}

Patients in Utrecht ( $\mathrm{n}=115)$ were recruited through pharmacists at the moment they visited the pharmacy for a refill of antihypertensive medication. Patients were eligible if they had a diagnosis of hypertension ${ }^{27}$ for at least a year prior to inclusion. The pharmacist did not measure blood pressure but it was assumed that patient were hypertensive because of the need for antihypertensive medication.

The Ethical Committees of the participating universities (Maastricht University and University of Utrecht) approved off the studies.

\section{Adherence measures}

\section{Brief Medication Questionnaire}

Patients were asked to complete the Brief Medication Questionnaire (BMQ). ${ }^{25}$ The BMQ is a self-report tool for measuring adherence. This questionnaire has the potential for self-administration by patients with multiple antihypertensive drugs. It includes a five-item Regimen Screen that asks patients how they took each of their medications in the past week, a two-item Belief Screen about drug efficacy and bothersome features, and a two-item Recall Screen about potential difficulties with remembering the dosing regimen. A positive response to any question in each subscale results in the corresponding screen being considered "positive" for potential non-adherence. Only patients in the Maastricht region completed the BMQ-questionnaire because this was not feasible in the Utrecht region due to logistic problems.

\section{Pharmacy records}

Pharmacy records were used to measure refill adherence during 12 months before completing the questionnaire. In order to determine refill adherence, patients' records from computerized pharmacy records were obtained. These records included the name(s) of the prescribed hypertensive drug(s), dosage, the quantity dispensed at each pharmacy fill and the dates of prescription fills. 
Refill adherence during the interval between two prescription fills was calculated as the number of days for which the pills were prescribed divided by the total number of days in this interval. Only those medications that were filled at least three times during the twelve months were taken into account, so refill adherence could be calculated for at least two intervals. For each antihypertensive drug average refill adherence was computed by summing the refill adherence in each interval and dividing the sum by the number of intervals.

\section{Electronic monitoring}

Adherence with antihypertensive medication was monitored electronically with the Medication Event Monitoring System ((MEMS), Aardex Ltd., Switserland) during two months after completing the first questionnaire. The MEMS is an electronic monitor that records the date and time of bottle cap openings. In one of the regions (Maastricht), each anti-hypertensive drug was provided in an electronically monitored package. In the other region (Utrecht), only one antihypertensive drug was provided in an electronically monitored package.

Patients were instructed carefully how to use the special pill containers and were aware of the fact that their adherence was monitored. After two months, adherence data from the MEMS boxes were downloaded to a personal computer using the dedicated software (PowerView, Aardex Ltd, Switserland). Each opening of the MEMS was considered as a presumptive dose. Adherence was defined as the percentage of days with doses taken as prescribed.

\section{Statistical analysis}

After collection and processing of the questionnaires, items that displayed low variation in responses $(>90 \%$ of all responses in two adjacent categories) were removed.

Subsequently, an exploratory factor analysis was performed to investigate the factor structure of the questionnaire. The number of factors to retain was determined using Catells's scree plot analysis.

The resulting factors were subjected to oblique (Oblimin) rotation because any observed dimensions of the questionnaire were expected to correlate with one another. Hyperplane items (i.e. items failing to show salient loadings on any of the factors) and items with substantial cross-loadings on the other factors were removed. Resulting items were studied for interpretability of the factors. Internal consistency of the identified scales was assessed by the Chronbach's alpha coefficient.

Test-retest reliability of the sum scores on the questionnaire scales was calculated with an interval of 30 days using the intraclass correlation coefficient (ICC). Only patients in the region Maastricht were asked to complete the questionnaire for a second time.

Convergent validity of the MUAH-questionnaire was assessed by evaluating the association between sum scores on the identified subscales and the three other 
adherence measures: 1) the BMQ, 2) pharmacy refill records and 3) electronic monitoring. For this purpose only the MUAH-data at baseline were used.

The magnitude and statistical significance $(\mathrm{p}<0.05)$ of the associations was evaluated using regression analysis. Logistic regression analysis was used with BMQ adherence as dependent variable (dichotomous outcome), whereas linear regression analysis was used with adherence level as measured by refill records or electronic monitoring as dependent variable (continuous outcome).

It was tested whether the regression coefficients corresponding with the sum scores on the identified sum scores differed significantly from zero $(\mathrm{p}<0.05)$.

All analyses were repeated within the two subgroups of patients recruited from the Utrecht en Maastricht region respectively, in order to evaluate whether differences in eligibility criteria and recruitment methods between the two regions influenced the results.

All analyses were conducted with SPSS version 12.0 (SPSS, Inc, Chicago, Illinois).

\section{Results}

Demographic and clinical data of the patient population are shown in Table 1. The questionnaire was completed by a total of 255 patients (164 patients in the region Maastricht and 91 patients in the region Utrecht). The first administered questionnaire had a response rate of $98 \%$ in the patients recruited in the region Maastricht and $80 \%$ of patients recruited in the region Utrecht.

Table 1 Demographic and clinical characteristics of included patients $(n=283)$

\begin{tabular}{|c|c|c|}
\hline Demographic characteristics & $(\%)$ & \\
\hline \multicolumn{3}{|l|}{ Age } \\
\hline$\leq 55$ & 23 & \\
\hline $56-65$ & 35 & \\
\hline 66-75 & 34 & \\
\hline$\geq 75$ & 8 & \\
\hline \multicolumn{3}{|l|}{ Gender } \\
\hline Male $(\%)$ & 50 & \\
\hline Clinical characteristics & Mean & $(\mathrm{SD})$ \\
\hline Years with hypertension & 9 & (9) \\
\hline Systolic blood pressure at inclusion & 158 & (24) \\
\hline Diastolic blood pressure at inclusion & 85 & $(12)$ \\
\hline \multicolumn{3}{|l|}{ Nr. of antihypertensive drugs (\%) } \\
\hline 1 & 40 & \\
\hline 2 & 43 & \\
\hline 3 & 15 & \\
\hline 4 & 2 & \\
\hline \multicolumn{3}{|l|}{ Dose Frequency ( $\%$ ) } \\
\hline 1 & 83 & \\
\hline 2 & 15 & \\
\hline 3 & 3 & \\
\hline
\end{tabular}


The average time to complete the questionnaire was 25 minutes. Missing values on one or more items occurred in 14 patients $(6 \%)$. Missing values were replaced by mean values.

Low variation in responses resulted in the exclusion of 5 items. Subsequently an exploratory factor analysis was performed on the remaining 39 items. Catell's scree plot analysis indicated that the factor structure was best described by four factors. Thus, a solution with four factors was attempted and subjected to oblique (Oblimin) rotation, which resulted in a 25 -item questionnaire. The cumulative variance accounted for by the four-factor solution was 30\%, with factor I accounting for $13 \%$, factor II for $10 \%$, factor III for $4 \%$ and factor IV for $3 \%$ of the variance among respondents. Inspection of the items indicated that factor I taps the belief of patients in the possibility to improve their health by complying with medical advice. This factor was labelled "positive attitude towards health care and medication". Items that loaded highly on factor II all pertained to the capability to take medication regularly. Therefore, factor II was labelled "lack of discipline". Items loading highly on factor III seemed to reflect reluctance to take medication and thus factor III was labelled "aversion towards medication". Finally, items indicating active coping with health problems loaded highly on factor IV and consequently factor IV was labelled "active coping behaviour". The four scales and corresponding items, including item means and standard deviations as well as rotated factor loadings for the 4-factor solution, are displayed in Table 2. The ranges of sum scores on the individual scales were 17-56, 6-42, 5-35 and 11-42 for scales I, II, III and IV, respectively.

Internal consistency as measured by Chronbach's alpha was $0.75,0.80,0.63$ and 0.76 for scales I, II, III and IV, respectively.

Test-retest reliability of the questionnaire, which was evaluated only in the Maastricht population, was satisfactory. No statistically significant difference in sum scores between the two measurements was observed. The intra class correlation coefficient (ICC), a measure of concordance, was 0.86, 0.80, 0.85 and 0.79 for scales I, II, III and IV, respectively.

In order to evaluate whether differences in eligibility criteria and recruitment methods between the two regions influenced the results, all analyses were repeated within the two subgroups. Separate analyses for the Maastricht and Utrecht region gave similar results (data not presented). 


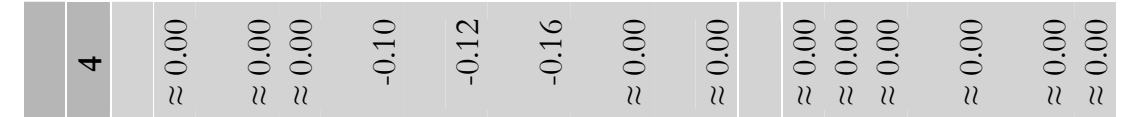

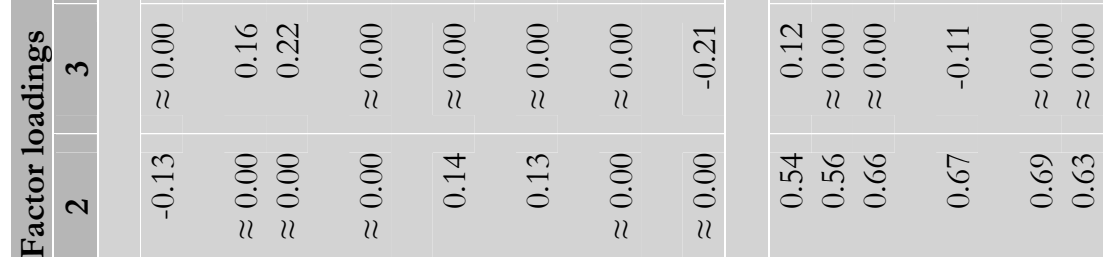

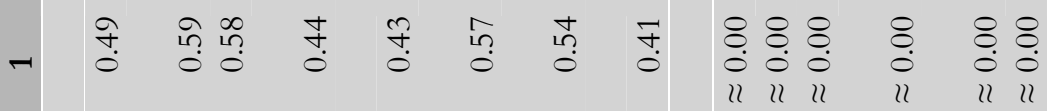
早

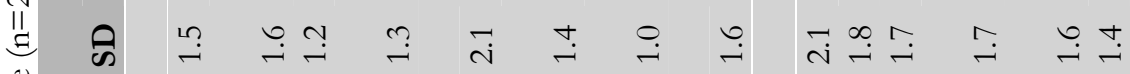

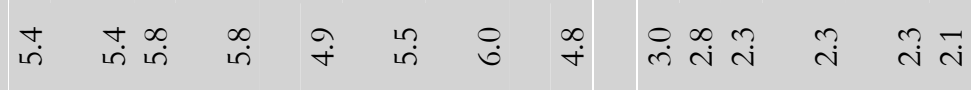

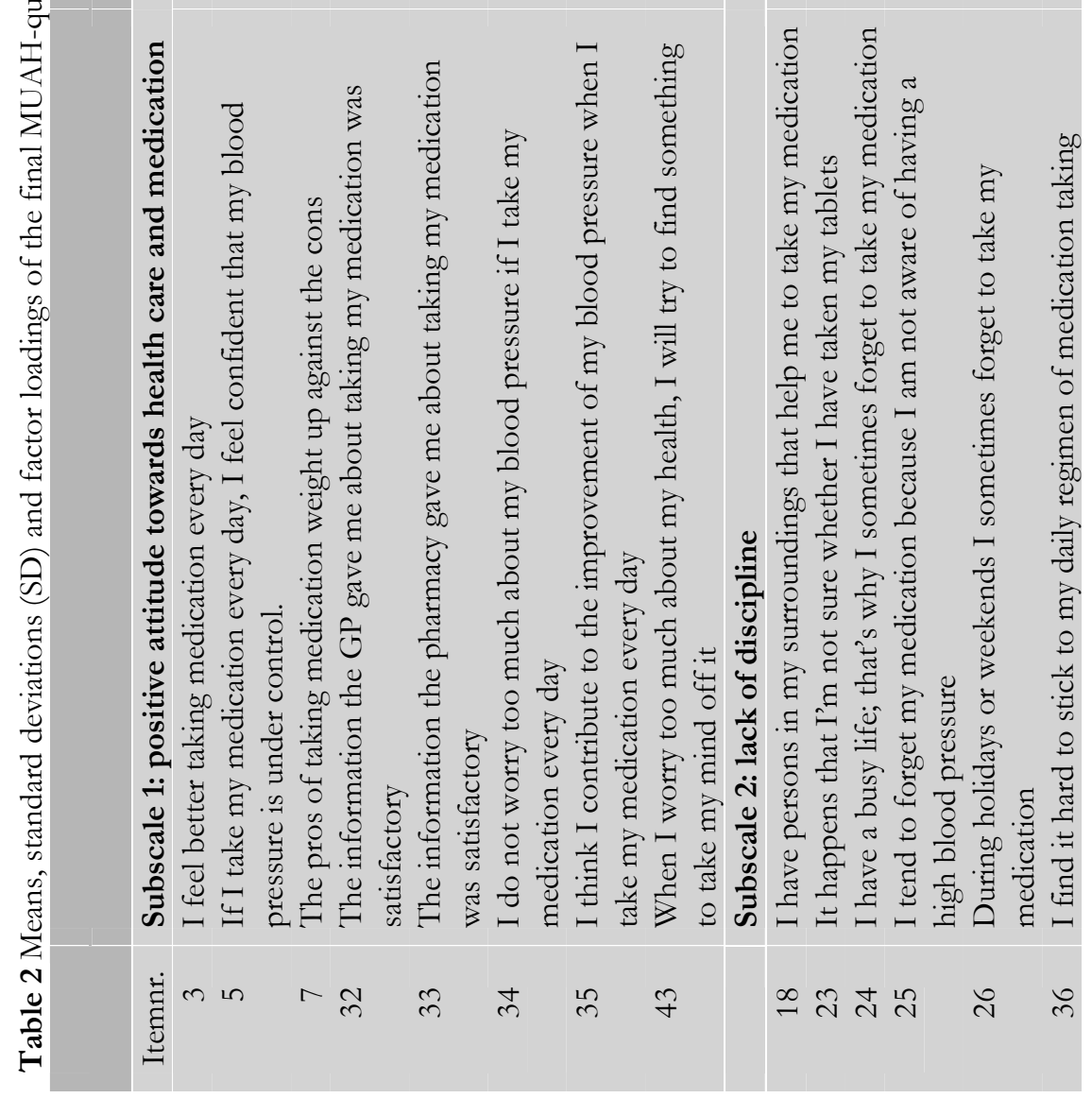




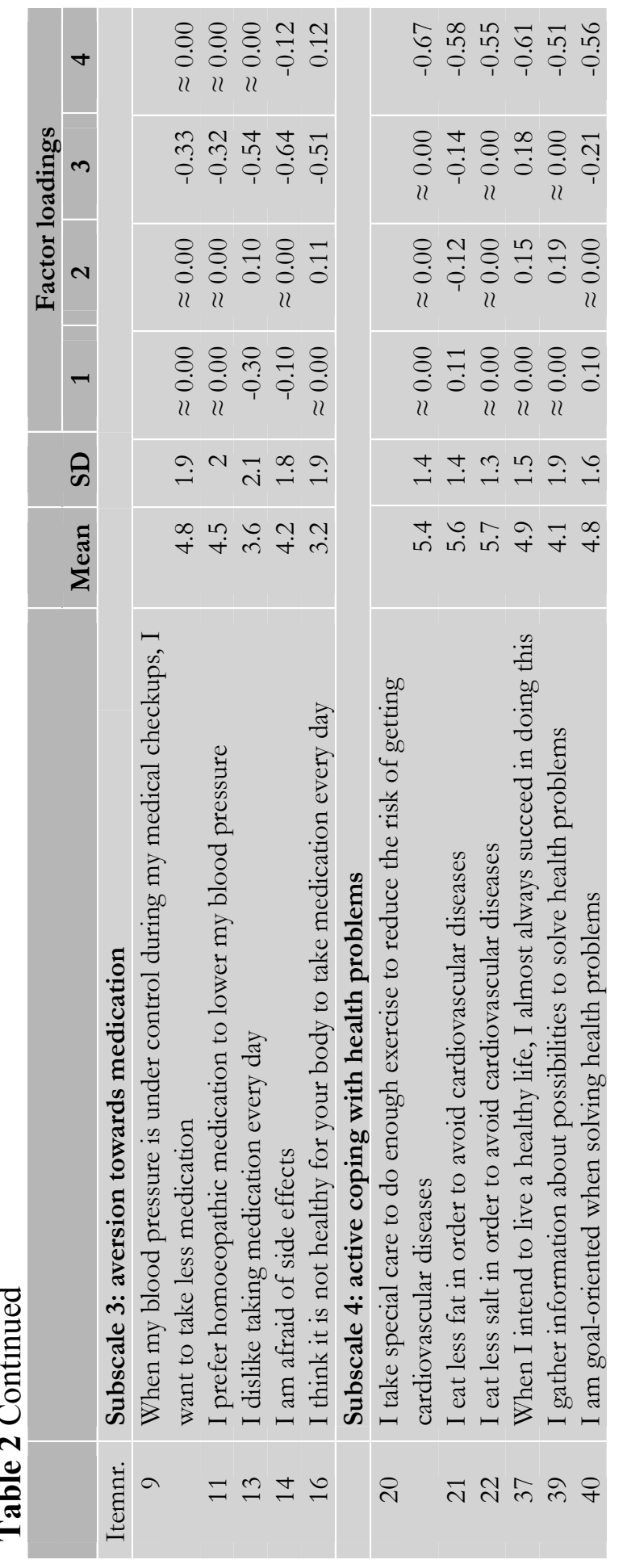


Convergent validity of the questionnaire was assessed by evaluating the association between sum scores on the identified subscales and, 1) the BMQ, 2) pharmacy refill records and 3) electronic monitoring. 140 patients completed the BMQ, refill adherence data were available for 229 patients, and electronic monitoring data were available for 238 patients.

Convergent validity was supported by statistically significant associations that were found between the sum score on subscale I (positive attitude towards health care and medication) and the BMQ Belief Screen, and between the sum score on subscale II (lack of discipline) and the BMQ Regimen and Recall Screen score, respectively (Table 3). Furthermore, a statistically significant association between the sum score on subscale II (lack of discipline) and electronic monitoring was demonstrated. No statistically significant associations were found between sum scores on the MUAH-subscales and the level of adherence as measured by refill adherence (Table 4).

Table 3 Logistic regression coefficients $\S$ corresponding with a one-unit increase in sum scores on the factors of the MUAH-questionnaire. Analysis based on 140 patients

\begin{tabular}{|c|c|c|c|}
\hline & $\begin{array}{l}\text { BMQ Regimen } \\
\text { Screen }\end{array}$ & $\begin{array}{l}\text { BMQ Belief } \\
\text { Screen }\end{array}$ & $\begin{array}{l}\text { BMQ Recall } \\
\text { Screen }\end{array}$ \\
\hline $\begin{array}{l}\text { Factor I: positive attitude towards } \\
\text { health care and medication }\end{array}$ & 0.03 & $-0.11 *$ & -0.05 \\
\hline Factor II: lack of discipline & $0.12^{*}$ & -0.02 & $0.11^{*}$ \\
\hline $\begin{array}{l}\text { Factor III: aversion towards } \\
\text { medication }\end{array}$ & -0.03 & 0.01 & -0.01 \\
\hline $\begin{array}{l}\text { Factor IV: active coping with } \\
\text { health problems }\end{array}$ & -0.07 & 0.01 & 0.03 \\
\hline \multicolumn{4}{|c|}{$\begin{array}{l}{ }^{*} \mathrm{p}<0.05 \\
\mathbb{S} \text { Interpretation: for example the association between a ten-unit increase in factor II (lack } \\
\text { of discipline) and being a poor adherer according to the BMQ Regimen Screen can be } \\
\text { expressed as an odds ratio }(\mathrm{OR})=3.32\left(\mathrm{e}^{0.12^{*} 10}\right) \text {. The association between a ten-uni } \\
\text { increase in factor I (positive attitude) and being a poor adherer according to the BMQ } \\
\text { Belief Screen can be expressed as an } \mathrm{OR}=0.33\left(\mathrm{e}^{-0.11^{*} * 10}\right)\end{array}$} \\
\hline
\end{tabular}


Table 4 Linear regression coefficients corresponding with a one-unit increase in sum scores on the factors of the MUAH-questionnaire. Analysis based on 229 and 238 patients for refill adherence and electronic monitoring, respectively.

\begin{tabular}{l|c|c|} 
& Refill adherence & $\begin{array}{c}\text { Electronic } \\
\text { monitoring }\end{array}$ \\
\hline $\begin{array}{l}\text { Factor I: positive attitude towards health } \\
\text { care and medication }\end{array}$ & 0.14 & 0.01 \\
\hline $\begin{array}{l}\text { Factor II: lack of discipline } \\
\text { Factor III: aversion towards medication }\end{array}$ & -0.21 & $-0.34^{*}$ \\
\hline $\begin{array}{l}\text { Factor IV: active coping with health } \\
\text { problems } \\
* \text { p }<0.05\end{array}$ & -0.43 & 0.10 \\
\hline
\end{tabular}

As shown in Table 5, the three BMQ Screens yielded very different results with respect to the percentage of patients scoring positively on being non-adherent. Using pharmacy refill data, 19\% of the patients could be identified as poor adherer, whereas this percentage was $7 \%$ according to electronic monitoring (adherence $<85 \%$ ).

Table 5 BMQ and adherence measures $(n=140)$

\begin{tabular}{|l|r|}
\hline BMQ Screens & $\begin{array}{c}\text { \% of patients with a } \\
\text { positive score }\end{array}$ \\
\hline $\begin{array}{l}\text { Regimen Screen } \\
\text { (Problems in taking medication in the past week) }\end{array}$ & 6.0 \\
\hline $\begin{array}{l}\text { Belief Screen } \\
\text { (Doubts how well drug(s) work or believes drug is bothersome) }\end{array}$ & 67.4 \\
\hline $\begin{array}{l}\text { Recall Screen } \\
\text { (Potential difficulties remembering or multiple dose regimen) }\end{array}$ & 21.8 \\
\hline \begin{tabular}{l} 
At least one of the three Screens \\
\hline
\end{tabular} & 79.0 \\
\hline
\end{tabular}

\section{Discussion}

The purpose of this study was to develop a valid and reliable questionnaire for the assessment of adherence problems that hamper intake of medication in patients who are prescribed antihypertensive drugs. Adherence with anti-hypertensive medication is often disappointingly low. Efforts to improve adherence with antihypertensive medication might improve not only the results of treatment but also the efficiency of health care by reducing unnecessary dose alterations or additions of drugs. ${ }^{6,28-30}$

Haynes et al. have identified over 200 factors that have been studied in relationship to adherence. ${ }^{31}$ 
Patient characteristics like age, sex, education, occupation, income, marital status, race, religion and ethnic background have not been definitely associated with adherence. ${ }^{3}$ On the other hand, illness-relevant cognitions, perceptions of disease factors and beliefs about treatment have stronger relationships with adherence ${ }^{3}$. Therefore, we aimed at developing a patient-oriented questionnaire that addressed cognitive and behavioural factors. The identification of factors such as "positive attitude towards health care and medication", "lack of discipline", "aversion towards medication" and "active coping behaviour with health problems", indicate that in this respect the MUAH-questionnaire serves the purpose. The MUAHquestionnaire provides valuable information about the reasons for poor adherence and serves as a tool to tailor specific interventions to improve adherence. The internal consistency of the scales, expressed by Cronbach's alpha coefficient, and test-retest reliability of the questionnaire were both excellent.

Convergent validity is partly supported. A strong association was found between the sum score on subscale II of the MUAH-questionnaire (lack of discipline) and adherence as measured by electronic monitoring. Scoring higher on lack of discipline was significantly associated with lower monitoring adherence $(b=-0.34)$. A higher sum score on subscale II was also significantly associated with a higher probability of scoring as a poor adherer on the BMQ Regimen screen $(b=0.12)$ and on the BMQ Recall Screen $(b=0.11)$. Furthermore, patients with a higher score on subscale I (positive attitude towards health care and medication) had a significantly lower probability of scoring as a poor adherer on the BMQ Belief screen $(b=-0.11)$. No associations were demonstrated between sum scores on the MUAHquestionnaire and refill adherence.

Convergent validity concerns the extent to which variables that assess the same construct (in this case adherence) are interrelated. We selected another self-report questionnaire (BMQ) because it has been validated in patients with hypertension, refill adherence because pharmacy data are increasingly used as a source of adherence information ${ }^{32}$ and monitoring adherence, because electronic monitoring is considered to be superior to any other available methods. ${ }^{13-15,17}$ However, all methods have limitations that may jeopardize their validity. A potential problem with electronic monitoring is that because of medical ethical considerations patients must be informed that their medication taking behaviour is being monitored. Recent studies suggest that monitoring might improve adherence, because the patient is aware that dosing patterns are being recorded. $16,33,34$

The fact that in the present study only $7 \%$ of patients were identified as poor complier, whereas according to refill adherence $19 \%$ of the patients are poor compliers, supports the hypothesis that monitoring itself increases adherence and raises questions about the validity of electronic monitoring under our trial conditions. 
Pharmacy refill records provide objective estimates of adherence measured over extended periods of time. The disadvantage of refill adherence is that there is no guarantee that medication, which is obtained by the patient, is actually taken. ${ }^{32}$ Another problem might be that patient not always goes to the same pharmacy. However, this issue has been investigated in the Utrecht-population and it turned out that "shopping" at other pharmacies and/or Internet was negligible. However, it remains difficult to measure adherence accurately because only a small fraction of the poor compliers will be identified using pharmacy records. These observations are in agreement with other studies. Choo et al., ${ }^{35}$ found a low agreement between electronically monitored adherence measured during a threemonth period and refill adherence in the twelve months before electronic monitoring. Furthermore, in a study of Cook at al., ${ }^{36}$ in which refill adherence was compared to various self-report tools, it was concluded that the selection of a useful adherence measure is difficult because of the weak concordance found among validated measures of adherence.

An explanation for the finding that the score on "lack of discipline" of the MUAH-questionnaire is associated with a higher probability of scoring positively on the BMQ Regimen and Recall Screen and with lower monitoring adherence could be that both questionnaires measure the tendency of patients to admit that they forget and miss doses. This tendency is associated with a decrease in electronic monitoring adherence. These patients may be candidates for a training specifically aimed at improving discipline.

The finding that lower sum scores on "positive attitude" and "active coping", and higher scores on "aversion" do not reflect itself in neither lower refill nor monitoring adherence could be due to lack of validity of refill records and electronic monitoring for measurement of actual adherence. For example, it is possible that patients despite scoring highly on aversion towards medication increase adherence because of the awareness of being monitored.

Finally, the association between the BMQ and MUAH-questionnaire is not surprising: both questionnaires are self-report tools that measure adherence related constructs. The fact that the BMQ score is associated with only two out of four factors of the MUAH-questionnaire might be explained by the fact that the MUAH covers a broader range of possible adherence barriers.

In this study certain limitations must be considered. The percentage of poor compliers identified using the BMQ was much higher than determined by refill adherence $(79 \%$ versus $19 \%)$. The most likely explanation is that $50 \%$ of the patients had doubts about the effectiveness of their medication, which results in a positive score on the Belief Screen of the BMQ. This high percentage may result from the inclusion criteria in the Maastricht region: at the time of inclusion, blood pressure had to be too high despite the use of antihypertensive medication. Leaving out the item "doubts on the effectiveness of their medication" resulted in a lower percentage of patients with a positive score on the BMQ, but the sum 
scores on the subscales "positive attitude" and "lack of discipline" of the MUAHquestionnaire were still significantly associated with BMQ scores.

The percentage of patients that could be identified as poor complier with electronic monitoring was low. Because of practical considerations, the duration of monitoring in this study was only two months.

It is possible that this percentage would be higher if the monitoring period was longer. Studies with a monitoring period exceeding 6 months showed a clear-cut decrease in adherence. ${ }^{34,37}$ Other studies on the validation of the MUAHquestionnaire with longer monitoring periods are needed.

Finally, there is much debate whether monitoring of adherence requires packaging of all prescribed drugs in a monitor or that it suffices to package only one of the prescribed drugs in a monitor. In our study, these two methods did not result in a difference in measured compliance.

\section{Conclusion}

The MUAH-questionnaire measures adherence-related dimensions such as attitude towards health care, lack of discipline, aversion towards medication and active coping with health problems. However, it is not clear to what extent the MUAHquestionnaire measures actual adherence, because other adherence measures, which were used to assess convergent validity, may not have been valid. Our findings indicate that the link between actual adherence and reported barriers that impede adherence is more complex than is generally believed.

\section{Practice implications}

Theoretically, in the clinical setting, the MUAH-questionnaire could be used in patients who are suspected to be poor adherers based on, for example, lack of response to treatment. The MUAH-questionnaire was designed to give a physician extended information as to why patients experience adherence problems. However the fact that the data on convergent validity are difficult to interpret, points to the need for validation of the MUAH-questionnaire in other studies. 


\section{References}

1. Burt VL, Cutler JA, Higgins M, Horan MJ, Labarthe D, Whelton P, Brown C, and Roccella EJ. Trends in the prevalence, awareness, treatment, and control of hypertension in the adult US population. Data from the health examination surveys, 1960 to 1991. Hypertension, 1995. 26(1): p. 60-9.

2. Joint National Committee on prevention, evaluation, and treatment of high blood pressure. The sixth report of the Joint National Committee on prevention, detection, evaluation, and treatment of high blood pressure. Arch Intern Med, 1997. 157(21): p. 2413-46.

3. Sabate E. Adherence to long-term therapies: evidence for action. WHO, 2003(Geneva).

4. O'Rorke JE and Richardson WS. Evidence based management of hypertension: What to do when blood pressure is difficult to control. BMJ, 2001. 322(7296): p. 1229-32.

5. Urquhart J. Partial compliance in cardiovascular disease: risk implications. Br J Clin Pract Suppl, 1994. 73: p. 2-12.

6. Mar J and Rodriguez-Artalejo F. Which is more important for the efficiency of hypertension treatment: hypertension stage, type of drug or therapeutic compliance? J Hypertens, 2001. 19(1): p. 149-55.

7. Nuesch R, Schroeder K, Dieterle T, Martina B, and Battegay E. Relation between insufficient response to antihypertensive treatment and poor compliance with treatment: a prospective casecontrol study. BMJ, 2001. 323(7305): p. 142-6.

8. Wright EC. Non-compliance--or how many aunts has Matilda? Lancet, 1993. 342(8876): p. 90913.

9. Benson J and Britten N. Patients' decisions about whether or not to take antihypertensive drugs: qualitative study. BMJ, 2002. 325(7369): p. 873

10. Oliveria SA, Lapuerta P, McCarthy BD, L'Italien GJ, Berlowitz DR, and Asch SM. Physicianrelated barriers to the effective management of uncontrolled hypertension. Arch Intern Med, 2002. 162(4): p. 413-20.

11. Urquhart J. Role of patient compliance in clinical pharmacokinetics. A review of recent research. Clin Pharmacokinet, 1994. 27(3): p. 202-15.

12. Urquhart J. Patient compliance with prescribed drug regimens: overview of the past 30 years of research. Clinical measurement in Drug Evaluation, 1995: p. 213-227.

13. Cramer JA. Microelectronic systems for monitoring and enhancing patient compliance with medication regimens. Drugs, 1995. 49(3): p. 321-7.

14. Urquhart J. The electronic medication event monitor. Lessons for pharmacotherapy. Clin Pharmacokinet, 1997. 32(5): p. 345-56.

15. Bertholet N, Favrat B, Fallab-Stubi CL, Brunner HR, and Burnier M. Why Objective Monitoring of Compliance is Important in the Management of Hypertension. J Clin Hypertens (Greenwich), 2000. 2(4): p. 258-262.

16. Burnier M, Schneider MP, Chiolero A, Stubi CL, and Brunner HR. Electronic compliance monitoring in resistant hypertension: the basis for rational therapeutic decisions. J Hypertens, 2001. 19(2): p. 335-41.

17. Mallion JM, Dutrey-Dupagne C, Vaur L, Genes N, Renault M, Elkik F, Baguet P, and Boutelant S. Benefits of electronic pillboxes in evaluating treatment compliance of patients with mild to moderate hypertension. J Hypertens, 1996. 14(1): p. 137-44.

18. Haynes RB, McKibbon KA, and Kanani R. Systematic review of randomised trials of interventions to assist patients to follow prescriptions for medications. Lancet, 1996. 348(9024): p. 383-6.

19. Davidson MH. Strategies to improve Adult Treatment Panel III guideline adherence and patient compliance. Am J Cardiol, 2002. 89(5A): p. 8C-20C; discussion 20C-22C.

20. Bond WS and Hussar DA. Detection methods and strategies for improving medication compliance. Am J Hosp Pharm, 1991. 48(9): p. 1978-88. 
21. McDonald HP, Garg AX, and Haynes RB. Interventions to enhance patient adherence to medication prescriptions: scientific review. JAMA, 2002. 288(22): p. 2868-79.

22. Craig HM. Accuracy of indirect measures of medication compliance in hypertension. Res Nurs Health, 1985. 8: p. 61-66.

23. Inui TS, Carter WB, and Pecoraro RE. Screening for non-compliance among patients with hypertension: Is self-report the best available measure? Med Care, 1981. 19: p. 1061-1064.

24. Haynes RB, Taylor DW, and Sackett DL. Can simple clinical measurements detect patient compliance? Hypertension, 1980. 2: p. 757-764.

25. Svarstad B, Chewning BA, Sleath BL, and Claesson C. The brief medication questionnaire: A tool for screening adherence and barriers to adherence. Patient Education and Counseling, 1999. 37: p. 113-124.

26. Morisky DE, Green LW, and Levine DM. Concurrent and predictive ability of a self-reported measure of medication adherence. Med Care, 1986. 24: p. 67-73.

27. Geijer RMM, Burgers JS, Van der Laan JR, Wiersma T, Rosmalen CFH, and Thomas S. NHGStandaard Hypertensie, tweede herziening, in NHG-standaarden voor de huisarts, deel 1. 1999, Elsevier/Bunge: Maarssen. p. 187-205.

28. Urquhart J. Some economic consequences of noncompliance. Curr Hypertens Rep, 2001. 3(6): p. 473-80.

29. Claxton AJ, Cramer J, and Pierce C. A systematic review of the associations between dose regimens and medication compliance. Clin Ther, 2001. 23(8): p. 1296-310.

30. Feely J. The therapeutic gap--compliance with medication and guidelines. Atherosclerosis, 1999. 147 Suppl 1: p. S31-7.

31. Haynes RB, Taylor DW, and Sackett DL. Compliance in Health Care, ed. . 1997: John Hopkins University Press.

32. Steiner JF and Prochazka AV. The assessment of refill compliance using pharmacy records: methods, validity, and applications. J Clin Epidemiol, 1997. 50(1): p. 105-16.

33. Waeber B, Vetter W, Darioli R, Keller U, and Brunner HR. Improved blood pressure control by monitoring compliance with antihypertensive therapy. Int J Clin Pract, 1999. 53(1): p. 37-8.

34. Waeber B, Leonetti G, Kolloch R, and McInnes GT. Compliance with aspirin or placebo in the Hypertension Optimal Treatment (HOT) study. J Hypertens, 1999. 17(7): p. 1041-5.

35. Choo PW, Rand CS, Inui TS, Lee MT, Canning C, and Platt R. Derivation of adherence metrics from electronic dosing records. J Clin Epidemiol, 2001. 54(6): p. 619-26.

36. Cook CL, Wade WE, Martin BC, and Perri M. Concordance among three self-reported measures of medication adherence and pharmacy refill records. Journal of the American Pharmacists Association, 2005. 45(2).

37. Bovet P, Burnier M, Madeleine G, Waeber B, and Paccaud F. Monitoring one-year compliance to antihypertension medication in the Seychelles. Bull World Health Organ, 2002. 80(1): p. 33-9. 
114 Determinants of poor adherence in hypertensive patients 


\section{Chapter 8}

All that glisters is not gold: a comparison of electronic monitoring versus filled prescriptions - an observational study

Gwenn E.C. Wetzels, Patricia J. Nelemans, Jan S.A.G. Schouten, Boris L.G. van Wijk and Martin H. Prins

BMC Health Services Research 2006, 6:8 


\section{Abstract}

\section{Background}

Poor compliance with antihypertensive medication is assumed to be an important reason for unsatisfactory control of blood pressure. Poor compliance is difficult to detect. Each method of measuring compliance has its own strengths and weaknesses.

The aim of the present study was to compare patient compliance with antihypertensive drugs as measured by two methods, electronic monitoring versus refill compliance.

\section{Methods}

161 patients with a diagnosis of hypertension for at least a year prior to inclusion, and inadequate blood pressure control (systolic blood pressure $\geq 160 \mathrm{mmHg}$ and/or diastolic blood pressure $\geq 95 \mathrm{mmHg}$ ) despite the use of antihypertensive drugs, were included. Patients' pharmacy records from 12 months prior to inclusion were obtained. Refill compliance was calculated as the number of days for which the pills were prescribed divided by the total number of days in this period. After inclusion compliance was measured with an electronic monitor that records time and date of each opening of the pillbox. Agreement between both compliance measures was calculated using Spearman's correlation coefficient and Cohen's kappa coefficient.

\section{Results}

There was very little agreement between the two measures. Whereas refill compliance showed a large range of values, compliance as measured by electronic monitoring was high in almost all patients with estimates between $90 \%$ and $100 \%$. Cohen's kappa coefficient was 0.005 .

\section{Conclusion}

While electronic monitoring is often considered to be the gold standard for compliance measurements, our results suggest that a short-term electronic monitoring period with the patient being aware of electronic monitoring is probably insufficient to obtain valid compliance data. We conclude that there is a strong need for more studies that explore the effect of electronic monitoring on patient's compliance. 


\section{Background}

Lack of compliance with antihypertensive drug regimens is assumed to be a major cause of failure to achieve adequate blood pressure control. ${ }^{1-3}$ It is estimated that that at least $50 \%$ of the patients in a general hypertensive population do not take their antihypertensive medication as prescribed. ${ }^{4}$ Improving compliance with prescribed drug regimens therefore remains a major challenge to the physician and it is extremely important to have accurate measures of compliance.

There is a continuing debate with regard to measurement of compliance, which is notoriously difficult. An ideal method to measure compliance should be valid and reliable. It should prove ingestion of the medication and give information about the timing of ingestion. Also the patient should not be aware of the compliance measurements and not be able to consciously influence the results. 5,6

At present, electronic monitoring is considered to be the new "gold standard".7 Electronic monitors are normal pill-bottles with a special cap that contains a microchip that registers time and date of every time that the bottle is opened. This method is more sensitive for detecting inadequate compliance than other methods, such as self-reports. However, its costs and other practical issues limit the use of electronic monitors in routine clinical practice.

Another method to assess compliance is the use of pharmacy records. Pharmacy refill records provide objective, unobtrusive and inexpensive estimates of compliance. Refill records of computerized pharmacy records are used increasingly as a source of compliance information. ${ }^{8}$ Because refill compliance data only give information about whether or not the medication is obtained by the patient, it provides an upper bound for medication consumption. It allows identification of those patients that cannot be compliant simply because they do not obtain enough medication. ${ }^{8}$ It is therefore to be expected that the actual proportion of patients with poor compliance is higher. To evaluate the value of using pharmacy records to identify poor compliers, it would be useful to compare the use of pharmacy records to determine compliance with a more sensitive measurement tool, such as electronic monitoring. However, comparisons of refill compliance with other objective compliance measurement methods within the same population are scarce.

The aim of the present study was therefore to compare compliance with antihypertensive drugs assessed by both refill compliance and electronic monitoring, within a population of patients with mild hypertension and to evaluate the agreement between these two compliance measures. 


\section{Methods}

\section{Study population}

Patients were recruited from general practices in the South of the Netherlands. Patients were eligible if they met all following criteria: a) they had a diagnosis of hypertension, b) they had inadequate blood pressure control despite the use of antihypertensive medication and c) treatment escalation seemed appropriate. Treatment escalation was defined as increase in dosage, addition or change of antihypertensive drugs. Hypertension was, according to the national guideline of the Dutch College of General Practitioners (update 1999), ${ }^{9}$ defined as a systolic blood pressure $(\mathrm{SBP}) \geq 160 \mathrm{mmHg}$ and/or diastolic blood pressure (DBP) $\geq 95$ mmHg. All patients gave written informed consent. The Ethical Committee of the Maastricht University approved of the study.

\section{Electronic monitoring}

Compliance with antihypertensive medication was measured by electronic monitoring during two months after inclusion. Medication was packaged in electronic pillboxes (Medication Event Monitoring System (MEMS), Aardex corp. Geneva). A microprocessor in the bottle cap registered the date and time of each opening. Each monitor was coded with an identification number that identified the study participant. At the end of the study, all data collected by the microprocessor were analysed using PowerView version 2 software (Aardex corp. Geneva). Each opening was considered as being a single dose intake. Participants were informed that the MEMS monitor recorded the date and time of each opening of the medication bottle. They were instructed to keep their medication in the monitoring vial, to use no other source of anti-hypertensive medication and to remove only one dose at a time. Patients received a MEMS-monitor for each antihypertensive drug they used. Monitoring compliance was expressed as taking compliance $=$ (total number of doses taken) / (total number of monitored days) x $100 \%$. Patients were considered to be compliant if taking compliance was $\geq 85 \%$ on each antihypertensive drug they used.

\section{Filled prescriptions}

Patients' records from computerized pharmacy systems were obtained. These records included the names of the prescribed antihypertensive drug(s), dosage, the quantity dispensed at each pharmacy fill and the dates of prescription fills. Refill compliance was determined from these pharmacy records during twelve months before the start of electronic monitoring.

Refill compliance during the interval between two prescription fills was calculated as the number of days for which the pills were prescribed divided by the total number of days in this interval. Only those medications that were filled at least three times during the twelve months were taken into account, so refill compliance could be calculated for at least two intervals. For each antihypertensive drug 
average refill compliance was computed by summing the refill compliance in each interval and dividing the sum by the number of intervals. Patients were considered to be compliant if average refill compliance was $\geq 85 \%$ on each antihypertensive drug they used.

\section{Statistical analysis}

First, monitoring compliance (taking compliance) was plotted against refill compliance in a scatter diagram. Agreement between the compliance measures on a continuous scale was calculated using Spearman's correlation coefficient. Second, patients were classified into two categories: adequate compliers versus poor compliers. For both refill compliance and taking compliance patients were considered to be poor complier if they took less than $85 \%$ of any prescribed antihypertensive drug. Agreement between dichotomised refill and taking compliance was assessed using overall proportion of agreement, positive agreement, negative agreement and Cohen's kappa coefficient, which corrects for chance agreement. ${ }^{10}$ In additional analyses, Cohen's kappa coefficient was determined using different cut-off points for compliance, namely 80\%, $90 \%$ and $95 \%$.

\section{Results}

Both monitoring and refill compliance data were available for 146 of 161 patients who participated in the study. Two patients had to be excluded from the analysis since they did not follow the instructions on the use of the electronic monitor. Furthermore, the data from two monitors could not be retrieved due to a technical error. Finally, from eleven patients' pharmacy records were not available mainly because the patients moved to other regions. The baseline characteristics of the patients included in the analysis are shown in Table 1.

\section{Compliance with antihypertensive medication}

Mean taking compliance as measured by electronic monitoring was $96.8 \pm 12.1 \%$. Five patients $(3.4 \%)$ were considered as poor compliers, because taking compliance of at least one of their prescribed medications was below 85\%. Average compliance in the group of poor compliers was $59.8 \pm 23.9 \%(\mathrm{p}<0.001)$.

Mean refill compliance was $108.9 \pm 28.3 \%$, indicating stockpiling of medication by patients. Twenty-seven patients $(18.4 \%)$ were identified as poor compliers, because refill compliance of at least one of their medications was below $85 \%$. Average refill compliance in these patients was $86.2 \pm 18.6 \%$ compared to $114.2 \pm 26 \%$ in patients with adequate compliance $(\mathrm{p}<0.001)$. From those 27 patients considered as poor compliers, 19 were prescribed more than one antihypertensive drug. In only four of these patients compliance was not satisfactory $(<85 \%)$ for each prescribed antihypertensive drug. 
Table 1 Demographic and clinical characteristics of included patients $(n=146)$

\section{Demographic characteristics ${ }^{\#}(\%)$}

\begin{tabular}{|c|c|c|}
\hline Age & & \\
\hline$\leq 55$ & 21 & \\
\hline $56-65$ & 44 & \\
\hline $66-75$ & 26 & \\
\hline$\geq 75$ & 8 & \\
\hline Gender & & \\
\hline Male & 48 & \\
\hline Female & 52 & \\
\hline Education & & \\
\hline Low & 22 & \\
\hline Middle & 32 & \\
\hline High & 33 & \\
\hline Very high & 11 & \\
\hline Employed & & \\
\hline Yes & 31 & \\
\hline No & 68 & \\
\hline Clinical characteristics & Mean & $(\mathrm{SD})$ \\
\hline Years with hypertension & 8.5 & $(8.8)$ \\
\hline SBP at inclusion & 168.4 & $(16.3)$ \\
\hline DBP at inclusion & 95.4 & $(9.8)$ \\
\hline Heart rate & 73.2 & $(12.2)$ \\
\hline BMI $\left(\mathrm{kg} / \mathrm{m}^{2}\right)$ & 28.6 & $(5.6)$ \\
\hline Nr. of prescribed antihyp & & \\
\hline 1 & 45 & \\
\hline 2 & 41 & \\
\hline 3 & 11 & \\
\hline$>3$ & 2 & \\
\hline Medication regimen (\%) & & \\
\hline Once daily & 84 & \\
\hline Twice daily & 13 & \\
\hline$>$ twice daily & 3 & \\
\hline
\end{tabular}

\section{Agreement between electronic monitoring and filled prescription}

Figure 1 presents a scatter plot for all patients of refill compliance (on the $\mathrm{X}$-axis) versus taking compliance (on the $\mathrm{Y}$-axis). There was very little agreement between the two measures and whereas refill compliance showed a large range of values, compliance as measured by electronic monitoring was high in almost all patients with estimates between $90 \%$ and 100\%. The Spearman's correlation coefficient was -0.02 (95\% CI: [-0.18 - 0.15]). After classification of patients into adequate compliers versus poor compliers, the agreement between refill compliance and taking compliance was also poor (Table 2). 
Figure 1 Comparison of refill compliance versus electronic monitoring (taking compliance)

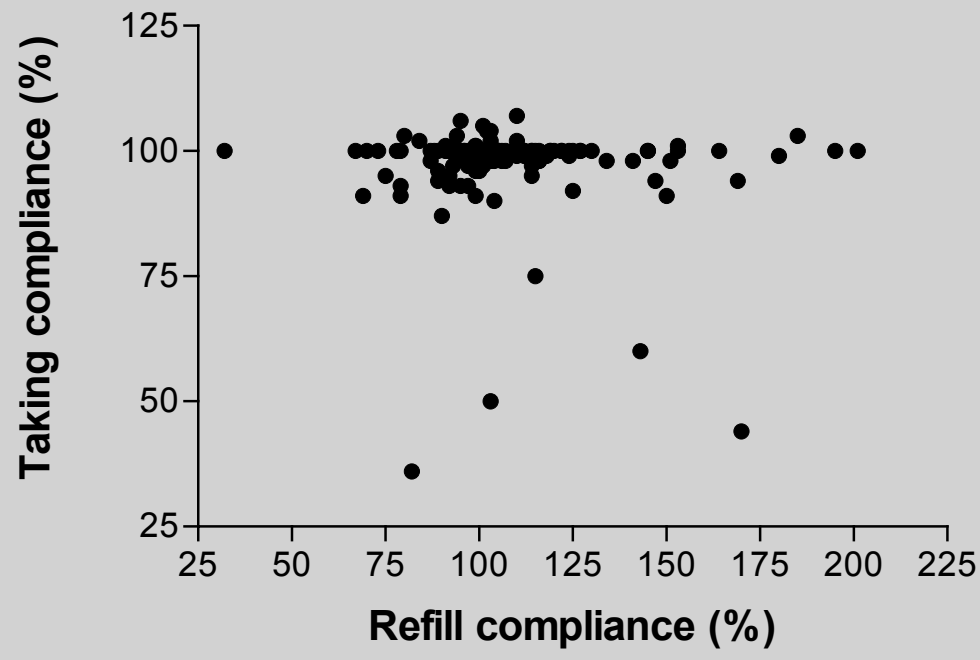

Table 2 Refill compliance versus electronic monitoring (taking compliance)

\begin{tabular}{|l|l|c|c|c|}
\hline & \multicolumn{4}{|c|}{ Taking compliance } \\
\hline & $\begin{array}{l}\text { Adequate } \\
\text { compliers }\end{array}$ & $\begin{array}{c}\text { Pdequate } \\
\text { compliers }\end{array}$ & $\begin{array}{c}\text { Poor } \\
\text { compliers }\end{array}$ & Total \\
\hline \multirow{2}{*}{$\begin{array}{l}\text { Refill } \\
\text { compliance }\end{array}$} & Poor compliers & $\mathbf{1 1 5}$ & $\mathbf{4}$ & 119 \\
\hline & Total & $\mathbf{2 6}$ & $\mathbf{1}$ & 27 \\
\hline & & 141 & 5 & 146 \\
\hline
\end{tabular}

The overall proportion of agreement was 0.8. The proportion of negative agreement, which is the proportion of patients that are identified as complier by both methods, was 0.89 . However, the proportion of positive agreement, defined as the proportion of patients that were identified as poor complier by both methods, was only 0.06. Cohen's kappa coefficient, which corrects for chance, was 0.005 indicating a very poor agreement between the two methods to determine compliance. Also when different cut-off points for compliance were used, the agreement between the two methods was poor. Using cut-off points of $80 \%, 90 \%$ and 95\%, Cohen's kappa was $-0.056,0.020$ and 0.009 respectively (Table 3). 
Table 3 Percentage of poor compliers and Cohen's kappa coefficients according to different cut-off points

\begin{tabular}{|l|l|r|r|r|r|}
\hline Cut-off points & & $\mathbf{8 0} \%$ & $\mathbf{8 5 \%}$ & $\mathbf{9 0} \%$ & $\mathbf{9 5 \%}$ \\
\hline \% Poor compliance & Taking compliance & 3.4 & 3.4 & 4.8 & 14.4 \\
\cline { 2 - 6 } & Refill compliance & 11.6 & 18.5 & 23.3 & 32.2 \\
\hline Cohen's kappa coefficient & & -0.056 & 0.005 & 0.020 & 0.009 \\
\hline
\end{tabular}

\section{Discussion}

This study demonstrates that there is a poor agreement between compliance measured by electronic monitoring and compliance determined by filled prescription data within the same population of hypertensive patients. A remarkable finding is that many patients, who according to refill compliance data are not compliant with antihypertensive medication, are not identified as such by electronic monitoring which is considered to be the "gold standard". With electronic monitoring, less than four percent of the patients could be identified as poor complier. Using refill data, the percentage of patients with inadequate compliance was 18.5 percent. Determination of compliance based on filled prescriptions was expected to be a rather insensitive method to measure compliance. Only a part of the poor compliers can be identified using this method, because obtaining the medication is no guarantee that the patient actually takes them. Therefore refill compliance is expected to identify the minimum proportion of poor compliers within a population. Despite this fact, the use of refill data identified a higher percentage of patients with inadequate compliance than electronic monitoring. Several explanations may account for these results.

First, it may be argued that the proportion of poor compliers identified with electronic monitoring would be much higher when a more stringent measure to define compliance, such as correct dosing, was used. Correct dosing reflects the percentage of days on which the medication is taken as prescribed and is therefore much more sensitive for deviations from the prescribed regimen than taking compliance data. However, when this measure was applied to our population only six instead of five patients were identified as poor complier.

Second, it is possible that electronic monitoring in itself improves compliance because patients are aware that their medication behaviour is being monitored. This awareness may have encouraged them to be more compliant than they used to be before the start of electronic monitoring. The hypothesis that electronic monitoring in itself improves compliance, is in agreement with the findings in other studies, which also point in this direction. First, most recent studies using electronic monitoring very often report relatively low proportions of patients with poor compliance ${ }^{11-18}$ in contrast with the general assumption that 40 to $50 \%$ of the patients do not take their antihypertensive medication as prescribed. Second, 
Burnier et al. ${ }^{14}$ demonstrated that a two-month period of monitoring of compliance was associated with a significant improvement of blood pressure, most likely resulting from increased compliance with antihypertensive drug therapy. Also Waeber et al., ${ }^{12}$ found that three-month period of monitoring was associated with a significant improved control of blood pressure.

It can be concluded that the findings in our study stress the importance of the conditions that need to be met before electronic monitoring can be used to obtain accurate compliance data. First, it seems extremely important to conceal the purpose of the monitor from the patient to obtain valid compliance data, but this is really hard to accomplish in practice. Kruse and Weber ${ }^{19}$ found a compliance of $91 \%$ in informed individuals compared to $78 \%$ in a group who did not understand the value of the electronic monitor. Second, studies with a monitoring period of at least 6 months demonstrate a clear-cut decrease in compliance over time suggesting that the effect of awareness of being monitored wanes over time ${ }^{20-22}$. From these studies it can be concluded that it is important to monitor compliance for at least six months in order to obtain valid measures of compliance. ${ }^{23}$

Some methodological issues deserve further attention. First, the time periods wherein refill and taking compliance were measured, differed. The short duration of electronic monitoring (two months) and low refilling frequency during this time precluded stable estimation of refill compliance during the monitoring period itself. In this respect the present study is comparable to the study performed by Choo et al., ${ }^{24}$ which found moderate agreement $(\mathrm{r}=0.32)$ between compliance measured during a three-month monitoring period and refill compliance in the twelve months before electronic monitoring. The additional value of the present study is that it gives information about the proportion of patients with inadequate compliance instead of mean values of compliance. Whereas mean values give the impression that refill compliance is higher than monitoring compliance, proportions indicate that it is the other way around: in comparison with electronic monitoring, refill compliance measurements trace more poor compliers.

Second, in the primary analysis a cut-off point for compliance of $85 \%$ was used. It is accepted that patients are considered adherent with the prescribed medication regimen when they take $80-90 \%$ of their medicines. ${ }^{25-27}$ However, historically used cut-off points are in many cases meaningless as some drugs are much more "forgiving" than others in term of missed dosing and the timing of ingestion. ${ }^{28}$ The answer to the question "how much compliance is enough" requires knowledge of the pharmacokinetic and pharmacodynamic properties, which vary between antihypertensive drugs and also vary between individuals.

At this stage we do not really know what level of compliance is necessary for individual antihypertensive medications. To undermine this problem Cohen's kappa was determined for different cut-off points. The agreement between both methods was poor, irrespective of the used cut-off point. 


\section{Conclusions}

To manage to problem of hypertension there is a need for accurate methods to measure compliance with medication. Unrecognised compliance problems may result in uncontrolled hypertension, unnecessary medication-switches and even hospitalisation. It can be concluded that a short-term electronic monitoring period with the patient being aware of electronic monitoring, is probably insufficient to obtain valid compliance data. Electronic monitoring may however be a very useful tool to improve compliance by giving patients insight into their own dosing history. We conclude that there is a strong need for more studies that explore the effect of electronic monitoring on patient's compliance. 


\section{References}

1. Mar J and Rodriguez-Artalejo F. Which is more important for the efficiency of hypertension treatment: hypertension stage, type of drug or therapeutic compliance? J Hypertens, 2001. 19(1): p. $149-55$.

2. O'Rorke JE and Richardson WS. Evidence based management of hypertension: What to do when blood pressure is difficult to control. BMJ, 2001. 322(7296): p. 1229-32.

3. Urquhart J. Partial compliance in cardiovascular disease: risk implications. Br J Clin Pract Suppl, 1994. 73: p. 2-12.

4. WHO. Adherence to long-term therapies: evidence for action. WHO, 2003(Geneva).

5. De Klerk E. Measurement of patient compliance on drug therapy: an overview. Advances in behavioral medicine assesment, ed. A. Vingerhoets. 2001: Harwood academic Publishers.

6. Rudd P. In search of the gold standard for compliance measurement. Arch Intern Med, 1979. 139(6): p. 627-629.

7. Cramer JA. Microelectronic systems for monitoring and enhancing patient compliance with medication regimens. Drugs, 1995. 49(3): p. 321-7.

8. Steiner JF and Prochazka AV. The assessment of refill compliance using pharmacy records: methods, validity, and applications. J Clin Epidemiol, 1997. 50(1): p. 105-16.

9. Walma EP, Grundmeyer HGJM, Thomas S, Prins A, Hoogen JPHvd, and Laan JRvd. NHGstandaard Hypertensie. Huisarts Wet, 1999. 42: p. 67-84.

10. Kundel H and Polansky M. Measurement of observer agreement. Radiology, 2003. 228: p. 303-308.

11. Mallion JM, Dutrey-Dupagne C, Vaur L, Genes N, Renault M, Elkik F, Baguet P, and Boutelant S. Benefits of electronic pillboxes in evaluating treatment compliance of patients with mild to moderate hypertension. J Hypertens, 1996. 14(1): p. 137-44.

12. Waeber B, Vetter W, Darioli R, Keller U, and Brunner HR. Improved blood pressure control by monitoring compliance with antihypertensive therapy. Int J Clin Pract, 1999. 53(1): p. 37-8.

13. Weidler D, Wallin JD, Cook E, Dillard D, and Lewin A. Transdermal clonidine as an adjunct to enalapril: an evaluation of efficacy and patient compliance. J Clin Pharmacol, 1992. 32(5): p. 444-9.

14. Burnier M, Schneider MP, Chiolero A, Stubi CL, and Brunner HR. Electronic compliance monitoring in resistant hypertension: the basis for rational therapeutic decisions. J Hypertens, 2001. 19(2): p. 335-41.

15. Eisen SA, Miller DK, Woodward RS, Spitznagel E, and Przybeck TR. The effect of prescribed daily dose frequency on patient medication compliance. Arch Intern Med, 1990. 150(9): p. 1881-4.

16. Waeber B, Brunner HR, and Metry JM. Compliance with antihypertensive treatment: implications for practice. Blood Press, 1997. 6(6): p. 326-31.

17. Leenen FH, Wilson TW, Bolli P, Larochelle P, Myers M, Handa SP, Boileau G, and Tanner J. Patterns of compliance with once versus twice daily antihypertensive drug therapy in primary care: a randomized clinical trial using electronic monitoring. Can J Cardiol, 1997. 13(10): p. 914-20.

18. Nuesch R, Schroeder K, Dieterle T, Martina B, and Battegay E. Relation between insufficient response to antihypertensive treatment and poor compliance with treatment: a prospective casecontrol study. BMJ, 2001. 323(7305): p. 142-6.

19. Kruse W and Weber E. Dynamics of drug regimen compliance-its assessment by microprocessor-based monitoring. European Journal of Clinical Pharmacology, 1990. 38: p. 561-565.

20. Bovet P, Burnier M, Madeleine G, Waeber B, and Paccaud F. Monitoring one-year compliance to antihypertension medication in the Seychelles. Bull World Health Organ, 2002. 80(1): p. 33-9.

21. Kruse W, Rampmaier J, Ullrich G, and Weber E. Patterns of drug compliance with medications to be taken once and twice daily assessed by continuous electronic monitoring in primary care. Int J Clin Pharmacol Ther, 1994. 32(9): p. 452-7.

22. Waeber B, Leonetti G, Kolloch R, and McInnes GT. Compliance with aspirin or placebo in the Hypertension Optimal Treatment (HOT) study. J Hypertens, 1999. 17(7): p. 1041-5. 
23. Wetzels GEC, Nelemans P, Schouten JS, and Prins MH. Facts and fiction of poor compliance as a cause of inadequate blood pressure control: a systematic review. J Hypertens, 2004. 22(10): p. 1849-55.

24. Choo PW, Rand CS, Inui TS, Lee ML, Cain E, Cordeiro-Breault M, Canning C, and Platt R. Validation of patient reports, automated pharmacy records, and pill counts with electronic monitoring of adherence to antihypertensive therapy. Med Care, 1999. 37(9): p. 846-57.

25. Sackett DL, Haynes RB, Gibson ES, Taylor DW, Roberts RS, and Johnson AL. Patient compliance with antihypertensive regimens. Patient Couns Health Educ, 1978. 1(1): p. 18-21.

26. Krall RL. Interactions of compliance and patient safety, in Patient compliance in medical practice and clinical trials, J.A. Cramer and B. Spilker, Editors. 1991, Raven Press: New York. p. 19-25.

27. Luscher TF, Vetter H, Siegenthaler W, and Vetter W. Compliance in hypertension: facts and concepts. J Hypertens Suppl, 1985. 3(1): p. S3-9.

28. Urquhart J. Patient compliance with prescribed drug regimens: overview of the past 30 years of research. Clinical measurement in Drug Evaluation, 1995: p. 213-227. 


\section{Chapter 9}

General Discussion 
128 General discussion 


\section{General discussion}

In this thesis, a number of studies related to the measurement and improvement of patient compliance are reported. This chapter will discuss the main findings and specific methodological considerations, draw conclusions, describe the implications for clinical practice and give suggestions for further research.

\section{Main findings}

The objective of this thesis was to considerably improve the management of hypertension by identifying and minimizing patient non-compliance with antihypertensive treatment. To this end, we performed a program of observational, interventional and economical research. Studies were set in primary care because patients with hypertension usually present first at the general practice. Therefore, it is expected that adequate management of non-compliance in an early phase will result in the most effective control of blood pressure, the best prevention of cardiovascular complications and the largest reduction of health care costs.

An important finding following from this thesis was that the percentage of patients that could be identified as poor complier by electronic monitoring was low in comparison with the general assumption that the percentage of inadequate compliers is $40-50 \% .{ }^{1,2}$ There could be several explanations for this phenomenon, these include:

- First, it could be possible that the generally perceived occurrence of noncompliance is exaggerated in literature due to invalid measurement methods. The percentage of patients with inadequate compliance varies tremendously between studies and the often quoted estimate that only $40-50 \%$ of the patient are compliant with their prescribed regimen seems to be based on few reliable data. ${ }^{2-4}$

- Second, compliance in our population could be higher than on average in clinical practice due to selection bias. Patients were informed about the study and gave written consent to participate in the study. Theoretically this could lead to a selection of patients who have fewer problems with taking their medication as prescribed. Such a selection could explain the overall high percentage of compliance as measured with electronic monitoring

- Finally, electronic monitoring itself may improve compliance. The awareness of patients of being monitored may have encouraged them to be more compliant than they used to be before the start of electronic monitoring

The first explanation does not hold when electronic monitoring data are compared with refill data of the same patients. Refill compliance data indicated that about $20 \%$ of the patients in our study could be labelled as poor complier in comparison to about $4 \%$ according to the electronic monitor. 
Because refill compliance only provides us with an upper bound for medication use, it can be argued that the actual percentage of poor compliers is (much) higher. The occurrence of selection bias also does not seem to explain the low percentage of poor compliers in our study. Refill compliance from all participants in the intervention study was compared with that of forty patients who refused to participate in the study. In $13 \%$ of the patients who refused to participate compliance was poor, compared to $20 \%$ in the group of participants. This finding indicates that patients with compliance problems, as defined by refill compliance, were more inclined to participate, making selection bias towards patients with good compliance less likely.

Hence, the most probable explanation for the low percentage of inadequate compliance found in our study is that electronic monitoring has improved compliance under our trial conditions. This explanation is in contrast with the general assumption that electronic monitoring can be considered as the "gold standard" for compliance measurements. ${ }^{5}$ Our results are, however, in agreement with other studies that also point in the direction that using electronic monitors might improve compliance. More evidence for this assumption is discussed in the next section.

\section{Electronic monitoring: the "gold standard" to measure compliance or an intervention to improve compliance?}

Chapter 3 reports the results of a randomised controlled trial that compared electronic monitoring with usual care in patients who had too high blood pressure despite the use of antihypertensive drugs. In this trial, 258 patients with high blood pressure despite the use of antihypertensive medication were assigned to either (1) a usual care strategy, which involved changes in prescribed medication if necessary without taking a possible lack of compliance into account, or (2) an experimental strategy in which compliance with antihypertensive medication was electronically monitored for two months without medication changes. It was concluded that electronic monitoring in comparison to usual care results in similar blood pressure control, but leads to less drug changes and drug use. These results are likely to be achieved through improved compliance in the electronic monitoring group and therefore it was concluded that electronic monitoring itself improves compliance in our study population.

The notion that electronic monitoring itself improves compliance with medication is also supported by findings in the literature.

- Indirect evidence comes from studies that have used electronic monitoring to determine compliance. Many of these are reviewed in chapter 2 and it was concluded that mean compliance rates ranged between 75 and 95\% depending on the definitions used. 
These percentages are not in agreement with the general assumption that compliance is inadequate in about $40 \%$ to $50 \%$ of patients. ${ }^{2}$ An explanation might be improved compliance due to monitoring

- Another recent example comes from a study by Schroeder at al. ${ }^{6}$ who included 245 participants with uncontrolled hypertension in his study and found that timing compliance, the most stringent measure of compliance that can be obtained through electronic monitoring, was higher than $90 \%$ in all study participants. The authors claimed that this high percentage could be explained by selection bias. However, this issue was not further addressed

- More direct evidence comes from studies of both Burnier ${ }^{7}$ and $\mathrm{Waeber}^{8}$, who have reported that a two or three-month period of monitoring of compliance was associated with a significant improvement of blood pressure, most likely resulting from increased compliance with antihypertensive drug therapy. However, both studies lacked a control group and therefore we can not be sure that the blood pressure reductions might be explained by other factors such as "white coat compliance", or "regression to the mean"

- Several studies, using electronic monitoring, show that compliance decreases in time..$^{9-11}$ In a study by Bovet et al. ${ }^{10}$, the percentage of patients that took their medication at at least 6 days a week, dropped from about $74 \%$ in the first month to about $55 \%$ after one year. It is possible that the compliance data found during the first months are influenced by monitoring itself, that this effect wanes after time, and that compliance data found in the latter part of the study better reflect usual compliance behaviour

Other chapters in this thesis provide additional evidence to support our hypothesis that electronic monitoring may improve compliance.

- Chapter 6 describes the results of a qualitative study, using in-depth interviews with patients with a normalized or substantially improved blood pressure after a two-month monitoring period without any changes in their prescribed antihypertensive medications. Interviews in 17 patients revealed that patients were highly motivated to improve their compliance and appreciated the value of the electronic monitor in this process. About half of the patients admitted that they were more focused on taking their tablets in time and changed their medication behaviour during monitoring

- In chapter 8, electronic monitoring is compared with refill compliance data within the same population. Many patients, who according to refill compliance data are not compliant with antihypertensive medication, were not identified as such by electronic monitoring. With electronic monitoring, less than $4 \%$ of the patients could be identified as poor complier. Using refill data, the percentage of patients with inadequate compliance was $18.5 \%$ 
Does this mean that electronic monitoring should no longer be regarded as "gold standard" method to measure compliance? Probably not. Electronic monitoring is still the most advanced compliance measurement instrument and it is the only method that gives day-to-day time patterns of dosing. However, the conditions that have to be met when using electronic monitoring as a valid measurement instrument are very strict. Ideally, patients should not be aware of their compliance being monitored. Kruse and Weber ${ }^{12}$ found a compliance of $95 \%$ in informed individuals compared to $77 \%$ in a group who did not understand the value of the electronic monitor.

Urquhart ${ }^{13}$ states there is a spectrum of possible ways to incorporate the monitored package into the patient's care, ranging from minimalist to maximalist modes of intervention. In the "minimalist mode" the monitor should be introduced to the patient in a low-key, offhand manner. Cramer et al., ${ }^{14}$ claims that using this approach has no discernible effect on measured compliance. This claim is not supported by our results. In our study the monitor was introduced to the patients in a low-key manner. The general practitioner was instructed not to discuss compliance related issues with the patient, and also the research nurse who performed the blood pressure measurements did not try to improve the patient's compliance by giving specific attention to the subject. However, because of medical ethical considerations, the purpose of the monitor (measurement of compliance) had to be mentioned in the patient letter that was handed over to the patient after signing the informed consent statement. Therefore, it was not possible to conceal the purpose of the monitor to patients and prevent awareness of being monitored.

At the moment, a solution for this problem seems to continue electronic monitoring for at least 6 months in the hope that the effects of this awareness will wane over time. The compliance that is measured after a longer period of monitoring may be more representative of usual behaviour, because patients become used to the idea that medication intake is "being watched" and are more likely to return to the pattern of behaviour, which they had before the start of monitoring.

\section{Interventions to improve compliance: what's important?}

\section{Clinical effects}

The primary goal in the treatment of hypertension is to reduce the incidence of adverse cardiovascular events. ${ }^{15}$ In this sense, compliance is only a means to achieve an end, not an end in itself. The goal of antihypertensive therapy is to help patients control their blood pressure and reduce cardiovascular events, not to arbitrarily enforce their compliance to their prescribed regimen. 
Studies regarding the effects of an intervention to improve compliance therefore always must address the effect of the tested intervention on blood pressure and/or cardiovascular outcomes. Schroeder et al. ${ }^{16}$ reported in his review on interventions to improve compliance with antihypertensive medication, that almost $40 \%$ of the included studies did not report a blood pressure outcome and none of the included studies examined major clinical end points. In our trial, blood pressure reductions were chosen as primary outcome measure.

\section{Detection of reasons for poor compliance}

Several studies suggest that simplifying the dose regimen seems to be an effective method to improve compliance. However, most patients who use blood pressure lowering medication are already on a simple once-daily regimen but compliance still remains a problem. Because reasons for poor compliance differ between patients, a key determinant in successfully improving compliance, is probably to offer an intervention specifically designed for the individual patient. ${ }^{4,17}$ The lack of patient-centered strategies might explain the inconsistent results of studies which are designed to evaluate interventions to improve compliance. Assessment of compliance should focus on the individual patient and thus any approach that is targeted in a general manner at heterogeneous groups is also less likely to be effective. ${ }^{18}$ Many patients are unaware of an erratic drug-taking pattern. This may result in poor compliance that is unintentional, arising from the conflict between varying degrees of disorganization in daily life and the need for regular dosing. ${ }^{19}$ Patients with unintentional compliance are likely to benefit from an intervention that enables them to be more disciplined in taking medication as prescribed, whereas such an intervention is less likely to be successful in patients with intentional compliance. Intentional poor compliance involves rationality and decision making on the part of the patient. The decision whether or not to adhere results from the socio-cultural background of the patient, from the extent of knowledge of the disease and drug, from the patient's perceptions of the risks of not adhering to treatment, from the patient's view of medicines in general, from the influence of the patient's relatives and friends, from the patient's trust in the prescriber and from many other physiological and behavioural determinants. ${ }^{2}$

One of the objectives of this thesis was to develop a questionnaire for the assessment of compliance problems that hamper intake of medication in patients who are prescribed antihypertensive drugs.

Chapter 7 reports on the psychometric properties and validity of the Maastricht Utrecht Adherence in Hypertension (MUAH)-questionnaire. This questionnaire measures four factors that account for a cumulative variance of 30\%: (1) positive attitude towards health care and medication, (2) lack of discipline, (3) aversion towards medication and (4) active coping with health problems. Therefore, the questionnaire helps to identify specific reasons for poor compliance and allows the treating physician to choose an intervention that fits with the underlying reasons for non-compliance. 
For instance, when compliance is poor mainly due to lack of discipline (unintentional non-compliance), electronic monitoring may help the patient in executing his daily medication regimen. On the other hand, when a patient has strong aversion against taking medication (intentional non-compliance), more complex multidisciplinary interventions will be necessary to obtain positive results in the long run.

\section{Long-term effects}

Patients might take their medication during monitoring to avoid a confrontation with their physician about their medication behaviour. It is to be expected that these patients return to their old medication behaviour when their compliance is not monitored anymore. On the other hand, in patients who are unaware of dosing errors, electronic monitoring of compliance, possibly extended with giving feedback on compliance data, may result in a very successful, easy-to-use, and long lasting intervention. In chapter 4 , the long-term follow-up data of our trial are presented. It was shown that the positive effects of a two-month monitoring period were still present after 12 months. This finding suggests that, especially in patients who are unaware of their erratic drug intake, a relatively short monitoring period is sufficient to change a patient's medication behaviour for a longer time. This probably reflects a patient's learning process in which daily medication intake eventually becomes incorporated as a habit.

\section{Cost-effectiveness}

From the results described in this thesis it can be concluded that electronic monitoring could be a successful method to improve compliance with antihypertensive medication and to achieve better blood pressure control. In order to evaluate weather electronic monitoring can lead to cost-savings due to reduction in medication use and/or better quality of life due to the decrease of adverse drug effect, a cost-effectiveness study was performed. In this study the differences in costs of the two strategies (monitoring vs. usual care) were related to differences in outcomes in terms of clinical effectiveness and generic quality of life.

Costs were quantified from both the health-care perspective and the societal perspective. The health-care perspective implies that only health-care costs are relevant (either paid for by an insurance company or the patients themselves).

The societal perspective incorporates all costs and health effects regardless of who incurs the costs and who obtains the effects. It should be noted that inclusion of non health-care costs and generic quality of life, as done from the societal perspective, are especially appropriate in studies evaluating interventions in which these parameters are likely to be influenced. In our study, in which the effect of a compliance-improving intervention was evaluated in a population of patients with mild to moderate hypertension, the impact of the intervention on non health-care costs and generic quality of life is turned out to be very small. 
In this respect, the societal perspective might not be the most optimal perspective and the health-care perspective might provide more relevant information. From the health-care perspective it was concluded that electronic monitoring saves approximately $€ 100$ per patient per year in medication costs. However, because of the price of the monitors, the intervention will only be cost-effective if the electronic monitor can be used multiple times in different patients. In case the electronic monitor is provided for single-use, the monitor costs are compensated by the higher medication costs in the usual care strategy only if the purchase price decreases to $€ 16,40$.

\section{Recommendations for clinical practice}

Electronic monitoring should be implemented in clinical health care. Electronic monitoring expands the therapeutic possibilities to treat hypertension and improves the management of hypertension. The fundamental problem in clinical practice is that the prescribing clinician is unable to readily identify inadequate compliers and to distinguish them from poor responders, resulting in unnecessary and costly dose or drug escalations. A period of electronic monitoring allows the treating physician to determine what blood pressure control can be obtained when a patient is taking his medication as prescribed. Furthermore electronic monitoring can be considered as an easy to use intervention to improve compliance, probably especially in patients who are poor compliers due to a lack of discipline or forgetfulness.

Patients probably will benefit most from electronic monitoring in a primary care setting because an early assessment of uncontrolled blood pressure may lead to a considerable reduction in referrals to a secondary setting. Moreover diagnostic work-up for diagnosing secondary hypertension may be prevented.

So, when should the clinician think about monitoring compliance in a patient?

When a clinician is confronted with a patient whose blood pressure is difficult to control despite antihypertensive medication and the occurrence of white coat hypertension or other aggravating factors has been excluded, a period of electronic monitoring would be useful. If blood pressure is lowered after a period of monitoring without medication changes, uncontrolled blood pressure can be attributed to poor compliance. Subsequently, it is important to assess the reasons for poor compliance by using, for example, a questionnaire.

If poor compliance with the antihypertensive medication was unintentional, monitoring of compliance with a short feedback on compliance data will probably be sufficient to improve compliance. When the patient has specific reasons for not taking antihypertensive medication, these reasons have to be addressed and a specific patient-tailored intervention might be helpful.

The costs of electronic monitors might be a barrier for its implementation in general practice. 
It can be concluded from chapter 5 that using electronic monitors in patients whose blood pressure is uncontrolled despite the use of antihypertensive in a primary care setting is cost-effective, and even reduces costs of medication, under the assumption that the electronic monitor can be re-used. However, at present, certain legal rules prohibit using the monitor in different patients. Another possibility is that the price of the monitors strongly decreases when introduced on large scale in medical practice. At a price of 16,40 euro per monitor, the monitor costs are compensated by the higher medication costs in the usual care strategy.

Finally, it is important to note that electronic monitoring may be useful in other chronic conditions and the results of this study can, most likely, be extended to other chronic asymptomatic conditions, such as osteoporosis, hypercholesterolemia, and corticosteroid treatment in asthma.

\section{Recommendations for further research}

The trial described in this thesis is the first randomised controlled trial that evaluates the effects of electronic monitoring on compliance and blood pressure reduction. Further randomised trials are necessary to confirm our results and to determine the exact value of electronic monitoring as an intervention to improve compliance.

However, some other important questions within the field of compliance need urgent attention. Despite the large amount of research that has been performed in the field of compliance in the last decades, a number of major issues still remains unanswered. One of the objectives of this thesis was to determine the magnitude of compliance problems in hypertensive patients. We have not been able to answer this question because electronic monitoring, although considered to be the "gold standard" for compliance measurements, influenced compliance under our trial conditions. According to literature, ${ }^{9-11}$ electronically monitored compliance decreases after 6 months, indicating that monitoring periods longer than six months seem necessary to obtain valid compliance data.

Furthermore, the pharmacokinetic and pharmacodynamic properties of most antihypertensive drugs are unknown at this stage. Knowledge of these parameters would be helpful in the determination of "how much compliance is enough?"

Finally, another question that needs attention is in what way the identification of reasons for poor compliance can be helpful in discriminating between those patients who benefit from electronic monitoring and those patients who need additional training or consultation. 


\section{Conclusion}

Contrary to the assumption that electronic monitoring should be regarded as "gold standard" for compliance measurements, it can be concluded from this thesis that electronic monitoring is more useful as a method to improve compliance than as an instrument to measure compliance. When using electronic monitoring as measurement instrument, it seems extremely important to conceal the purpose of the monitor from the patient to obtain valid compliance data, but this is really hard to accomplish in practice. Another possibility is to monitor compliance until the effect of the monitor itself diminishes, but, according to literature, ${ }^{9-11}$ this takes at least six months.

Electronic monitoring, however, seems promising as a successful, easy to use (and cost-effective) intervention to improve compliance in contrary to other interventions that have been evaluated in randomised controlled trials. 


\section{References}

1. Sackett DL, Haynes RB, Gibson ES, Taylor DW, Roberts RS, and Johnson AL. Patient compliance with antihypertensive regimens. Patient Couns Health Educ, 1978. 1(1): p. 18-21.

2. Sabate E. Adherence to long-term therapies: evidence for action. WHO, 2003(Geneva).

3. Schroeder K, Fahey T, Ebrahim S, and Peters TJ. Adherence to long-term therapies: recent WHO report privide some answers but poses even more questions. J Clin Epidemiol, 2004. 57: p. 2-3.

4. Haynes RB, McDonald HP, and Garg AX. Helping patients follow prescribed treatment: clinical applications. JAMA, 2002. 288(22): p. 2880-3.

5. Urquhart J. The electronic medication event monitor. Lessons for pharmacotherapy. Clin Pharmacokinet, 1997. 32(5): p. 345-56.

6. Schroeder K, Fahey T, Hollinghurst S, and Peters TJ. Nurse-led adherence support in hypertension: a randomized controlled trial. Family Practice, 2005. 22: p. 144-151.

7. Burnier M, Schneider MP, Chiolero A, Stubi CL, and Brunner HR. Electronic compliance monitoring in resistant hypertension: the basis for rational therapeutic decisions. J Hypertens, 2001. 19(2): p. 335-41.

8. Waeber B, Vetter W, Darioli R, Keller U, and Brunner HR. Improved blood pressure control by monitoring compliance with antihypertensive therapy. Int J Clin Pract, 1999. 53(1): p. 37-8.

9. Kruse W, Rampmaier J, Ullrich G, and Weber E. Patterns of drug compliance with medications to be taken once and twice daily assessed by continuous electronic monitoring in primary care. Int J Clin Pharmacol Ther, 1994. 32(9): p. 452-7.

10. Bovet P, Burnier M, Madeleine G, Waeber B, and Paccaud F. Monitoring one-year compliance to antihypertension medication in the Seychelles. Bull World Health Organ, 2002. 80(1): p. 33-9.

11. Waeber B, Leonetti G, Kolloch R, and McInnes GT. Compliance with aspirin or placebo in the Hypertension Optimal Treatment (HOT) study. J Hypertens, 1999. 17(7): p. 1041-5.

12. Kruse $W$ and Weber E. Dynamics of drug regimen compliance-its assessment by microprocessor-based monitoring. European Journal of Clinical Pharmacology, 1990. 38: p. 561-565.

13. Urquhart $J$ and Nelemans P. Therapietrouw met antihypertensive medicatie, in Handboek Hypertensie, W.H. Birkenhager and P.W. de Leeuw, Editors. 2003, De Tijdstroom Uitgeverij: Utrecht. p. 255-272.

14. Cramer JA, Quelette VL, and Mattson RH. The effect of microelectronic observation on compliance. Epilepsia, 1990. 31: p. 617-618.

15. Chobanian AV, Bakris GL, Black HR, Cushman WC, Green LW, Izzo JL, Jones DW, Materson BJ, Oparil S, Wright JT, Jr., and Roccella EJ. The seventh report of the Joint National Committee on Prevention, Detection, Evaluation, and Treatment of High Blood Pressure: the JNC 7 report. $J A M A, 2003$. 289: p. 2560-2572.

16. Schroeder K, Fahey T, and Ebrahim S. How can we improve adherence to blood pressurelowering medication in ambulatory care. Arch Intern Med, 2004. 164: p. 722-732.

17. McDonald HP, Garg AX, and Haynes RB. Interventions to enhance patient adherence to medication prescriptions: scientific review. JAMA, 2002. 288(22): p. 2868-79.

18. Meredith PA. Enhancing patients'compliance. BMJ, 1998. 316: p. 393-394.

19. Cramer JA. Microelectronic systems for monitoring and enhancing patient compliance with medication regimens. Drugs, 1995. 49(3): p. 321-7. 


\section{Summary Samenvatting}


140 | Summary / Samenvatting 


\section{Summary and conclusions}

According to literature antihypertensive medication is often prescribed but only $50 \%$ of the patients in a general hypertensive population take their medication as prescribed. Lack of compliance is assumed to be an important contributor to treatment failure. Therefore, improving compliance with prescribed antihypertensive medication remains a major challenge to treating physicians.

The objective of this thesis was to considerably improve the management of hypertension by identifying and minimizing patient non-compliance with antihypertensive treatment. To this end, we performed a program of observational, interventional and economical research.

\section{Electronic monitoring of compliance with antihypertensive medication}

In chapter 2, we performed a systematic review that summarized and compared all recent studies in which electronic monitoring was used to determine compliance with antihypertensive medication. Thirty studies were identified. The included studies varied highly in methods to quantify compliance. Compliance was higher in once-daily regimens compared to twice-daily regimens. Proportions of patients with compliance $\leq 80 \%$ were provided by only five studies and ranged from 9 to $37 \%$. Studies with a monitoring period exceeding six months showed a distinct decrease in compliance over time. Studies on the association between achieved blood pressure and compliance gave inconsistent results. We concluded that convincing empirical evidence to support the hypothesis that poor compliance is an important explanation for inadequate blood pressure control, is lacking. Furthermore we concluded that there is a strong need for randomised trials that are designed to evaluate whether normalization of blood pressure occurs more often in patients who are monitored than in patients without monitoring. Such a finding would provide indirect evidence that lack of compliance is a cause of inadequate blood pressure control.

\section{Electronic monitoring as a tool to improve compliance}

In chapter 3, the results of a randomised controlled trial to evaluate whether electronic monitoring of compliance can be used as a tool to improve blood pressure control, are reported. 258 patients with hypertension despite use of antihypertensive medication were assigned to either (1) a usual care strategy, which involved immediate changes in prescribed medication, or (2) an experimental strategy in which compliance with antihypertensive medication was electronically monitored for eight weeks without medication changes.

At five months, $51 \%$ of the patients in the usual care group reached adequate blood pressure versus $54 \%$ in the experimental strategy. The percentages of drug additions and/or increases in dosage were however much higher in the usual care group compared to the experimental strategy.

It was demonstrated that electronic monitoring in comparison to usual care results in similar blood pressure control, but leads to less drug changes and drug use. 
We concluded that electronic monitoring can be considered as an easy to use method to improve compliance and therefore blood pressure control.

In chapter 4, the long-term effects (12 months) of the successful intervention to improve compliance as discussed in chapter 3 , are reported. It was concluded that 10 months after stopping with electronic monitoring of compliance, the percentage of patients with normalized blood pressure did not differ between the experimental and usual care strategy. This, in combination with the observation that the number of dose increases or addition of drugs since inclusion was higher in the usual care group, demonstrates that the effects of the intervention are still present at 12 months after inclusion. However, the results also seem to indicate that the effect of monitoring on blood pressure wanes over time.

In chapter 5, the cost effectiveness of our experimental strategy in which compliance with antihypertensive medication was electronically monitored, was determined in comparison to a usual care strategy. Outcome parameters included proportion patients with normalized blood pressure at five months and Quality Adjusted Life Years (QALYs). Costs were quantified from the healthcare and societal perspective. At five months 3.1\% more patients had normalized blood pressure, and 0.003 more QALYs were generated in the experimental strategy. It was concluded that for a time horizon of 5 months a difference in both cost and effect could not be detected between a compliance improving program compared to usual care for hypertensive patients. However, since electronic monitoring costs are relatively low, and the probability of cost-effectiveness was reasonable, this adherence enhancing program may be a cost-effective intervention.

In chapter 6, a qualitative study using in-depth interviews with 17 hypertensive patients whose compliance was electronically monitored, is described. The main objective of this study was to examine the influence of electronic monitoring on medication intake and to gather information about the usefulness of the electronic monitor as a tool to improve the management of hypertension. Furthermore, general perceptions towards hypertension and antihypertensive drugs were examined.

It appeared that patients had ambivalent feelings about taking antihypertensive medication but balanced these feelings in favour of taking medication. Poor adherence often did not seem to be an active decision but merely a case of thoughtlessness and negligence. About half of the patients felt that they changed their medication behaviour during monitoring and by doing so, improved their compliance. None of the patients interviewed had negative feelings about their adherence being monitored.

Most patients considered electronic monitoring of their compliance as additional care and attention for their condition. Electronic monitoring was considered as a valuable tool in the management of hypertension. 


\section{Determinants of compliance and measuring instruments}

In chapter 7, we aimed to develop a valid and reliable questionnaire for the assessment of compliance problems in patients who use antihypertensive drugs. Such instrument would be useful to select patients with certain barriers to take medication and to develop patient-centered interventions to improve adherence. The empirically developed questionnaire consisted of four scales: I: positive attitude towards health care and medication, II: lack of discipline, III: aversion towards medication, and IV: active coping with health problems. The internal consistency of the scales, expressed by Cronbach's alpha coefficient, and test-retest reliability of the questionnaire were both excellent. Convergent validity of the questionnaire was assessed by evaluating the association between sum scores on the identified subscales and three other adherence measures: 1) the Brief Medication Questionnaire (BMQ), 2) pharmacy refill records and 3) electronic monitoring. The sum scores on scales I and II, were associated with adherence according to the BMQ and sum scores on scale II were associated with electronic monitoring. No association between sum scores and the level of adherence as determined by pharmacy records could be demonstrated. We concluded that, although the questionnaire did not seem to predict actual compliance, it is a useful tool to address specific compliance problems and it can be used to develop patient-tailored interventions to improve compliance.

In chapter 8, we compared two methods to determine patient compliance with antihypertensive drugs namely 1) electronic monitoring, often considered as "gold standard" for compliance measurements, and 2) refill compliance, an often-used method based on pharmacy records. There was very little agreement between the two measures. Whereas refill compliance showed a large range of values, compliance as measured by electronic monitoring was high in almost all patients with estimates between $90 \%$ and $100 \%$. Contrary to expectation, the percentage of poor compliers that could be identified using refill compliance data was much higher than the percentage of poor compliers according to electronic monitoring. We concluded that that a short-term electronic monitoring period with the patient being aware of electronic monitoring is probably insufficient to obtain valid compliance data and stated that that there is an urgent need for more studies that explore the effect of electronic monitoring on patient's compliance.

In chapter 9, the results of the studies are discussed. Furthermore implications for clinical practice, suggestions for further research and some future perspectives are given.

An important finding following from this thesis was that the percentage of patients that could be identified as poor complier by electronic monitoring is low in comparison with the general assumption that the percentage of inadequate compliers is $40-50 \%$. These results are likely to be achieved through improved 
compliance in the electronic monitoring group and therefore it was concluded that electronic monitoring itself improves compliance in our study population. Contrary to the assumption that electronic monitoring should be regarded as "gold standard" for compliance measurements, it is concluded that short-term electronic monitoring is more useful as a method to improve compliance than as an instrument to measure compliance. Electronic monitoring seems promising as a successful, easy to use (and cost-effective) intervention to improve compliance in contrary to other interventions that have been evaluated in randomised controlled trials. 


\section{Samenvatting en conclusies}

Medicijnen tegen hoge bloeddruk (antihypertensiva), worden vaak voorgeschreven maar volgens schattingen slechts door $50 \%$ van de gebruikers volgens voorschrift ingenomen. Gebrek aan therapietrouw wordt beschouwd als een belangrijke oorzaak van onvoldoende behandelresultaat. Met de bevordering van de therapietrouw valt derhalve veel winst te behalen.

In dit proefschrift worden een aantal deelstudies gepresenteerd rondom het centrale thema "therapietrouw met antihypertensiva". De studies betreffen zowel observationeel, interventioneel als economisch onderzoek. De studies zijn uitgevoerd in de eerstelijns gezondheidszorg in samenwerking met apothekers en huisartsen.

\section{Elektronische monitoring van de therapietrouw met antihypertensive medicatie}

In hoofdstuk. 2 wordt een systematische review beschreven waarin een overzicht wordt gegeven van alle recente studies die elektronische monitoring met behulp van zogenaamde MEMS-potjes hebben gebruikt om de therapietrouw met antihypertensiva te bepalen. MEMS-potjes zijn pillenpotjes met een microchip in de deksel waarmee de datum en tijd van opening van het potje geregistreerd wordt. Uit deze studies blijkt dat er veel verschillende methoden worden gebruikt om therapietrouw zoals gemeten met MEMS-potjes, te kwantificeren. Hoewel in de literatuur vaak een afkappunt van $80 \%$ wordt gehanteerd om goede en slechte therapietrouw te onderscheiden, bleek dat slecht vijf van de dertig studies informatie geven over het percentage patiënten waarvan de therapietrouw lager dan $80 \%$ lag. Dit percentage varieerde van 9 tot 37\%. De therapietrouw was beter bij patiënten die hun medicijnen eenmaal daags gebruikten ten opzichte van patiënten die tweemaal daags hun tabletten moesten slikken. In studies waarin de therapietrouw langer dan een half jaar gemeten werd, vond een afname van de therapietrouw plaats naarmate er langer gemeten werd. Studies waar de relatie tussen de mate van therapietouw en de bloeddruk bepaald werd, lieten geen eenduidige resultaten zien. Naar aanleiding van de resultaten in de 30 studies werd geconcludeerd dat er weinig empirisch bewijs is voor de veel aangehaalde bewering dat slechte therapietrouw een belangrijke oorzaak is van een slechte bloeddrukregulatie. Verder kan worden gesteld dat het ontbreekt aan studies die specifiek zijn opgezet om te onderzoeken of normalisatie van de bloeddruk vaker voorkomt bij patiënten waarvan de bloeddruk gemonitord wordt in vergelijking met patiënt waarin dat niet gebeurt. Een dergelijke bevinding zou namelijk een indirect bewijs vormen dat gebrek aan therapietrouw inderdaad een belangrijke oorzaak is van een slechte bloeddrukregulatie. 


\section{Elektronische monitoring als middel om therapietrouw te verbeteren}

In de hoofdstukken 3 en 4 worden de resultaten beschreven van een studie die opgezet is om te onderzoeken of elektronische monitoring van de therapietrouw met behulp van MEMS-potjes gebruikt kan worden als interventie om de bloeddrukregulatie te verbeteren bij patiënten met een te hoge bloeddruk ondanks het gebruik van antihypertensiva. In deze studie werd een nieuwe interventie, bestaande uit twee maanden monitoring van de therapietrouw door middel van de MEMS-potjes waarna de patiënt feedback kreeg over zijn medicatiegebruik, vergeleken met de standaardbehandeling (aanpassing van de antihypertensive medicatie middels dosisverhoging, verandering van de medicatie en/of toevoeging van medicatie).

$\mathrm{Na}$ vijf maanden was het effect op de bloeddrukdaling in beide groepen vergelijkbaar (50\% van de patiënten had een normale bloeddruk volgens de NHGstandaard), maar in de interventiegroep (de MEMS-groep) werd dit resultaat bereikt met veel minder medicijnen. Deze resultaten tonen aan elektronische monitoring van de therapietrouw even effectief is als medicatieaanpassing, maar leidt tot minder medicijngebruik. Geconcludeerd kan worden dat elektronische monitoring beschouwd kan worden als een eenvoudige methode om de therapietrouw, en daarmee de bloeddrukregulatie, te verbeteren.

In hoofdstuk vier wordt aangetoond dat na het stoppen van monitoring van de therapietrouw, het positieve effect op de bloeddruk gedurende langere tijd blijft bestaan. Tien maanden nadat gestopt was met monitoring bleek dat het percentage patiënten met een normale bloeddruk nog steeds ongeveer gelijk was in beide groepen. Bovendien was het medicijngebruik in de interventiegroep (de MEMSgroep) nog steeds lager. Wel bleek het positieve effect van monitoring op de bloeddrukregulatie geleidelijk minder werd.

In hoofdstuk 5 wordt de kosten-effectiviteit beschreven van de interventie om de therapietrouw en daarmee de bloeddrukregulatie te verbeteren.

De kosten van de interventie werden berekend vanuit het perspectief van de gezondheidszorg en vanuit het maatschappelijk perspectief. Het maatschappelijk perspectief omvat alle kosten en gezondheidseffecten, het gezondheidszorg perspectief omvat alleen de directe ziekte-gerelateerde kosten en effecten. Opgemerkt dient te worden dat dit laatste perspectief waarschijnlijk het meest relevant is.

Vanuit het maatschappelijk perspectief word geconcludeerd dat, uitgaande van een tijdshorizon van vijf maanden, er geen verschil is tussen de interventiegroep en de controle groep wat betreft kosten en effectiviteit.

Vanuit het gezondheidszorg perspectief kan gesteld dat het inzetten van de monitors tot een besparing van de kosten van antihypertensiva van circa $€ 100$ per patiënt per jaar kan bedragen. Echter, gezien de prijs van de monitors is de vraag belangrijk of hergebruik van de monitors in verschillende patiënten is toegestaan. 
Indien hergebruik niet is toegestaan dan zijn de interventie gerelateerde kosten van de elektronische monitoring en de standaardbehandeling hetzelfde, indien de kosten van de monitor (het MEMS-potje) zouden dalen tot circa $€ 16$.

Hoofdstuk 6 beschrijft een kwalitatief onderzoek bestaande uit diepte-interviews met 17 patiënten wiens bloeddruk verbeterde toen hun therapietrouw gemonitord werd. Doelstelling van dit onderzoek was om na te gaan in hoeverre het monitoren van therapietrouw het medicijngebruik beïnvloedt. Tevens werd informatie verzameld met betrekking tot de bruikbaarheid van de MEMS-potjes als interventie om de bloeddrukregulatie te verbeteren, vanuit het gezichtpunt van de patiënt.

Ondanks het feit dat de meeste patiënten ambivalente gevoelens hebben over het gebruik van antihypertensiva, blijkt dat de meeste patiënten er toch bewust voor kiezen om antihypertensiva te gebruiken om hun bloeddruk te reguleren. Gebrek an therapierouw was meestal het gevolg van onzorgvuldigheid en vergeetachtigheid en niet zozeer een bewuste keuze om de tabletten ( af en toe) niet te nemen. Ongeveer de helft van de patiënten gaf aan dat ze hun medicatiegebruik aanpast hadden toen hun therapietrouw gemonitord werd. Geen van de patiënten had negatieve gevoelens over het feit dat hun therapietrouw gemonitord werd. In tegendeel, de meeste mensen ervoeren het monitoren van de therapietrouw als extra zorg en aandacht voor hun aandoening.

\section{Determinanten van therapietrouw en meetinstrumenten}

In boofdstuk. 7 wordt een onderzoek beschreven naar de ontwikkeling en validering van een vragenlijst om mogelijke problemen rondom therapietrouw bij patiënten op te sporen. Een dergelijke vragenlijst zou in de klinische praktijk bruikbaar zijn om patiënten met een mogelijke slechte therapietrouw te selecteren en een specifieke interventie te ontwikkelen om de therapietrouw te verbeteren. De empirisch ontwikkelde vragenlijst bestaat uit vier domeinen of schalen te weten: I) een positieve houding ten opzichte van de gezondheidszorg en medicatie, II) gebrek aan discipline, III) aversie tegen het gebruik van medicatie en IV) "active coping" met gezondheidsproblemen. De interne consistentie van de schalen, uitgedrukt door de Cronbach's alfa coëfficiënt, en de test-hertest betrouwbaarheid van de vragenlijst waren beide uitstekend.

De somscores van de individuele subschalen werden vergeleken met drie andere methoden om therapietrouw te meten namelijk: 1) de Brief Medication Questionnaire (BMQ), 2) Refill compliance (therapietrouw berekend op basis van apotheekgegevens) en 3) elektronische monitoring van de therapietrouw met behulp van MEMS-potjes. Het bleek dat de somscores van schaal I en II waren geassocieerd met de therapietrouw gemeten met de BMQ en dat schaal II tevens geassocieerd was met de uitkomsten van de elektronische monitoring. Er bestond geen verband tussen de somscores van de individuele schalen en refill compliance. 
Hoewel de vragenlijst de daadwerkelijke mate van therapietrouw niet lijkt te voorspellen kan wel gesteld worden dat de vragenlijst een bruikbaar middel is om specifieke therapietrouwproblemen bij patiënten op te sporen. Bovendien kan de vragenlijst gebruikt worden om specifieke, patiëntgerichte interventies te ontwikkelen.

In hoofdstuk 8, worden twee methoden om therapietrouw te meten met elkaar vergeleken. Refill compliance wordt berekend met behulp van informatie van apothekers over prescripties voor antihypertensiva en uitgedrukt als percentage van de voorgeschreven doseringen die in een bepaalde periode door de patiënt zijn afgehaald. De methode werd vergeleken met elektronische monitoring met behulp van MEMS-potjes, de methode die momenteel beschouwd wordt als gouden standaard voor therapietrouwmetingen. Het blijkt dat er weinig overeenkomst is tussen beide methoden. De "refill compliance" liet een zeer grote spreiding zien terwijl de therapietrouw zoals gemeten met de MEMS-potjes bij alle patiënten tussen de 90 en 100\% lag. De verwachting dat het aantal patiënten met een slechte therapietrouw dat geïdentificeerd kan worden met behulp van de MEMS-potjes hoger zou liggen dan wanneer uitgegaan wordt van apotheekgegevens, werd niet bevestigd.

Concluderend wordt gesteld dat een relatief korte monitoring periode (twee maanden) waarbij de patiënt weet dat hij gemonitord wordt, waarschijnlijk geen valide meetmethode is om de daadwerkelijke therapietrouw te bepalen. Verder werd geconstateerd dat studies die het effect van monitoring op de therapietrouw onderzoeken, noodzakelijk zijn.

In hoofdstuk 9 worden de resultaten van alle deelstudies bediscussieerd. De implicaties van het onderzoek voor de dagelijkse klinische praktijk worden besproken en er worden een suggesties voor verder onderzoek gegeven.

In de literatuur wordt aangenomen dat zo'n 40 tot $50 \%$ van de hypertensive patiënten onvoldoende therapietrouw is.

Een belangrijke conclusie van dit onderzoek is dan ook dat het percentage patiënten dat met behulp van elektronische monitoring geïdentificeerd kan worden als onvoldoende therapietrouw, veel lager ligt dan verwacht. Deze resultaten kunnen waarschijnlijk verklaard worden door een verbetering van de therapietrouw onder invloed van monitoring in onze onderzoeksgroep. In tegenstelling tot de veronderstelling dat het elektronisch monitoren van de therapietrouw de "gouden standaard" voor therapietrouwmetingen is, kan eerder gesteld worden dat elektronisch monitoren van de therapietrouw een eenvoudige methode is om de therapietrouw te verbeteren. De onderzoeksresultaten leveren nieuwe inzichten op die kunnen leiden tot nieuwe behandelingsmogelijkheden en preventiestrategieën. Ondanks het feit dat gebrek aan therapietrouw al jarenlang erkend wordt als een 
belangrijke oorzaak van therapeutisch falen zijn er weinig succesvolle strategieën ontwikkeld om de therapietrouw te verbeteren.

De resultaten van dit proefschrift laten zien dat de bruikbaarheid van de elektronische monitors om de therapietrouw te verbeteren, veelbelovend is. 
150 | Summary / Samenvatting 


\section{Dankwoord}

Tja, en dan komt nu toch de echte afronding van dit proefschrift in zicht. Het dankwoord, het onderdeel van een proefschrift waarvan je in ieder geval zeker weet dat het door de meeste mensen gelezen wordt. Waar zal ik eens beginnen? Clichés als "promoveren doe je niet alleen" zijn helemaal waar maar niet echt mijn stijl. Laat ik dus maar gewoon beginnen bij het begin.

Patty, Jan en Martin, jullie vormden de sollicitatiecommissie toen ik solliciteerde op een baan als onderzoeker voor het TULIPA-onderzoek.

Ik ben jullie gezichtsuitdrukkingen toen ik de kamer binnen kwam voor het sollicitatiegesprek nog niet vergeten. Jan had pretlichtjes in zijn ogen en straalde duidelijk uit " $\mathrm{hmm}$, ben benieuwd wat we nu weer voor een vlees in de kuip hebben". Martin had zijn bekende neutrale semi-nonchalante blik opgezet en Patty was, ook zoals gebruikelijk, kritisch maar ik zou dan ook de eerste onderzoeker worden die ze moest begeleiden.

Patty, ik had me geen betere begeleider en co-promotor kunnen wensen. Ik ben blij dat ik je heb mogen leren kennen, je bent een bijzonder iemand en ik heb veel van je geleerd. Dank voor de vrijheid die je me gaf om de dingen op mijn manier te doen terwijl je deur altijd openstond voor advies. We hebben behoorlijk pittige discussies gehad. Mensen beschrijven mij wel eens als eigenwijs maar ik weet nu beter. Het valt best wel mee! Troost je, eigenwijsheid is een goede eigenschap voor een onderzoeker zeggen ze, en jij steekt dan ook met kop en schouders boven mij uit.

Jan, als mijn andere co-promotor vormde jij een perfecte combinatie met Patty. Waar Patty meestal direct wist welke richting het op zou moeten gaan, en ik nog twijfelde, stond jij tot aan het eind open voor allerlei andere varianten en alternatieven. Aan het begin van een gesprek met jou had ik altijd een duidelijke rode draad in mijn hoofd. Gaandeweg bleek er altijd een compleet netwerk van rode kabels te bestaan. Na zo'n gesprek bleef ik altijd een beetje "flabbergasted" achter met een duidelijke behoefte om een en ander weer te structuren. Geen probleem, Patty was altijd dichtbij! Jan, hartelijk dank voor je inbreng!

Martin, als promotor heb ik met name je pragmatische kijk op veel zaken erg gewaardeerd. Bij problemen kwam je vaak direct met heldere oplossingen.

Nadat ik was aangenomen, bleek dat we zo'n 60 huisartsen en apothekers bereid moesten vinden om deel te nemen aan het onderzoek. Dit bleek gelukkig vrij voorspoedig te lopen maar wie zou alle metingen bij de, maar liefst 258 patiënten uitvoeren? Zo werd Claudia Gulikers dus aangenomen als onderzoeksassistente.... 
Claudia, ik moet bekennen dat ik in het begin heel even mijn twijfels had. Zal een meisje met een voorliefde voor naveltruitjes wel geaccepteerd worden door onze, grotendeels bejaarde, onderzoekspopulatie? Mijn twijfels bleken geheel onterecht. Met je oprechte en vrolijke persoonlijkheid sloten de patiënten je meteen in hun hart en je kwam dan ook regelmatig terug van de huisbezoeken met zelfgebakken wafels, gebreide sloffen en aanverwante stukjes huisnijverheid die je cadeau kreeg. Dank voor alle patiëntbezoeken en je nauwkeurige en efficiënte manier van dataverzameling. We zullen deze promotie samen afmaken! Ik ben blij dat je bij de verdediging van dit proefschrift naast me zult staan als paranimf.

Bij elk zichzelf respecterend onderzoeksteam hoort natuurlijk een projectgroep. Zodoende raakten Jelle Stoffers en Trudy van der Weijden van huisartsengeneeskunde, Carmen Dirksen en Manuela Joore van de afdeling Klinische Epidemiologie and Medical Technology Assessment (KEMTA) en Rob Janknegt, ziekenhuisapotheker te Sittard bij het TULIPA-onderzoek betrokken.

Jelle bij jou kon ik terecht met vragen over de gang van zaken in de gemiddelde huisartsenpraktijk. Je bleek geen gemiddelde huisarts maar je opmerkingen waren waardevol. Trudy, je was altijd zeer oprecht betrokken bij mijn onderzoek en dat heb ik erg gewaardeerd.

Carmen, je opmerking dat het hoofdstuk over de kosteneffectiviteit het belangrijkste hoofdstuk van mijn proefschrift is, zet me nog steeds aan het denken en ik ben er nog niet helemaal uit. Dank voor je constructieve commentaar tijdens de vergaderingen. En Manuela, dank voor de literatuur die je regelmatig opstuurde zodat ik niet helemaal verdwaald raakte in het KEA-gebeuren. Rob, dank voor de hulp op afstand.

Danielle, bedankt voor de uitvoering van de kosteneffectiviteitanalyse.

Ben van Steenkiste, jij raakte betrokken bij het TULIPA-onderzoek toen we iemand nodig hadden met verstand van zogenaamd kwalitatief onderzoek. Dit soort onderzoek is een hele andere tak van sport en ik was dan ook heel blij dat je kwam helpen. Het was leuk om met je samen te werken. Nadat je gehoord had wat overgewicht allemaal met kleine pony's kan doen, kwam je standaard binnen met een grote glimlach en de vraag: "En hoe is het met je pony, is ie al afgevallen?

Dank voor al je hulp bij het afnemen van de interviews en de analyse van de bandopnames. Ik wens je heel veel succes met je eigen promotie.

Oh ja, het gaat goed met de pony hoor, hij is weer aardig op gewicht!

Ans, jij was mijn favoriete kamergenoot. Het was leuk om regelmatig onze eigen geestestoestand te vergelijken met die van de rest van de leden van de capaciteitsgroep epidemiologie. Volgens mij hebben we het profiel van de gemiddelde epidemioloog nog steeds niet vervolmaakt....we blijven eraan werken, nietwaar? Fijn dat je mijn paranimf wilt zijn. 
Yvonne, bedankt voor je hulp bij het drukklaar maken van dit boekje.

Wiel, hartelijk dank voor het redden van hoofdstuk 6 toen mijn USB-stick het begeven had.

Prof. Urquhart, thank you for your involvement in this project. As professor in pharmaco-epidemiology at the department, you made it possible that the letter $\mathrm{L}$ in TULIPA exists.

Prof. de Leeuw, dank voor uw advies met betrekking tot de publicatie van de gerandomiseerde trial. Uw opmerking "Je moet gewoon het licht een beetje anders laten schijnen, het beeld blijft dan hetzelfde maar de schaduw valt net ietsje anders, begrijp je wel?", zal ik onthouden. Nadat we het licht wat anders hadden laten schijnen vond niemand de schaduw meer een probleem en werd het artikel direct geaccepteerd.

Huisartsen en apothekers, heel hartelijk dank voor jullie deelname aan het TULIPA-onderzoek. Zonder jullie betrokkenheid was dit boekje niet tot stand gekomen! Hopelijk biedt dit onderzoek een aantal handvaten om de problemen rondom therapietrouw in de toekomst te verminderen.

Gregorio bedankt voor alles! Iedere dag opnieuw.........

En tot slot wil ik alle patiënten bedanken voor hun bereidheid om mee te werken aan het onderzoek. Zonder hun medewerking zou het onderzoek niet eens hebben plaats kunnen vinden. 
154 Dankwoord 


\section{Curriculum Vitae}

Gwenn Wetzels was born on September 24, 1973 in Heerlen. After completing secondary school (VWO) at the St. Janscollege in Hoensbroek, she studied Biological Health Sciences at Maastricht University which resulted in a Master's degree in November 1996. During her study she fulfilled an internship at the department of Pharmacology and Toxicology at the same university. Topic of this internship was "Signal transduction in rat mesenteric arteries; alterations during experimental heart failure". From January 1997 till September 1998, she worked as a PhD student at the department of Pharmacology and Toxicology on a research project evaluating the pharmacological consequences of vascular smooth muscle cell differentiation. Thereafter, from October 1998 till March 2002, she worked as a Sales Representative/Area Manager for the pharmaceutical company GlaxoSmithKline. In April 2002 she started to work at the TULIPA-project at the department of Epidemiology, Maastricht University. This project resulted in the present thesis. In August 2005 she was registered as Epidemiologist-A. Since October 2005, she works as a Clinical Research Specialist at the Medtronic Bakken Research Center in Maastricht. 


\section{Publications}

- H.J. Raat, G.E.C. Wetzels and J.G.R. De Mey. Calcium-contraction relationship in rat mesenteric arterial smooth muscle. Effects of exogenous and neurogenic noradrenaline. European Journal of Physiology, 1998, 436(2)

- G.E.C. Wetzels, G.M.J. Janssen and J.G.R. De Mey. $\alpha 1$-Adrenoceptor subtypes in superior epigastric and caudal arteries of the rat. FASEB, 1998, 12(4), p A703 (Abstract)

- $\quad$ G.E.C. Wetzels, P.J. Nelemans, J.S. Schouten and M.H. Prins. Facts and fiction of poor compliance as a cause of inadequate blood pressure control: a systematic review. Journal of Hypertension, 2004, 22: 1849-1855

- $\quad$ G.E.C. Wetzels, P.J. Nelemans, J.S.A.G Schouten, B.L.G. van Wijk and M.H. Prins. All that glitters is not gold: a comparison of electronic monitoring versus filled prescriptions. BMC Health Services Research, 2006, $6: 8$

- $\quad$ G.E.C. Wetzels, P.J. Nelemans, J.S.A.G. Schouten, C.D. Dirksen, T. van der Weijden, H.E.J.H. Stoffers, R. Janknegt, P.W. de Leeuw and M.H. Prins. Electronic monitoring of compliance as a tool to improve blood pressure control: a randomised controlled trial. American Journal of Hypertension, 2006, In press.

- $\quad$ G.E.C. Wetzels, P.J. Nelemans, J.S.A.G Schouten, B.L.G. van Wijk and M.H. Prins. Determinants of non-compliance in hypertensive patients; development and predictive ability of the "Maastricht Utrecht Compliance and Hypertension (MUCH) questionnaire". Patient Education and Counseling, 2006. In press.

- Gwenn Wetzels, Ben van Steenkiste, Claudia Gulikers, Trudy van der Weijden, Patricia Nelemans and Martin Prins. Electronic monitoring of adherence as a tool to improve blood pressure control: a qualitative study. Patient Education and Counseling, 2006. Submitted

- Danielle E.M. Brunenberg, Gwenn E.C. Wetzels, Patricia J. Nelemans, Carmen D. Dirksen, Henri E.J.H. Stoffers, Jan S.A.G. Schouten, Martin H. Prins, Johan L. Severens, Peter W. de Leeuw, Manuela A. Joore. Costs and cost-effectiveness of an adherence improving program in hypertensive patients. Pharmacoeconomics, 2006. Submitted. 